\title{
Development and Demonstration of Large-Scale Metal Additive Manufacturing for Military Vehicle Applications - Final Report
}

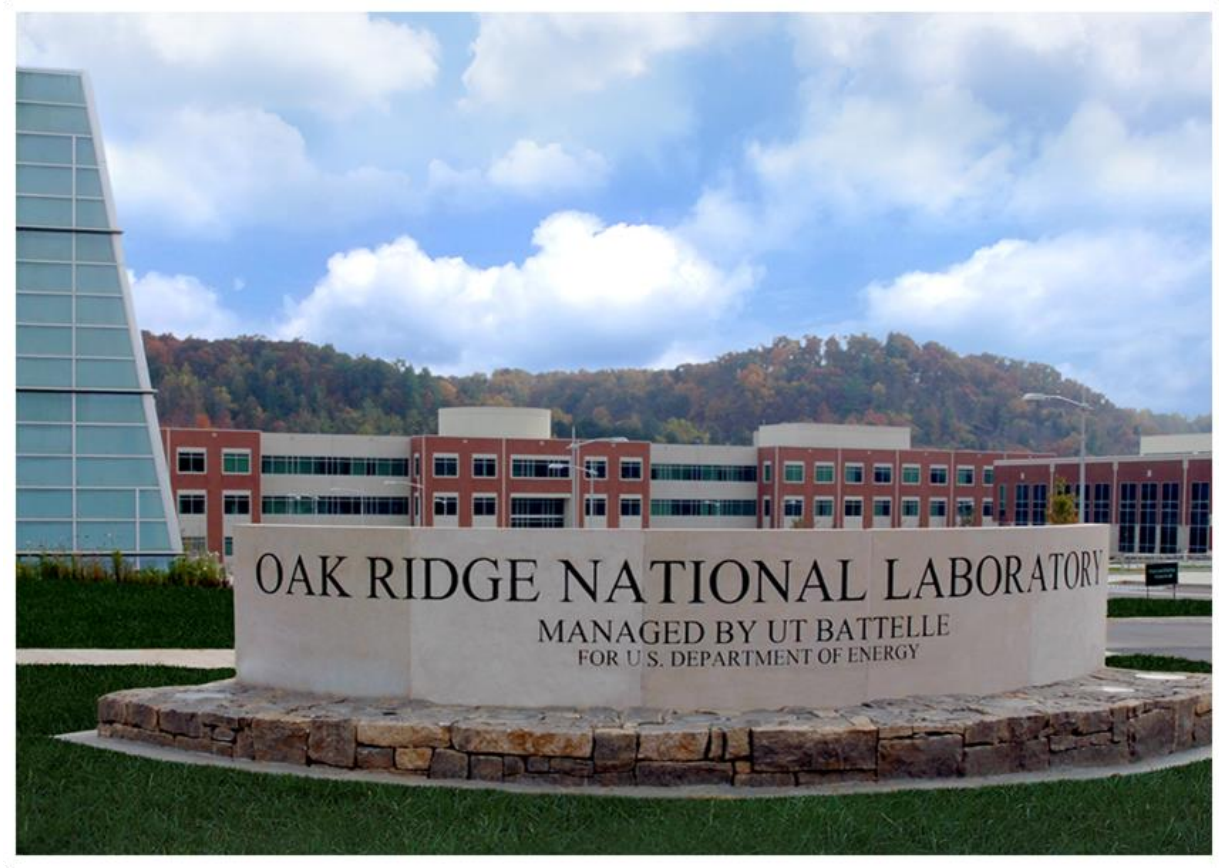

Lonnie J. Love, Ph.D. Andrez Nycz, Ph.D. Mark Noakes, Ph.D. Brian Post, Ph.D. Alex Roschli Suresh Babu, Ph.D.

December 2016 


\section{DOCUMENT AVAILABILITY}

Reports produced after January 1, 1996, are generally available free via US Department of Energy (DOE) SciTech Connect.

Website http://www.osti.gov/scitech/

Reports produced before January 1,1996, may be purchased by members of the public from the following source:

National Technical Information Service

5285 Port Royal Road

Springfield, VA 22161

Telephone 703-605-6000 (1-800-553-6847)

TDD 703-487-4639

Fax 703-605-6900

E-mail info@ntis.gov

Website http://classic.ntis.gov/

Reports are available to DOE employees, DOE contractors, Energy Technology Data Exchange representatives, and International Nuclear Information System representatives from the following source:

Office of Scientific and Technical Information

PO Box 62

Oak Ridge, TN 37831

Telephone 865-576-8401

Fax 865-576-5728

E-mail reports@osti.gov

Website http://www.osti.gov/contact.html

This report was prepared as an account of work sponsored by an agency of the United States Government. Neither the United States Government nor any agency thereof, nor any of their employees, makes any warranty, express or implied, or assumes any legal liability or responsibility for the accuracy, completeness, or usefulness of any information, apparatus, product, or process disclosed, or represents that its use would not infringe privately owned rights. Reference herein to any specific commercial product, process, or service by trade name, trademark, manufacturer, or otherwise, does not necessarily constitute or imply its endorsement, recommendation, or favoring by the United States Government or any agency thereof. The views and opinions of authors expressed herein do not necessarily state or reflect those of the United States Government or any agency thereof. 
Energy and Environmental Sciences Division

\title{
DEVELOPMENT AND DEMONSTRATION OF LARGE-SCALE METAL ADDITIVE MANUFACTURING FOR MILITARY VEHICLE APPLICATIONS
}

\author{
Lonnie J. Love, Ph.D. \\ Andrez Nycz, Ph.D. \\ Mark Noakes, Ph.D. \\ Brian Post, Ph.D. \\ Alex Roschli \\ Suresh Babu, Ph.D.
}

December 2016

\author{
Prepared by \\ OAK RIDGE NATIONAL LABORATORY \\ Oak Ridge, TN 37831-6283 \\ managed by \\ UT-BATTELLE, LLC \\ for the \\ US DEPARTMENT OF ENERGY \\ under contract DE-AC05-00OR22725
}




\section{TABLE OF CONTENTS}

TABLE OF CONTENTS ............................................................................................................

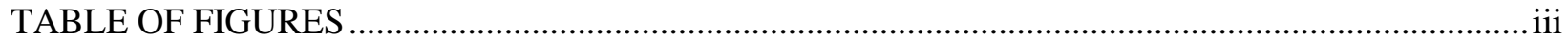

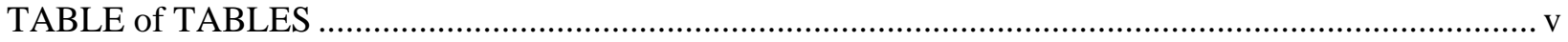

EBAM Electron Beam Additive Manufacturing .................................................................. vii

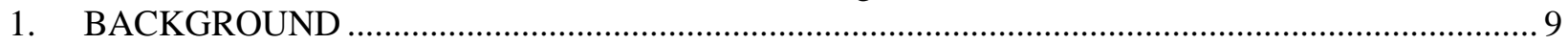

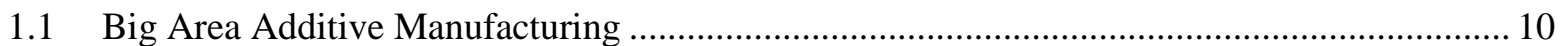

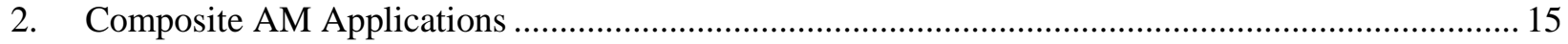

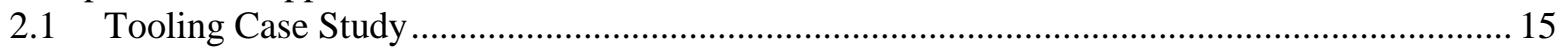

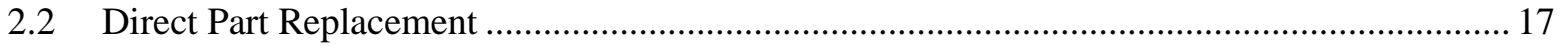

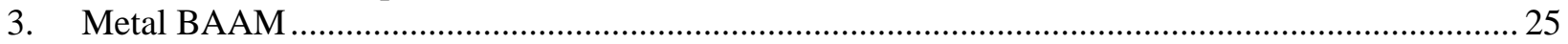

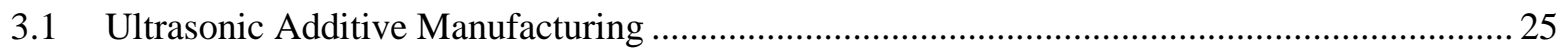

3.2 Electron Beam Additive Manufacturing (EBAM) ............................................................. 26

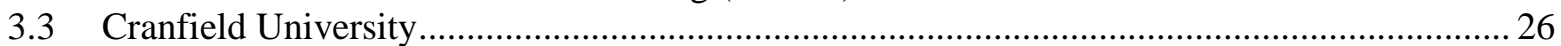

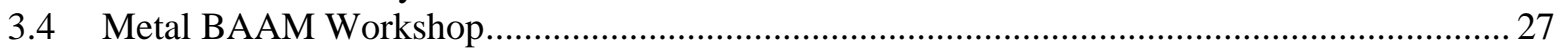

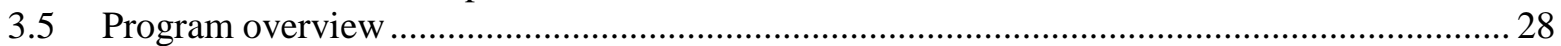

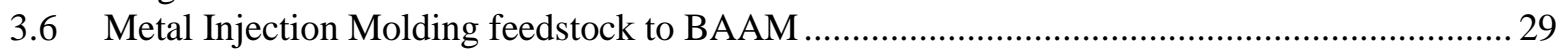

3.7 Robotic Tungsten Inert Gas Welding Metal AM System ....................................................... 31

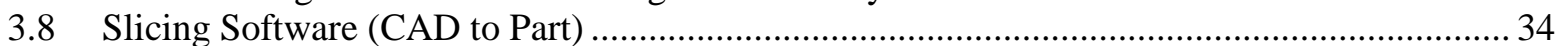

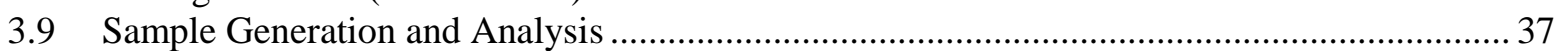

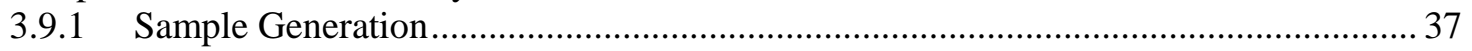

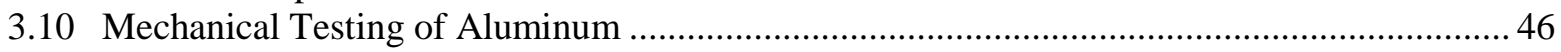

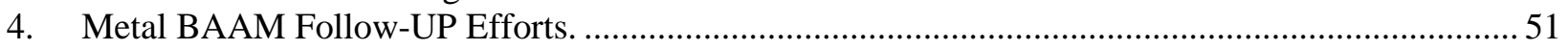

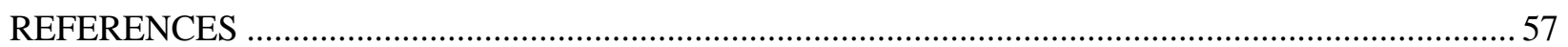




\section{TABLE OF FIGURES}

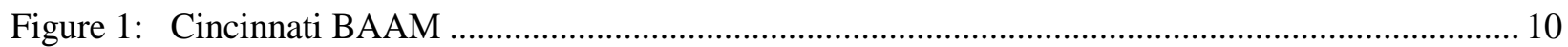

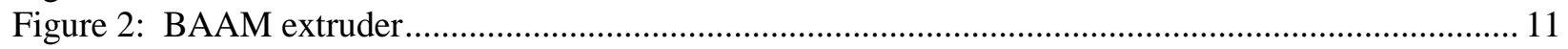

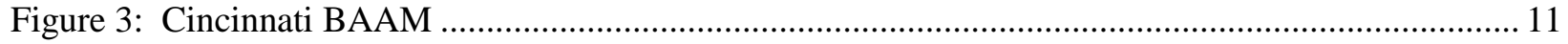

Figure 4: Section of a wind turbine mold …………………......................................................... 11

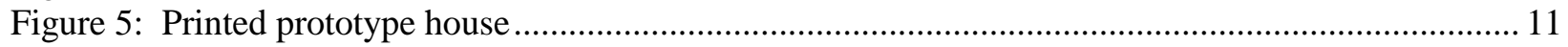

Figure 6: Energy intensity of manufacturing ………………...................................................... 12

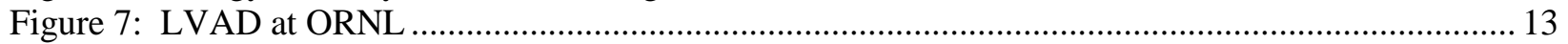

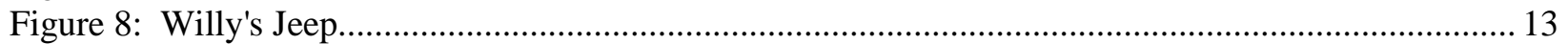

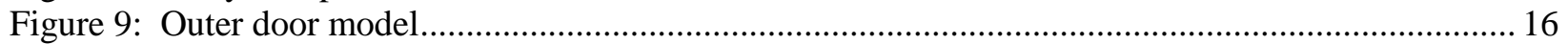

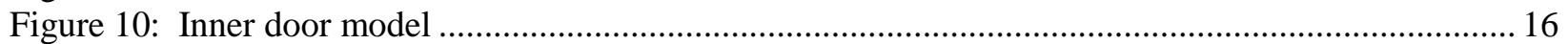

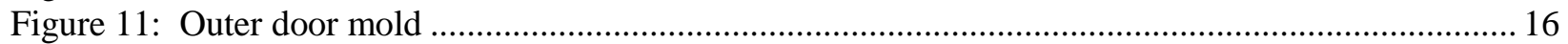

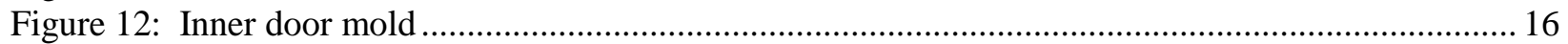

Figure 13: CAD model of LVAD roof............................................................................................. 18

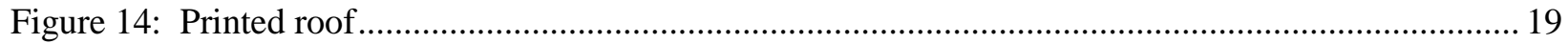

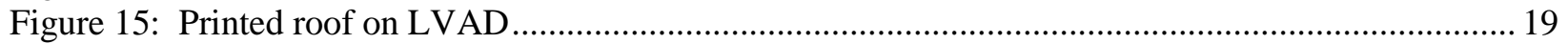

Figure 16: Original 1953 Willy's Jeep....................................................................................... 20

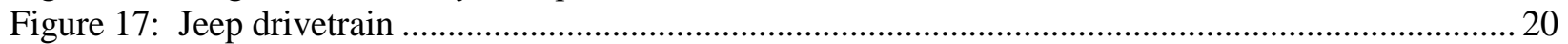

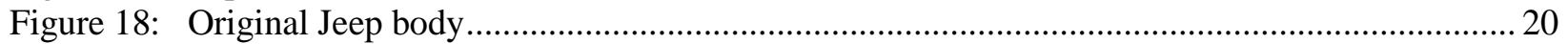

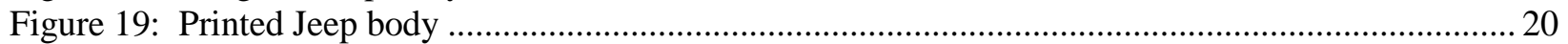

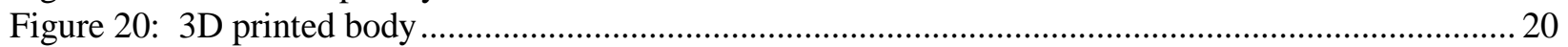

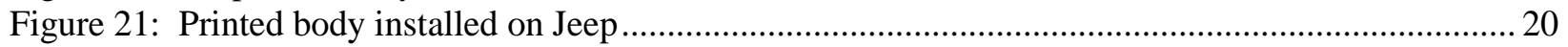

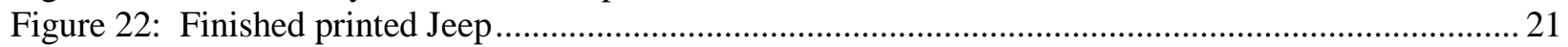

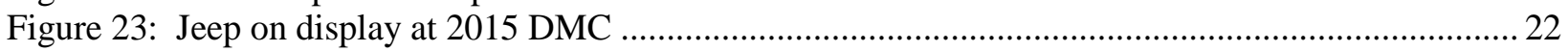

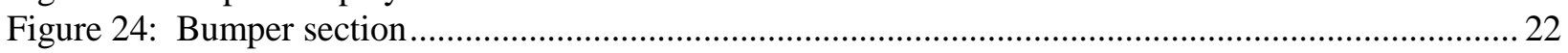

Figure 25: Finished bumper ………………………………………………………………. 23

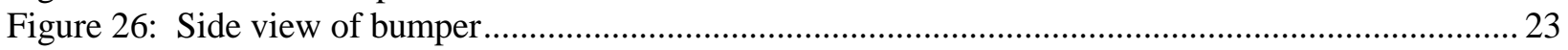

Figure 27: Front view of bumper ............................................................................................... 23

Figure 28: Ultrasonic AM system (a), ultrasonic head (b), and (c) machining stage ………………….....2 25

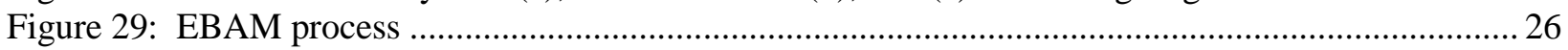

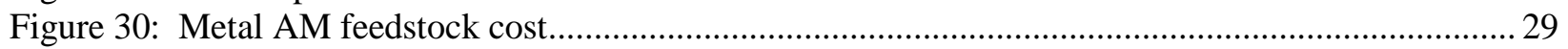

Figure 31: Printed rare earth magnets ………………………..................................................... 30

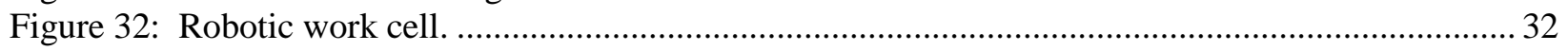

Figure 33: Robotic work cell during active printing ………….......................................................... 33

Figure 34: Custom torch and wire feed alignment mechanism................................................................... 33

Figure 35: The ORNL Slicer with an ORNL part loaded into the visualizer.............................................. 34

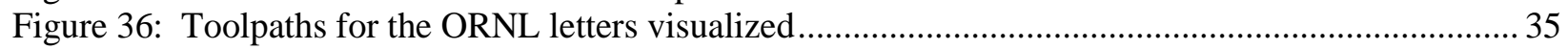

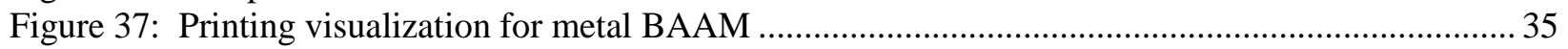

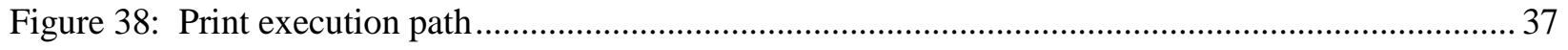

Figure 39: Z build architecture top view............................................................................................ 39

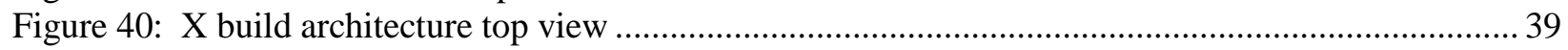

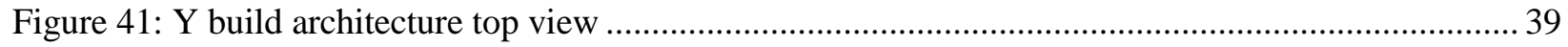

Figure 42: Tensile testing dog bone dimensions (in inches) .................................................................... 40

Figure 43: Tensile testing dog bone samples …………….............................................................. 40

Figure 44: Charpy samples .................................................................................................... 41

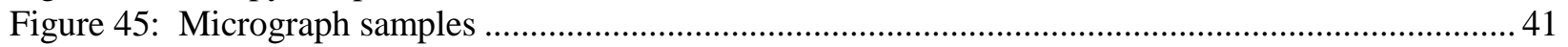

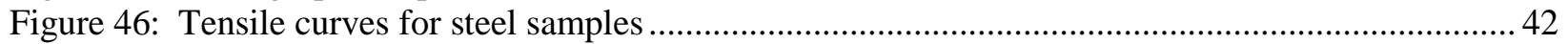


Figure 47: (a) Schematic illustrating the various testing orientations of the samples (b) Charpy impact toughness test results showing that the sample fabricated in the X-direction shows a significant reduction in toughness.

Figure 48: (a-c) Light optical micrographs of samples fabricated in X, Y, and Z-directions respectively. Note the changes in the microstructure (d) electron backscatter diffraction (EBSD) micrograph of the sample fabricated in the X-direction that showed good ductility (30\% total elongation) (e) EBSD micrograph of the sample that showed a reduction in ductility (4\% total elongation) (f) EBSD micrograph of the sample that was fabricated in the Z-direction. Note the fine polygonal ferrite with islands of Widmanstätten ferrite.

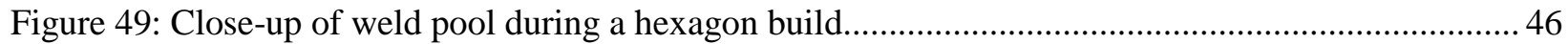

Figure 50: Thermal image of the build in process with temperature scale ............................................ 46

Figure 51: Tensile curves from samples fabricated in various orientations............................................ 47

Figure 52: Optical micrographs of the samples (a) Fabricated in the X-direction (b) Samples fabricated in the Y-direction (c) Samples fabricated in the Z-direction ....................................... 48

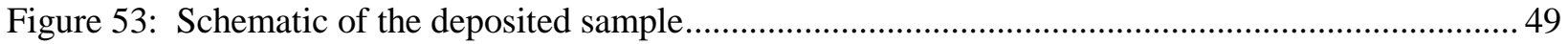

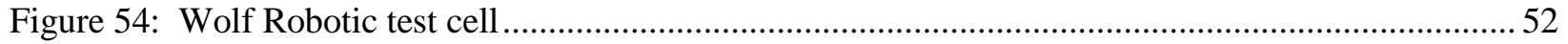

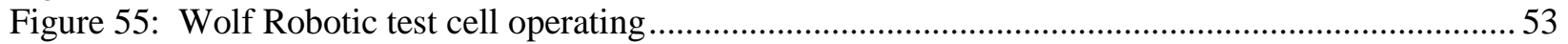

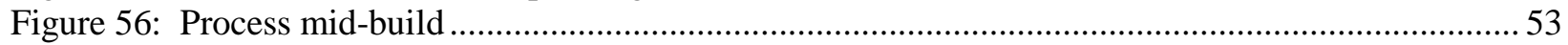

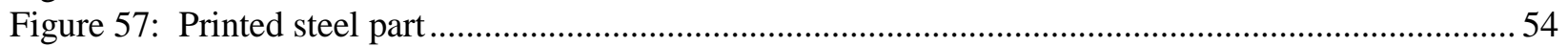

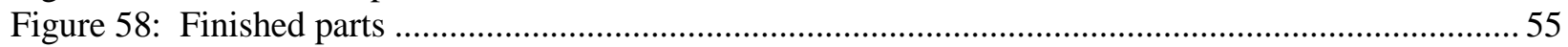

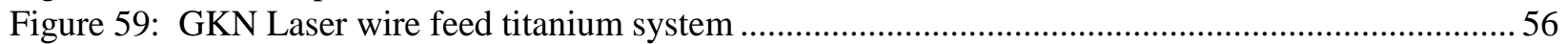




\section{TABLE OF TABLES}

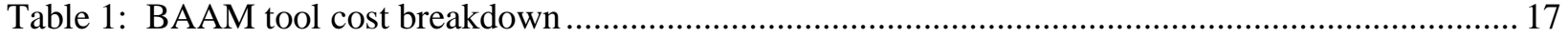

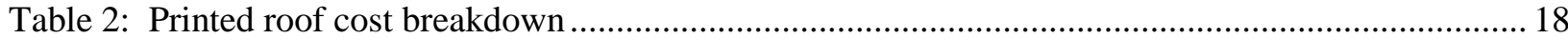

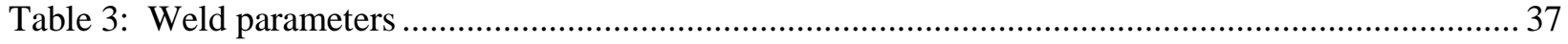

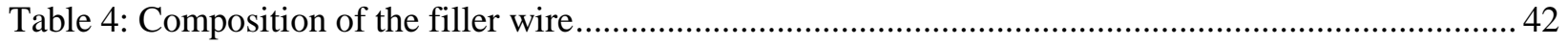

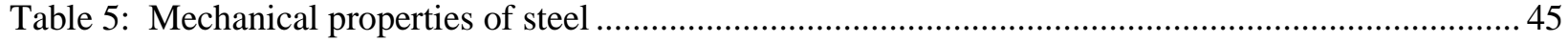

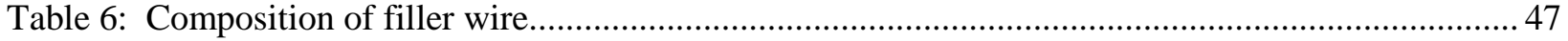

Table 7: Effect of porosity on the mechanical strength of Al-5XXX samples ....................................... 48 


\section{TABLE OF ACRONYMS}

3D

Three-Dimensional

AM Additive Manufacturing

AMO Advanced Manufacturing Office

BAAM Big Area Additive Manufacturing

CAD Computer-Aided Design

CF ABS

CRADA

DMC

DOE

DOF

EBAM

EBSD

FDM

Carbon Fiber Reinforced Acrylonitrile Butadiene Styrene Cooperative Research and Development Agreement HPC4MFG

LVAD

Defense Manufacturing Conference

MDF Department of Energy

MIG Degrees of Freedom

MIM

OEM

ORNL

PA10

STL

TIG Electron Beam Additive Manufacturing Electron Backscatter Diffraction
.......Fused Deposition Modeling High Performance Computing for Manufacturing Low Velocity Airdrop Delivery UAM Manufacturing Demonstration Facility

UTS Metal Inert Gas WAAM Metal Injection Molding Original Equipment Manufactures Oak Ridge National Laboratory Mitsubishi PA10-7C Robot Sterolithography Tungsten Inert Gas Ultrasonic Additive Manufacturing . Ultimate Tensile Strength Wire Arc Additive Manufacturing 


\begin{abstract}
Additive Manufacturing (AM) is a process by which complex parts can be manufactured directly from a basic feedstock without the need for tooling. From a defense perspective, this will enable the direct manufacture of parts and tooling for legacy equipment. However, current AM technologies are limited to small part sizes (approximately 1 cubic foot), slow production rates (less than 5 cubic inch per hour), and expensive feedstocks (approximately $\$ 100 / 1 b$ ). The objective of this project was to explore the impact large-scale, high production rate AM can have on maintaining legacy military vehicles. First, the program explored the use of existing composite large-scale systems (Big Area Additive Manufacturing - BAAM) for both tooling and direct part replacement with the use of the Army's Low Velocity Airdrop Delivery (LVAD) system and a 1953 Willy's Jeep. The case study provides the cost and time required for the development of both tooling and direct replacement parts using the BAAM process. Second, the program focused on expanding the BAAM technology to directly manufacture metal (steel and/or aluminum) components. A robotic welding system was developed, test articles were manufactured, and mechanical properties were characterized. The final deliverable of a steel bumper additively manufactured was installed on the Jeep. This report covers the results of the program and describes follow-up efforts to commercialize the technology.
\end{abstract}

\title{
1. BACKGROUND
}

Most conventional manufacturing techniques (drilling, milling, turning, etc.) are classified as subtractive because these techniques remove excess or unwanted material from a starting block of material. By contrast, AM selectively adds material in a layered format to build up the final shape of the part. The machine derives instructions for making an AM component directly from the three-dimensional (3D) computer-aided design (CAD) model. This feature eliminates the need for extensive drawing packages or process planning (procuring specific sized stock material as a function of part size). AM processes build up components layer by layer, which enables the possibility of designing and building incredibly complex parts. As a result, AM deposits material only where it is needed, making very efficient use of time, energy, and raw materials. This leads to significant savings in time, energy, and costs associated with manufacturing highly advanced components. In fact, $\mathrm{AM}$ is the only manufacturing technique in which it may be faster, cheaper, and more energy efficient to produce a more complex part.

Currently, AM systems face three fundamental flaws:

1. Part sizes are generally limited to volumes less than 1 cubic foot in volume,

2. The processes use expensive feedstock, which exceed $\$ 100$ per pound, and

3. Production rates are generally less than 5 cubic inches per hour

Oak Ridge National Laboratory (ORNL) has developed a new, large-scale, high speed, low cost, and energy efficient AM technology that explores materials and processes to enable room temperature AM. Currently, the technology known as BAAM has been commercialized by Cincinnati Incorporated (see Figure 1). 


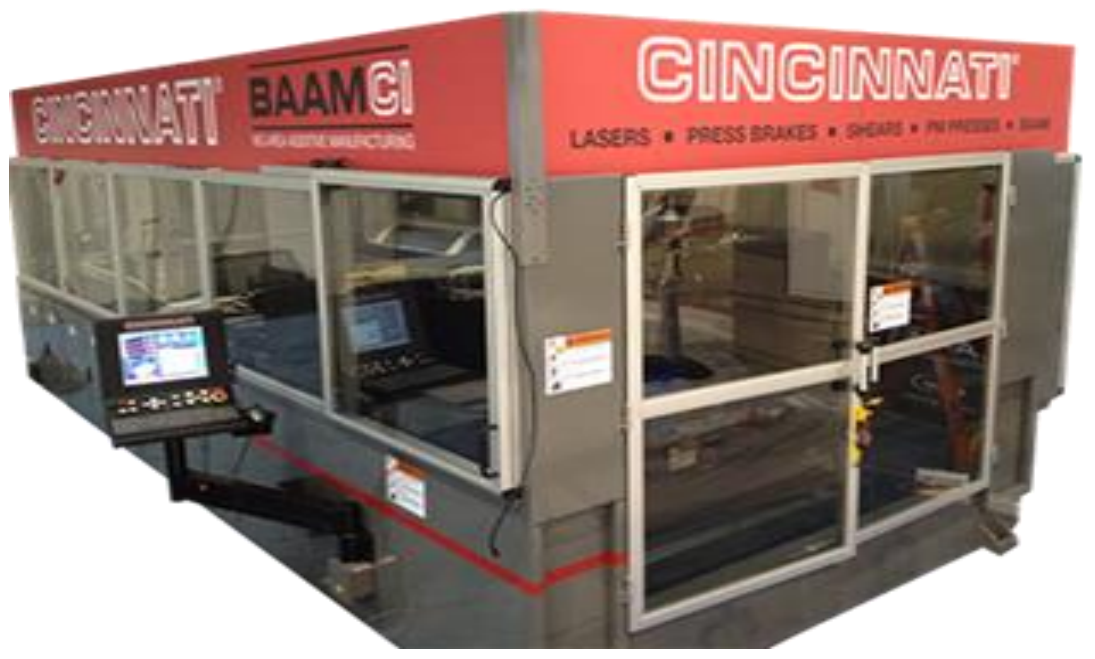

Figure 1: Cincinnati BAAM

\subsection{Big Area Additive Manufacturing}

Conventional fused deposition modeling (FDM) is based on melting and extruding a filament of thermoplastic feedstock. Prior work shows that the peak flow rate is limited by the rate at which the filament can be melted(Monzon 2013). Big Area Additive Manufacturing is an extrusion process that uses injection molding material for the feedstock and a single screw extruder for melting and metering the flow rate (see Figure 2) (Holshouser, Newell et al. 2013). A gantry system, commercialized by Cincinnati Incorporated, moves the extruder in $\mathrm{x}, \mathrm{y}$, and $\mathrm{z}$ directions to build the part. The extruder is capable of delivering $100 \mathrm{lbs} /$ hour of thermoplastic materials from pellet feedstock. The gantry system is capable of achieving $200 \mathrm{inch} / \mathrm{second}$ peak velocities with $64.4 \mathrm{in} / \mathrm{s}^{2}$ accelerations and position accuracy of 0.002 " (see Figure 3). As previously reported, the use of carbon fiber reinforcement in the thermoplastic resins increases the part strength and stiffness(Tekinalp, Kunc et al. 2014). Just as important, it increases thermal conductivity and reduces the coefficient of thermal expansion, which lessens the need for a heated chamber to produce large parts (see Figure 4 and Figure 5) (Love, Kunc et al. 2014). The elimination of the oven significantly decreases the energy intensity ormanufacturing energy required per kilogram of product. As shown in Figure 6, FDM systems with heated chambers have a $100 \mathrm{~kW}-\mathrm{hr} / \mathrm{kg}$ energy intensity. Desktop systems that have similar production rates have a $5.5 \mathrm{~kW}$-hr/kg energy intensity suggesting that the oven accounts for approximately $95 \%$ of the energy utilization in FDM production. BAAM further reduces the energy intensity to $1.1 \mathrm{~kW}$ $\mathrm{hr} / \mathrm{kg}$ by increasing productivity from $1 \mathrm{ci} / \mathrm{hr}$ to $2500 \mathrm{ci} / \mathrm{hr}$ and is manufactured at room temperature. 


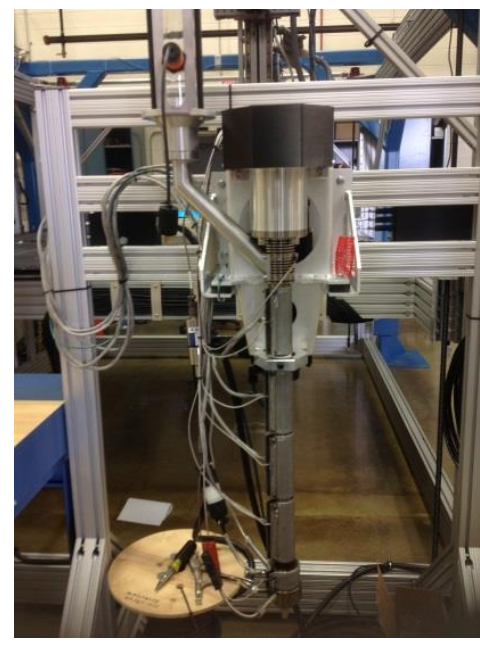

Figure 2: BAAM extruder

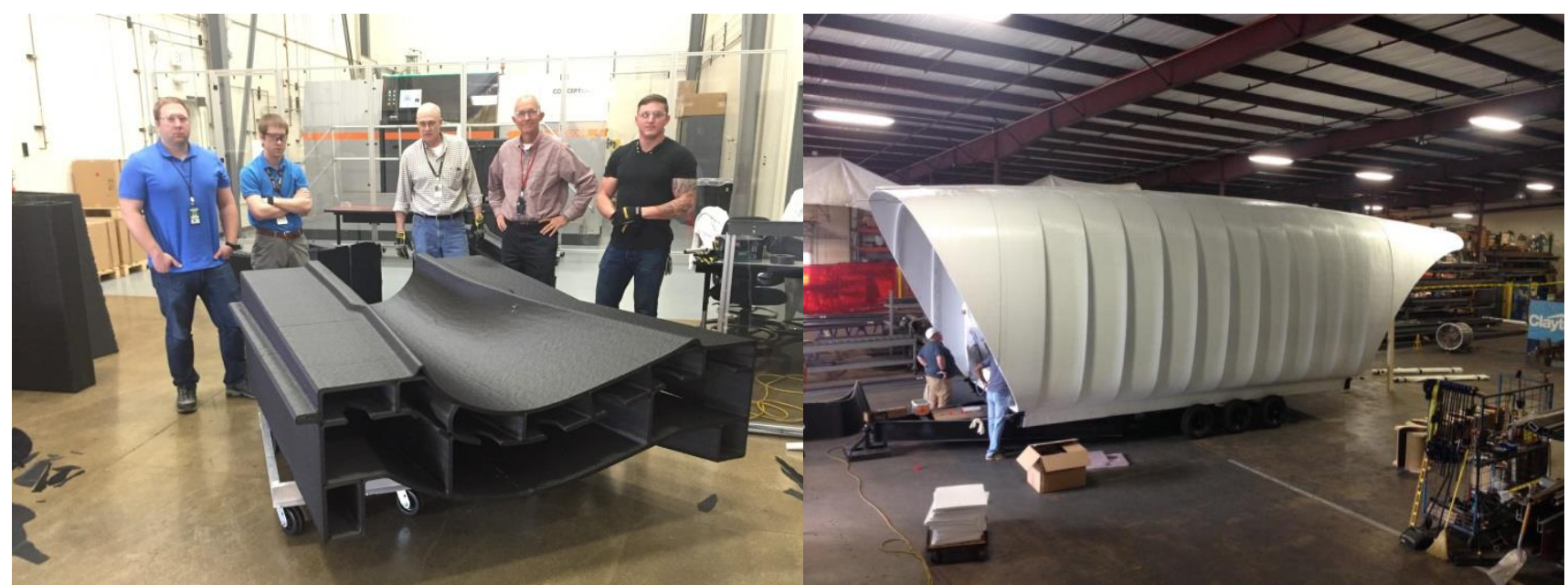

Figure 4: Section of a wind turbine mold

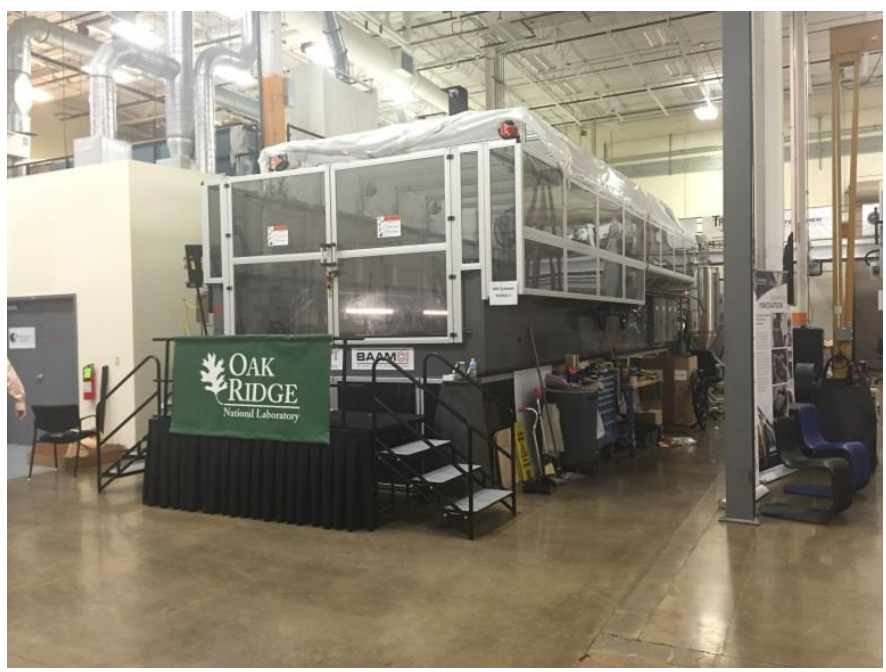

Figure 3: Cincinnati BAAM
Figure 5: Printed prototype house 


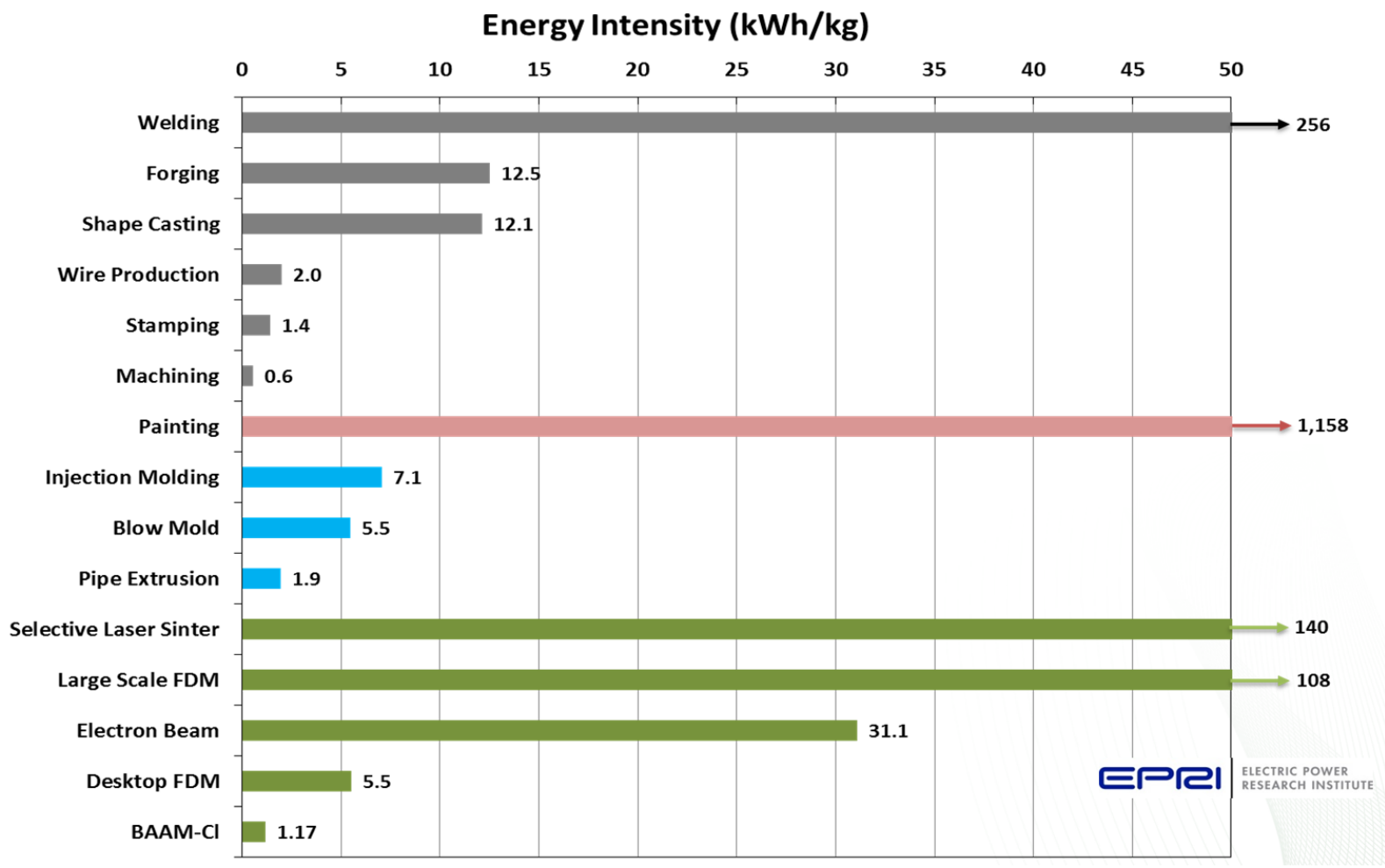

Figure 6: Energy intensity of manufacturing

Therefore, the combination of lower energy intensity, higher productivity, and lower material costs suggests that there will be a significant production cost reduction with BAAM when compared to conventional AM systems.

There are two objectives of this project. The first objective was to explore the utility of BAAM for rapid tooling and direct part replacement for existing legacy military vehicles. The two vehicles under investigation are the LVAD vehicle and a 1953 Willy's Jeep (see Figure 7 and Figure 8). Tooling was designed and parts were reverse engineered, manufactured, and integrated into both systems. The second objective was to develop a metal BAAM technology that would enable the direct manufacture of steel or aluminum parts. As a final deliverable and fulfilment of the second objective, the team directly manufactured a steel bumper for the Willy's Jeep. 


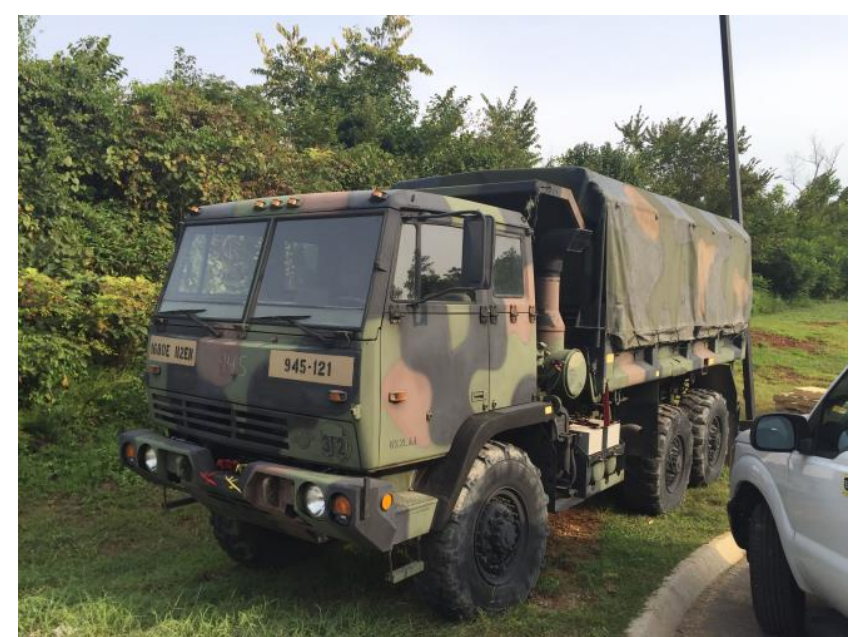

Figure 7: LVAD at ORNL

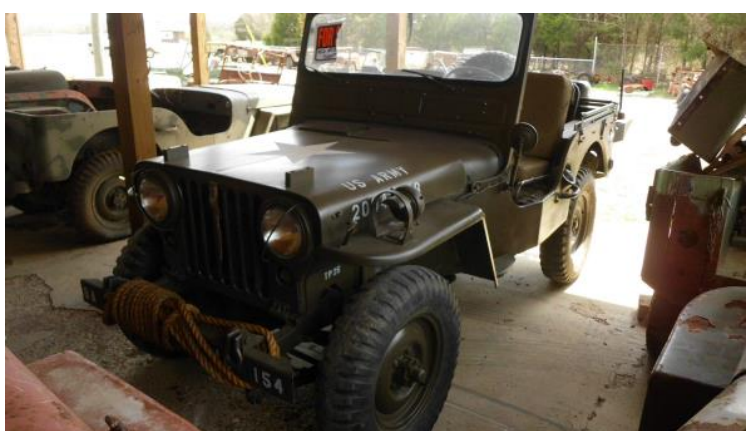

Figure 8: Willy's Jeep 


\section{COMPOSITE AM APPLICATIONS}

The first objective in this program was to explore the military use for BAAM in both the tooling and direct part replacement applications.

\subsection{Tooling Case Study}

Tooling is the foundation of many manufacturing industries. Molds are used in the aerospace, automotive, and appliance industry to shape metal, plastic, and composite parts. As an example, the automotive industry generally spends $\$ 200 \mathrm{M}$ on tooling for each car model. ${ }^{1}$ By 2018 , tooling for the automotive industry is expected to exceed $\$ 15.2 \mathrm{~B}$ per year. ${ }^{2}$ Tooling is generally very expensive ( $\$ 10 \mathrm{~K}$ 's to $\$ 100 \mathrm{~K}$ 's per mold) and is used for long lead items (months to years). Tooling is generally one of a kind parts that have significant complexity. AM's strength is the ability to manufacture one of a kind complex parts. Therefore, there is great potential for revolutionizing the tool and die industry through the use of AM.

For the military, lack of tooling from the original equipment manufacturers (OEM) makes maintaining equipment problematic. The first task for this project focused on manufacturing a mold for the door and a direct part replacement for the roof of the LVAD. There are a number of methods available for manufactured door panels. Conventional sheet metal forming approaches include stamping and hydroforming, which is the formation of a metal object by pressing a metal sheet between a male and female die or male die and pressurized bladder. For composite structures, processes include resin infusion and compression forming. In each case, the requirements of pressure and temperature for the tooling is different, but the costs, geometries, and surface finishes are similar. For this study, we elected to explore resin infusion for composite structures.

Activities of the program focused on using the original CAD models for the parts to design molds (shown in Figure 11 and Figure 12). Surfaces of the skins were transformed to solid CAD structures suitable for printing. The file was then converted to a stereolithography file (STL). STL files are a common file structure used as the input to almost all 3D printers. The files were then oriented and processed to create toolpaths for manufacturing the parts on the Cincinnati BAAM. This process, called slicing, is one of the other strengths of AM. The process of generating instructions, or GCode, for the AM machine tools is automated, so it only takes a few minutes to load the part, orient it, and slice.

The team explored two options for achieving the target surface finish. The first option consisted of the part being grown approximately 0.10 " oversized and machined, meaning smoothed or ground, back down to achieve the target surface finish (see Figure 11). The advantage of this process is there is no secondary application process. The parts can be removed from the printer and directly machined. However, almost all BAAM manufactured parts have carbon or glass fiber reinforcement. These reinforcements can be abrasive and wear out cutting tools. This

\footnotetext{
${ }^{1}$ Direct conversation between engineers at Ford, Honda, VW and Diversified Tooling and ONRL MDF staff

${ }^{2}$ http://www.dbusiness.com/July-August-2014/Tooling-Under-Pressure/\#.WG-8xo-cFJk
} 
BAAM process also leads to some porosity the process must be monitored and controlled to ensure a completely dense layer of material on the machined surface. The second option (see Figure 12) was to grow the part slightly under the target size of 0.10 " and then coat the part with a coating suitable for resin infusion. The advantages of this process are the direct use of a standard material for the interface with the resin infusion, the ability to achieve vacuum integrity with the application of a coating, and less abrasion on cutting tools. The disadvantages of this process are a slightly higher manufacturing cost and an additional manufacturing step.

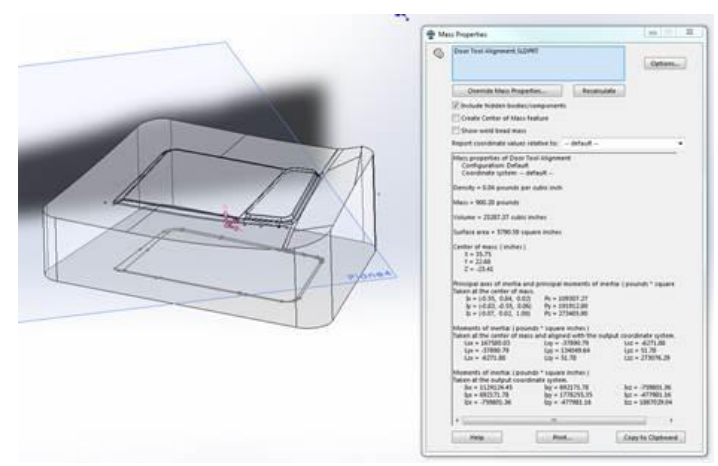

Figure 9: Outer door model

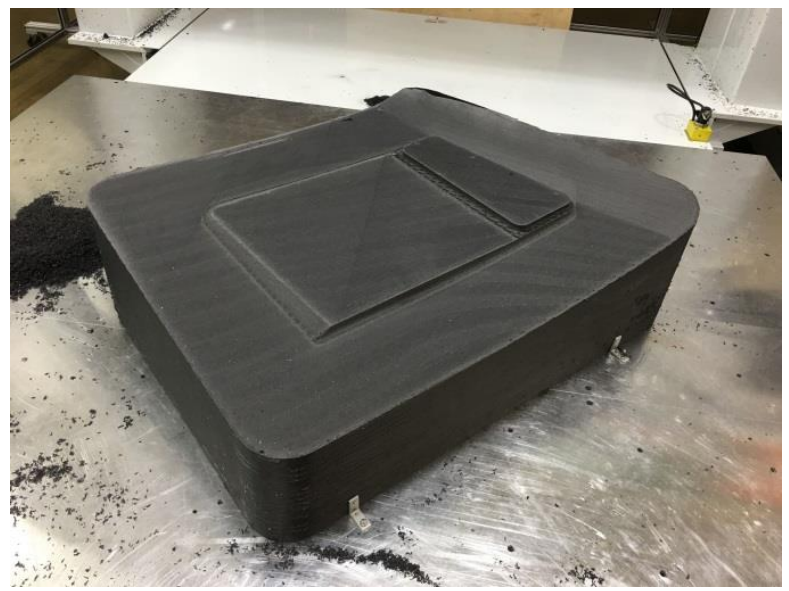

Figure 11: Outer door mold

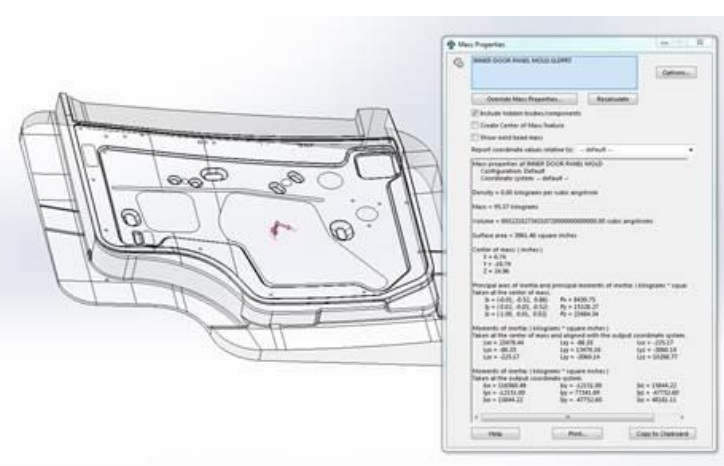

Figure 10: Inner door model

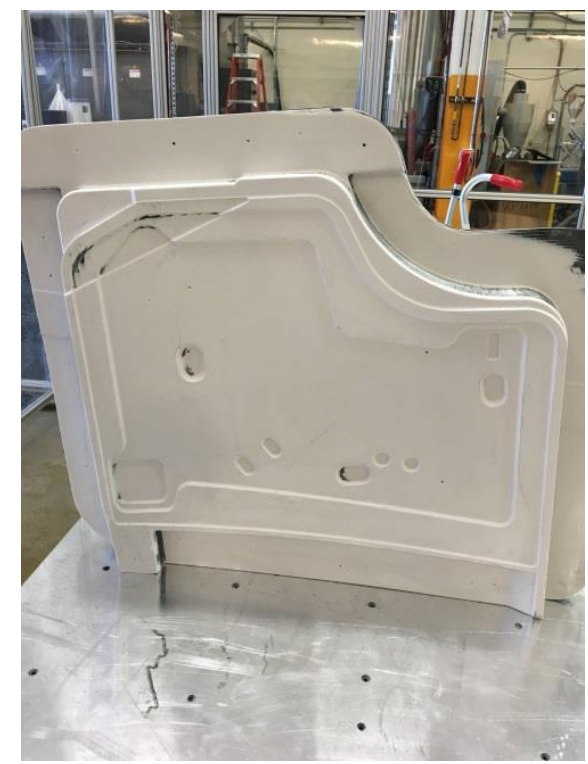

Figure 12: Inner door mold

For the molds, the base material choice was $20 \%$ carbon fiber (by weight) reinforced acrylonitrile butadiene styrene (CF ABS). The material cost was approximately $\$ 4.50 / 1 \mathrm{~b}$. The outer door mold weighed approximately 680 pounds, and the inner door mold weighed approximately 160 pounds. Preprocessing time, including machine setup and slicing the model, was approximately 2 hours for each mold. The outer door mold was grown approximately 0.100 " oversized and machined, using a Thermwood router, to the final size. Conversely, the inner door mold was approximately 0.100 " under sized and covered with 0.25 " of coatings. The coatings cost approximately $\$ 50$ gallon, and it took approximately 3 gallons of material to coat 
the mold. It took approximately 2 hours to transfer each of the molds to the router and another 4 to 5 hours to machine. Assuming labor rates of $\$ 50 / \mathrm{hr}$ and machining rates of $\$ 150 / \mathrm{hr}$, the outer door mold cost approximately $\$ 1870$, and inner door cost approximately $\$ 2670$ to manufacture. In terms of manufacturing time, from start to finish, it took approximately 1 day to fully manufacture the outer door mold, and it took approximately 3 days to manufacture the inner door mold. These cost estimates include the manufacturing cost and exclude engineering time.

Table 1: BAAM tool cost breakdown

\begin{tabular}{|l|l|l|l|l|}
\hline & \multicolumn{3}{|l|}{ Outer door mold } & \multicolumn{2}{l|}{ Inner door mold } \\
\hline & Time/material & Cost & Time/material & Cost \\
\hline Preprocessing & 2 hours & $\$ 100$ & 2 hours & $\$ 100$ \\
\hline Material & $680 \mathrm{lbs}$ & $\$ 3060$ & $160 \mathrm{lbs}$ & $\$ 720$ \\
\hline$\quad$ Coating & & & 3 gallons & $\$ 150$ \\
\hline Processing & 12 hours & $\$ 3200$ & 3 hours & $\$ 600$ \\
\hline Post processing (labor) & & & & \\
\hline$-\quad$ Labor & 2 hours & $\$ 100$ & 10 hours & $\$ 500$ \\
\hline$-\quad$ machine & 5 hours & $\$ 750$ & 4 hours & $\$ 600$ \\
\hline Total & 9 hours & $\$ 1870$ & 19 hours & $\$ 2670$ \\
\hline
\end{tabular}

While we do not have direct comparisons for traditionally manufactured molds, it is quite common for molds of this size to be manufactured out of Kirksite alloy for low volume production. Kirksite costs approximately $\$ 1 / \mathrm{lb}$ (approximately $25 \%$ the cost of the CF ABS) but has a density of $0.25 \mathrm{lb} / \mathrm{ci}(6.6 \mathrm{X}$ the density of CF ABS). The CF ABSis approximately $\$ 4.50 / \mathrm{lb}$ with a density of $0.0376 \mathrm{lb} / \mathrm{ci}$. Therefore, the outer door mold would weigh approximately 4500 lbs and have a material cost of $\$ 4500$ when manfacuted with Kirksite. In contrast, the outer door mold weighs $680 \mathrm{lbs}$ and has a material cost of $\$ 3060$ when manufactured with CF ABS. It is very difficult to lighten a Kirksite cast billet, but AM allows for easy light weighting, which reduces material used and processing cost and time.Likewise, the inner door mold would weigh approximately $1060 \mathrm{lbs}$ and have a material cost of \$1060 if manufactured with Kirksite, but it only weighs $160 \mathrm{lbs}$ with a material cost of $\$ 870$ when manufactured with CFABS. Furthermore, a separate structure must be manufactured to cast the Kirksite mold. This is a typical approach for manufacturing low cost tooling. While we do not have a direct comparison of costs, the BAAM demonstrates a method to manufacture low volume tooling at a lower material cost with a significantly lighter mold. The BAAM process is also highly automated, which reduces labor costs and processing time.

\subsection{Direct Part Replacement}

The second application of the BAAM technology was for direct part replacement. There were two case studies: direct replacement of the roof of the LVAD and full body replacement of the Jeep. The direct replacement of the roof section required very little engineering work. The roof was removed from the LVAD, critical measurements at the intersections of the roof and cab were measured, a CAD model was generated from those measurements, and the part was printed. The total engineering time was approximately 2 days to generate a model of the roof. Table 2 provides a breakdown of the cost and time associated with manufacturing the part, but it does not include engineering cost. 
Table 2: Printed roof cost breakdown

\begin{tabular}{|l|l|l|}
\hline & Time/material & Cost \\
\hline Preprocessing & 2 hours & $\$ 100$ \\
\hline Material & $180 \mathrm{lbs}$ & $\$ 810$ \\
\hline Processing & 3 hours & $\$ 600$ \\
\hline Post processing (labor) & & \\
\hline$-\quad$ Labor & 2 hours & $\$ 100$ \\
\hline$-\quad$ machine & 3 hours & $\$ 450$ \\
\hline Total & 10 hours & $\$ 2060$ \\
\hline
\end{tabular}
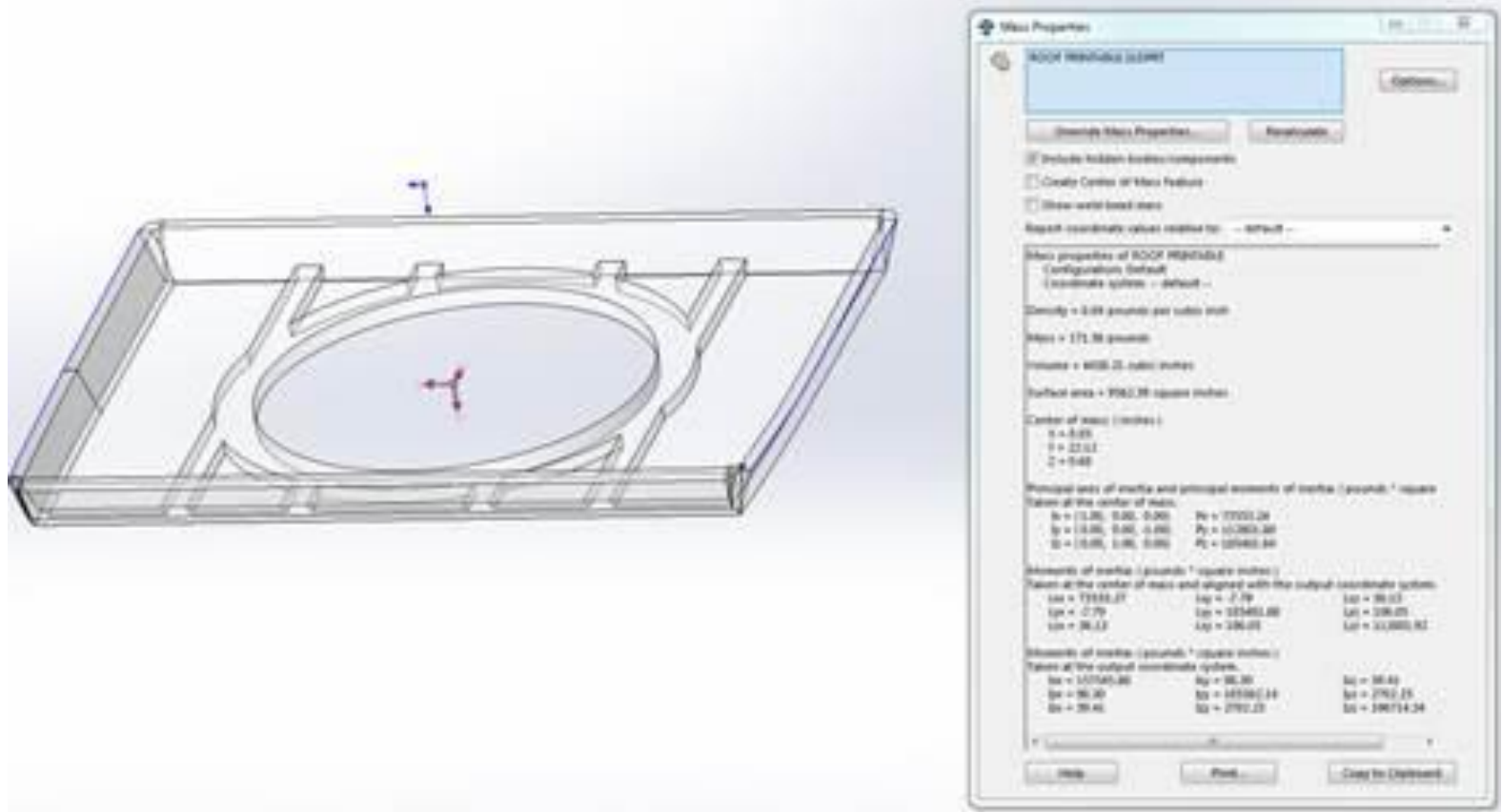

Figure 13: CAD model of LVAD roof 


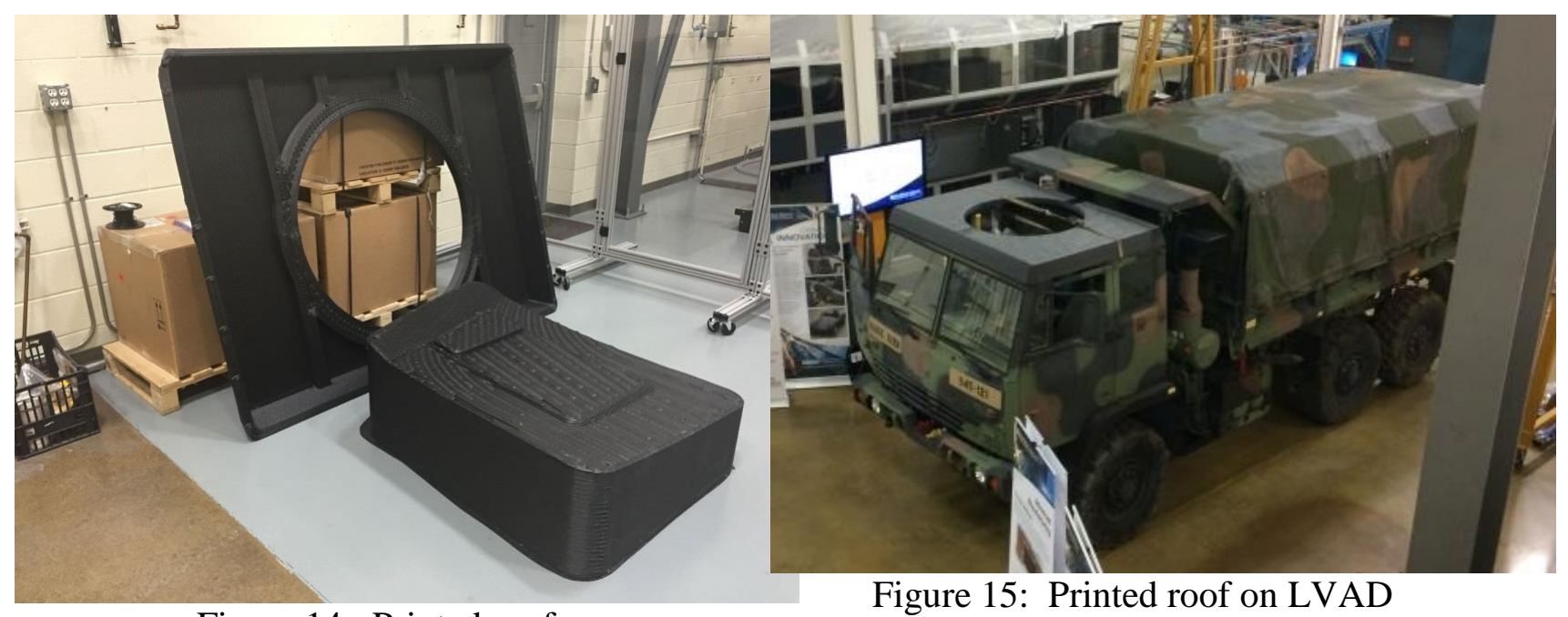

Figure 14: Printed roof

Figure 15: Printed roof on LVAD

The second case study was the manufacture of a replacement body for a full vehicle, a 1953 Willy's Jeep. A refurbished Jeep was purchased for the project. The body was removed leaving only the frame and drivetrain (see Figure 16 and Figure 17). A 3D model of the body was designed using SolidWorks with critical dimensions measured using a laser tracker (see Figure 18 and Figure 19). 


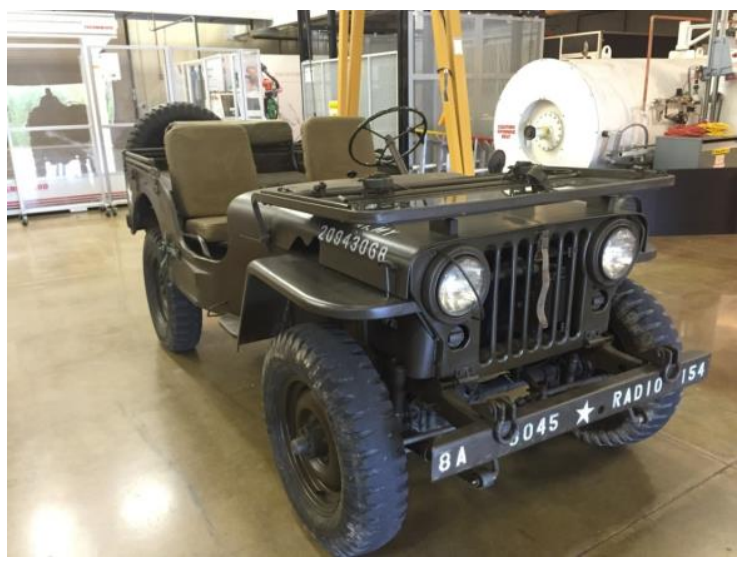

Figure 16: Original 1953 Willy's Jeep

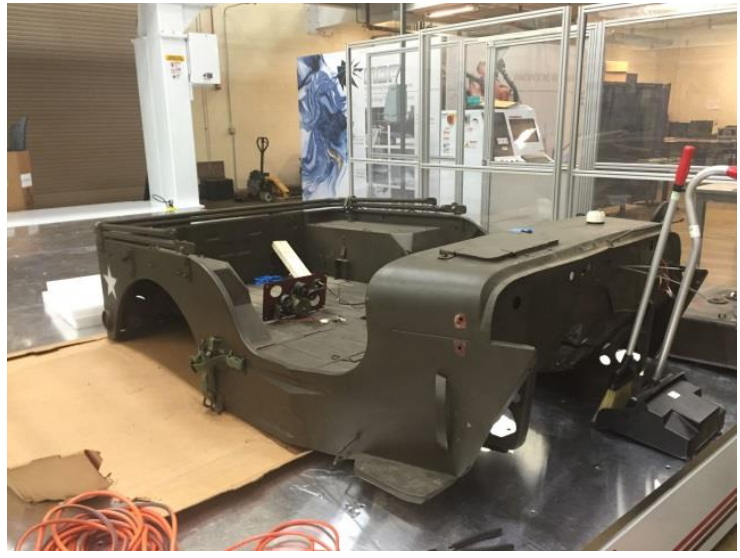

Figure 18: Original Jeep body

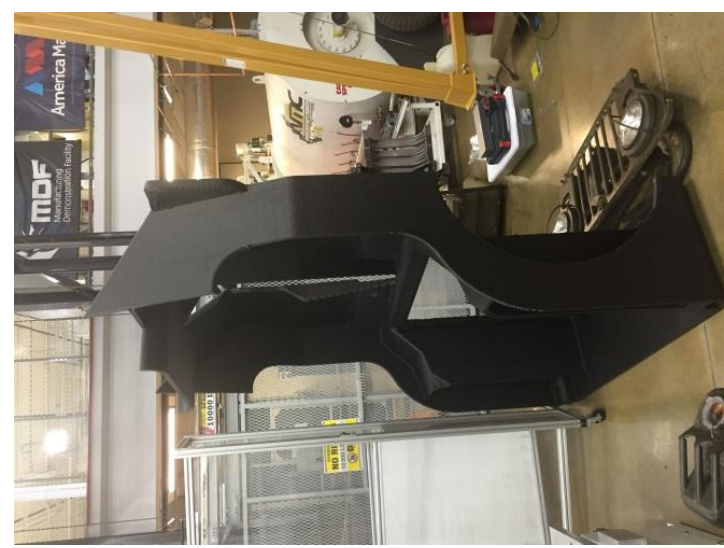

Figure 20: 3D printed body

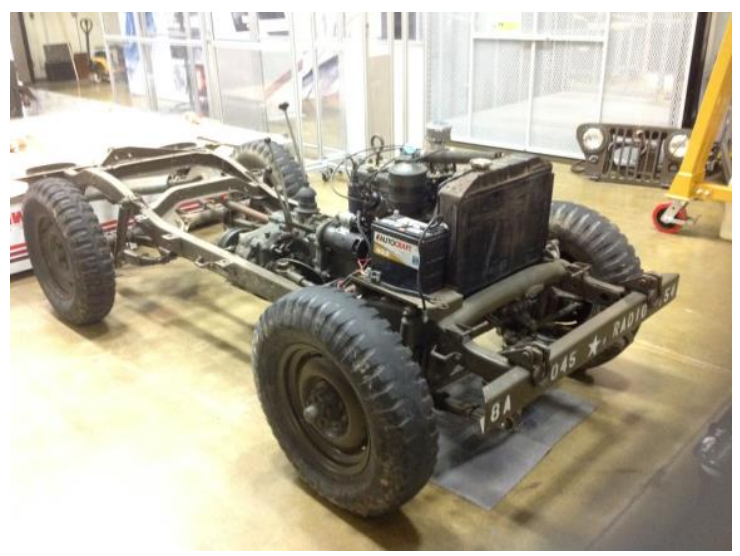

Figure 17: Jeep drivetrain

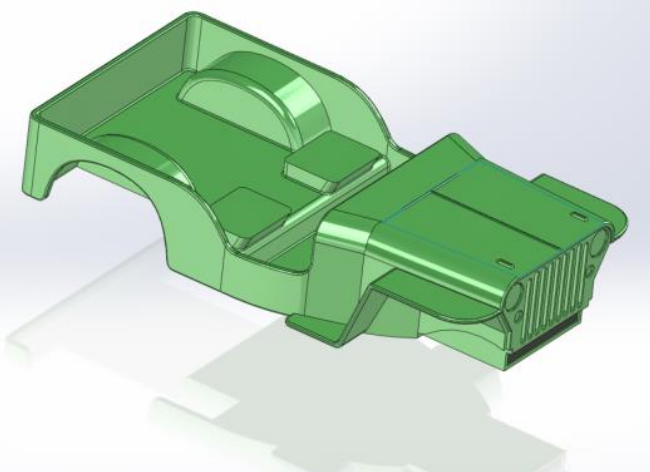

Figure 19: Printed Jeep body

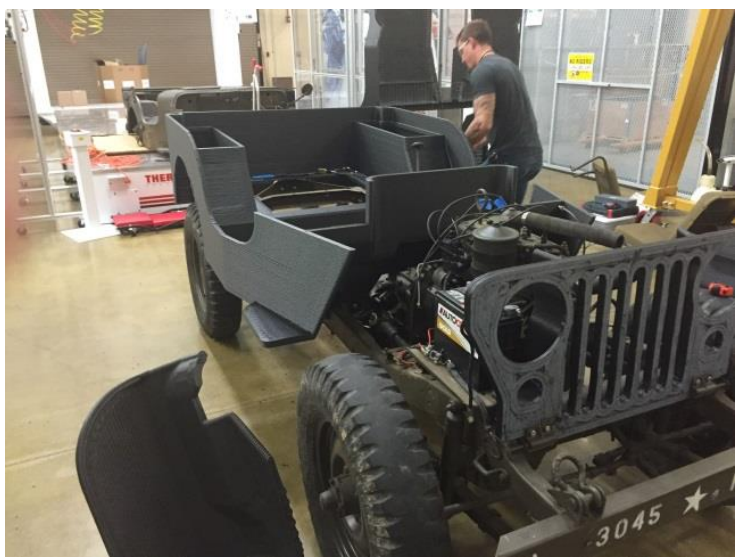

Figure 21: Printed body installed on Jeep

The final effort focused on application of coatings to provide a smooth surface finish to the body. ORNL worked with a local company, TruDesign, on the development of new coatings for CF 
ABS. The result of this effort led to a partnership between TruDesign and Polynt Composites on coatings for $3 \mathrm{D}$ printed parts. ${ }^{3}$

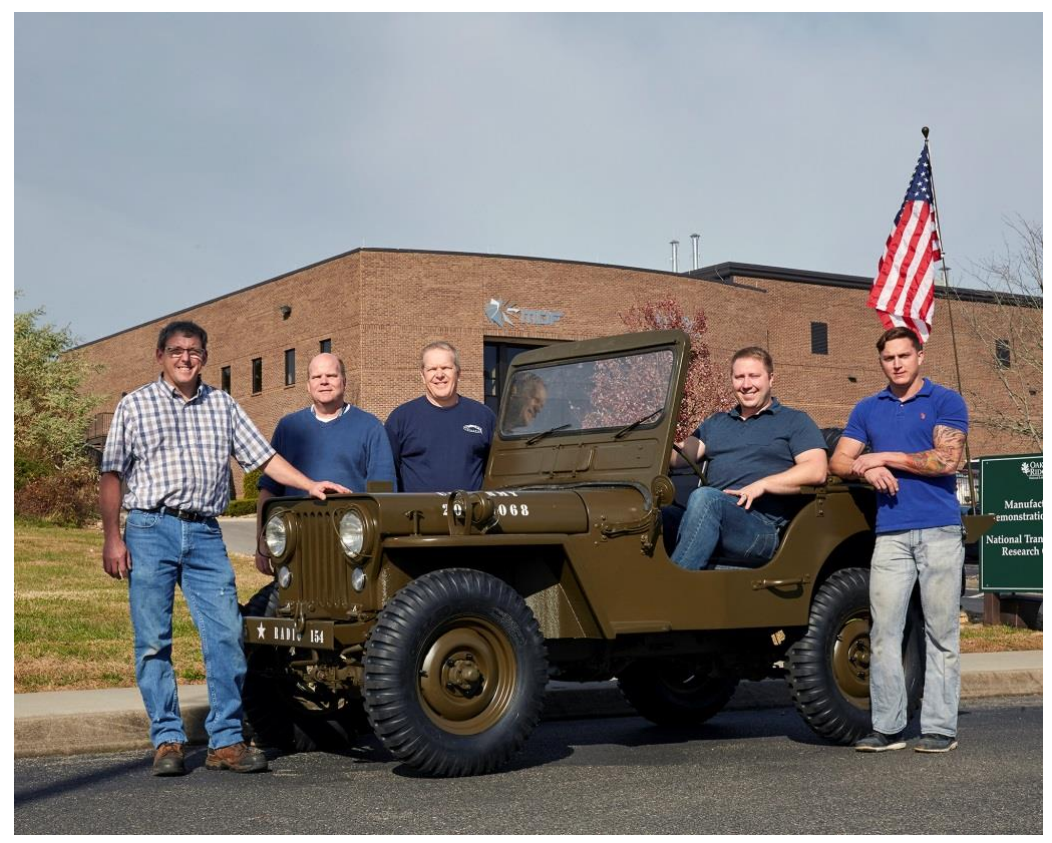

Figure 22: Finished printed Jeep

The Jeep took less than one month to procure, design, print, assemble, and finish. The final vehicle was on display at the 2015 Defense Manufacturing Conference (DMC). Another outcome of the project was ORNL hiring an Army veteran who served in Afghanistan, Matt Sallas (assembling the Jeep in Figure 21 and far right on Figure 22) to help finish the Jeep. Sallas is now a full time staff at ORNL. Sallas also attended the DMC and answered questions about the Jeep (see Figure 23).

\footnotetext{
${ }^{3}$ http://www.businesswire.com/news/home/20160923005071/en/Tru-Design-LLC-Polynt-Composites-USAPartner-Develop
} 


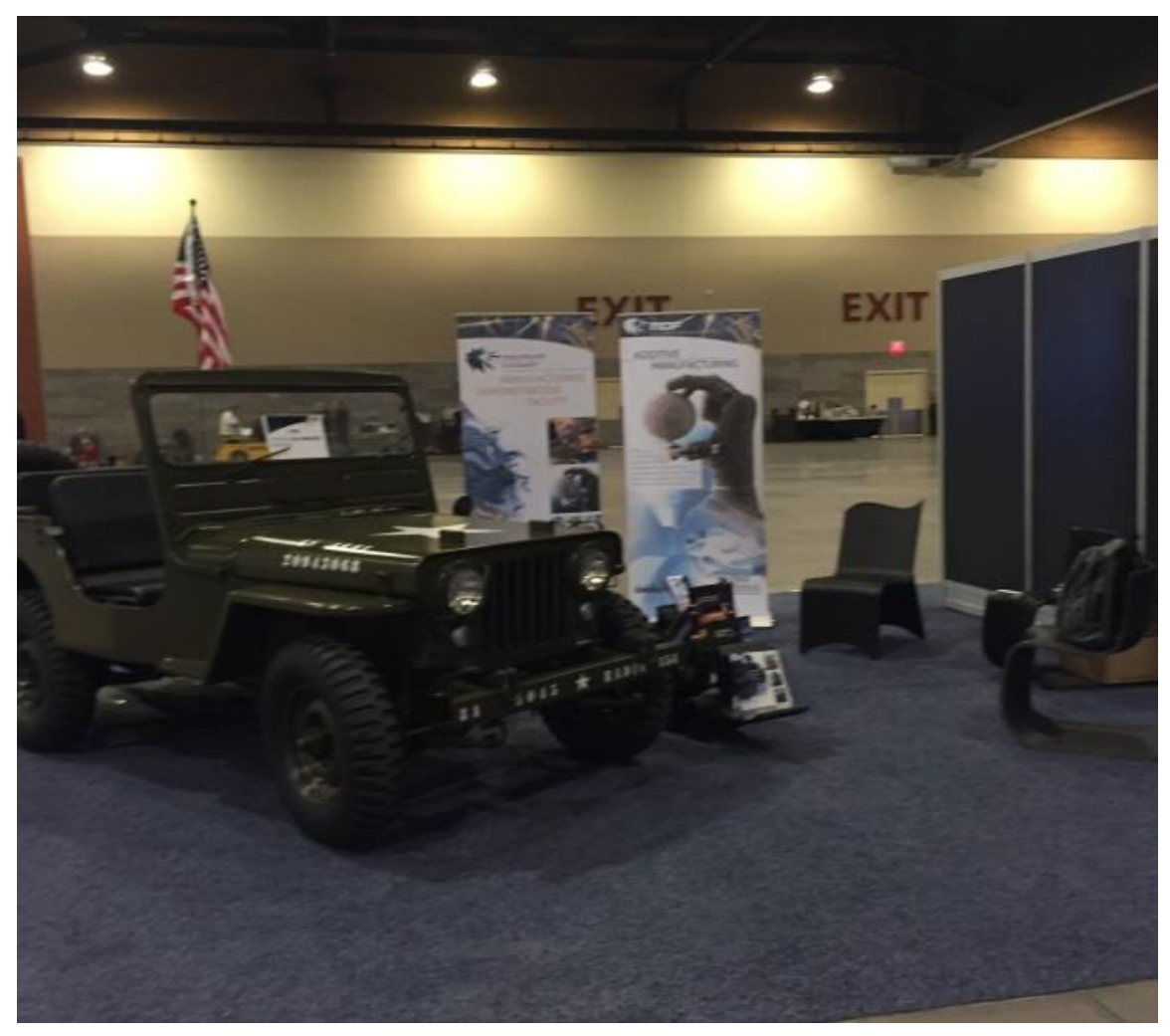

Figure 23: Jeep on display at 2015 DMC

Efforts, described in the next section, focused on the development of technologies for large-scale metal AM. The final deliverable for the project was a printed metal bumper for the Jeep. Preliminary work focused on printing the bumper in a horizontal plane (see Figure 24). The full bumper was then printed, machined, and installed on the Jeep (see Figure 25 through Figure 27).

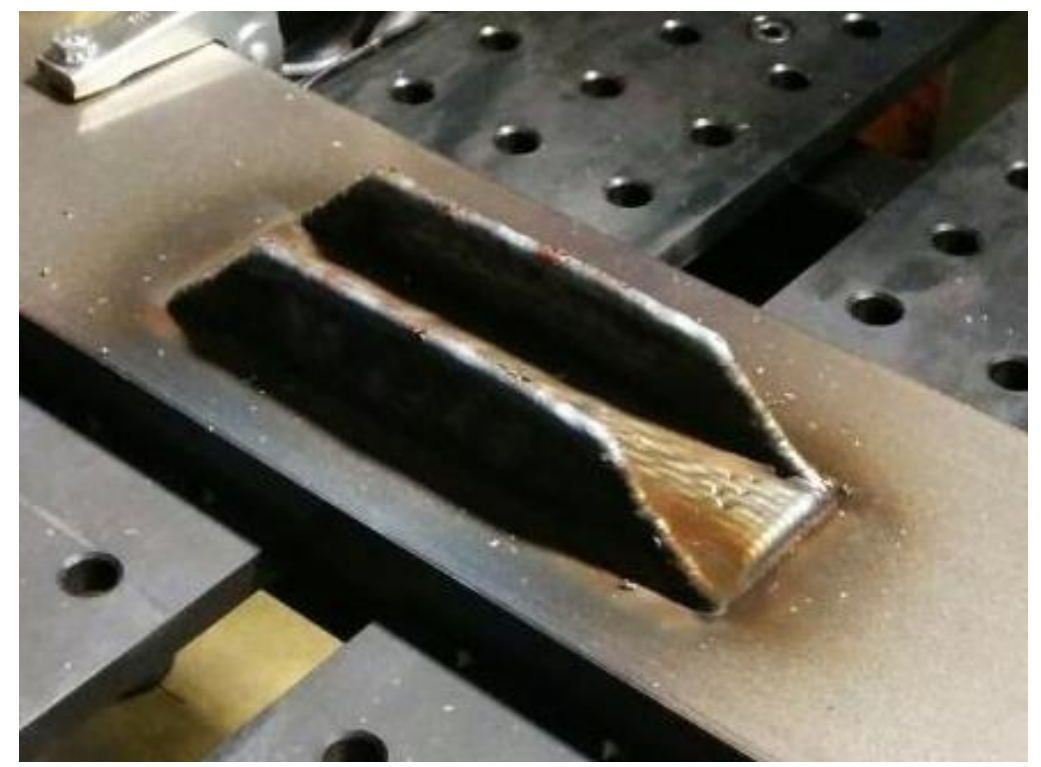

Figure 24: Bumper section 


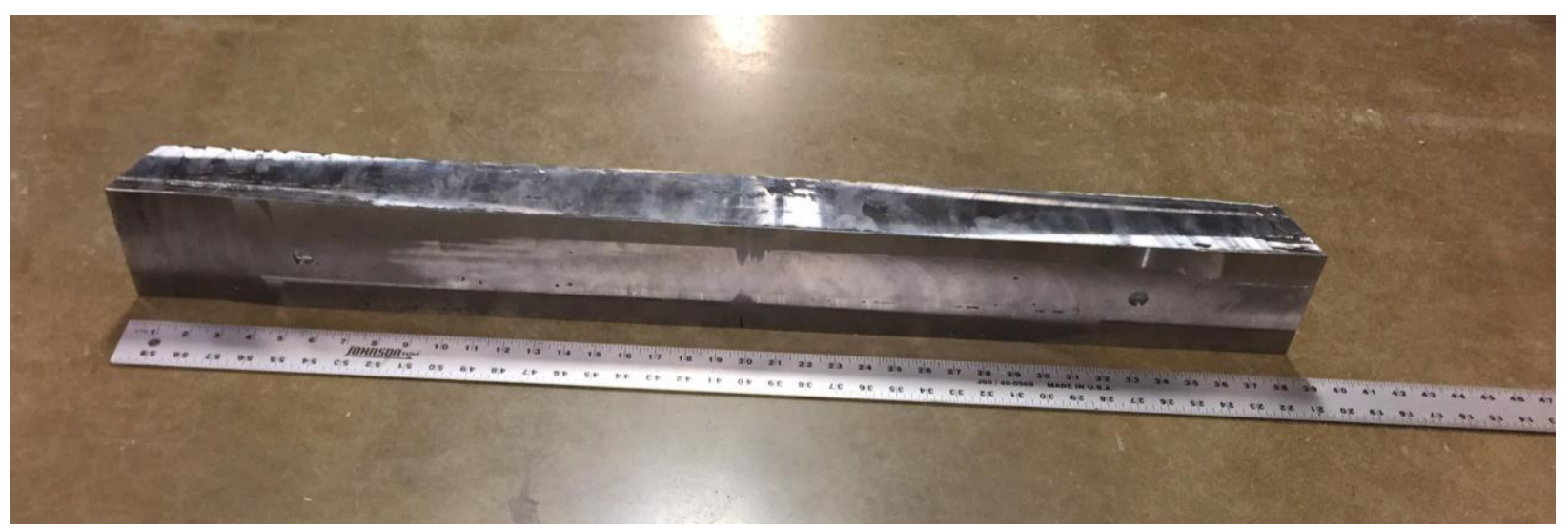

Figure 25: Finished bumper
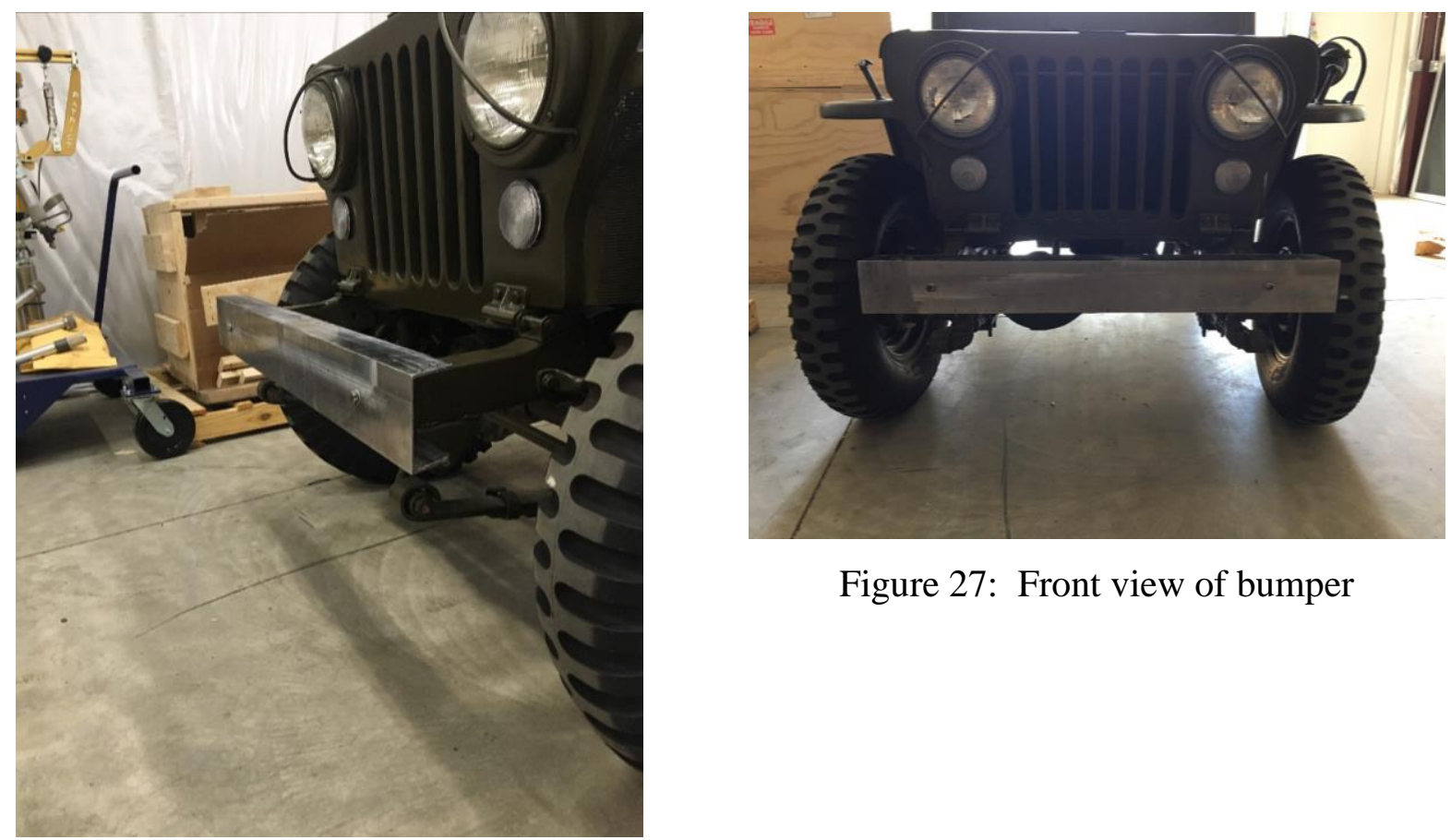

Figure 27: Front view of bumper

Figure 26: Side view of bumper 


\section{METAL BAAM}

As stated previously, there is growing interest in AM for direct part replacement and tooling for military applications. However, almost all existing commercial AM systems are limited to small part sizes (less than 1 cubic foot), low production rates (approximately 1 cubic inch per hour), and very expensive feedstocks (in excess of $\$ 100 / \mathrm{lb}$ ). Prior work at ORNL has focused on largescale (greater than 100 cubic foot), high deposition rate (in excess of 2500 cubic inches per hour), and low cost (less than $\$ 5 / \mathrm{lb}$ ) composite AM. This BAAM technology has rapidly progressed from prototype to product in less than three years. Primary applications of BAAM technology today are tooling and prototyping. The primary focus of the second part of this program was to determine if it is possible to apply BAAM technologies to large-scale metal additive manufacturing.

There has been prior work in the area of large-scale metal additive manufacturing. In terms of commercial systems, there are currently two options: ultrasonic additive manufacturing (UAM) and wire fed electron beam welding.

\subsection{Ultrasonic Additive Manufacturing}

UAM is an approach to AM based on building structures by using an ultrasonic energy to fuse types of material, which buildsthe structure layer by layer. The process operates near room temperature using vibration, rather than melting the feedstock, as the primary energy source. The ultrasonic vibration fractures surface oxides and creates metal-to-metal bonds.
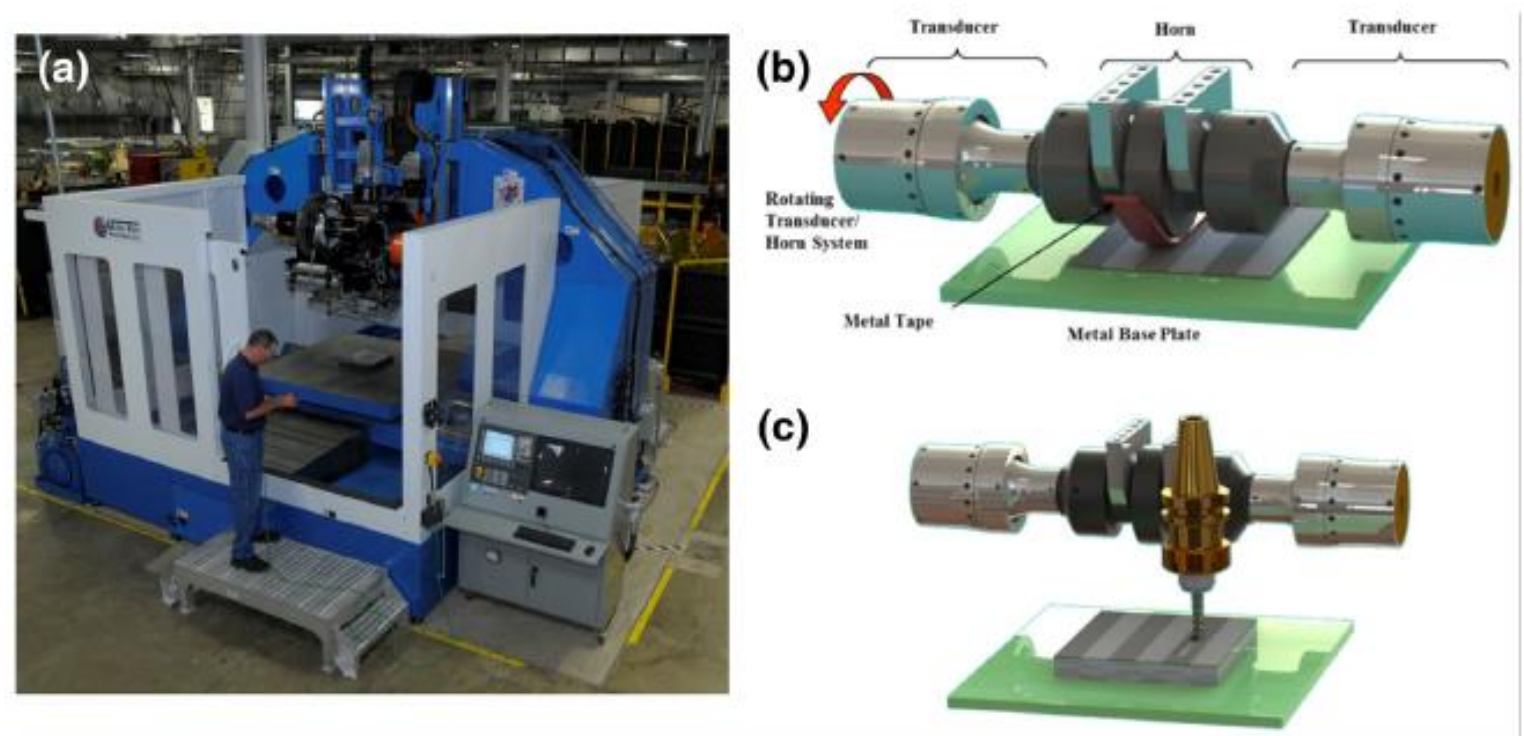

Figure 28: Ultrasonic AM system (a), ultrasonic head (b), and (c) machining stage

The primary advantage of UAM is the ability to join softer materials (aluminum, copper, soft steels) that are typically difficult to weld because of its low temperature manufacturing 
capabilities. The primary disadvantages are the limitation to softer alloys and the need for integrated machining to achieve near-net shape parts.

\subsection{Electron Beam Additive Manufacturing (EBAM)}

In 2009, Sciaky introduced the first electron beam wire feed welding system intended for additive manufacturing. The original intention of the technology was to rapidly manufacture large titanium aerospace parts. The EBAM process utilizes wire feedstock and an electron beam heat source to produce near-net shape parts. The advantage is the process is relatively fast (up to $20 \mathrm{lbs} / \mathrm{hr}$ ). However, the EBAM process requires a vacuum chamber which increases cost and limits part size. In addition, the process melts the material resulting in extremely high temperature gradients and results in high residual stress.

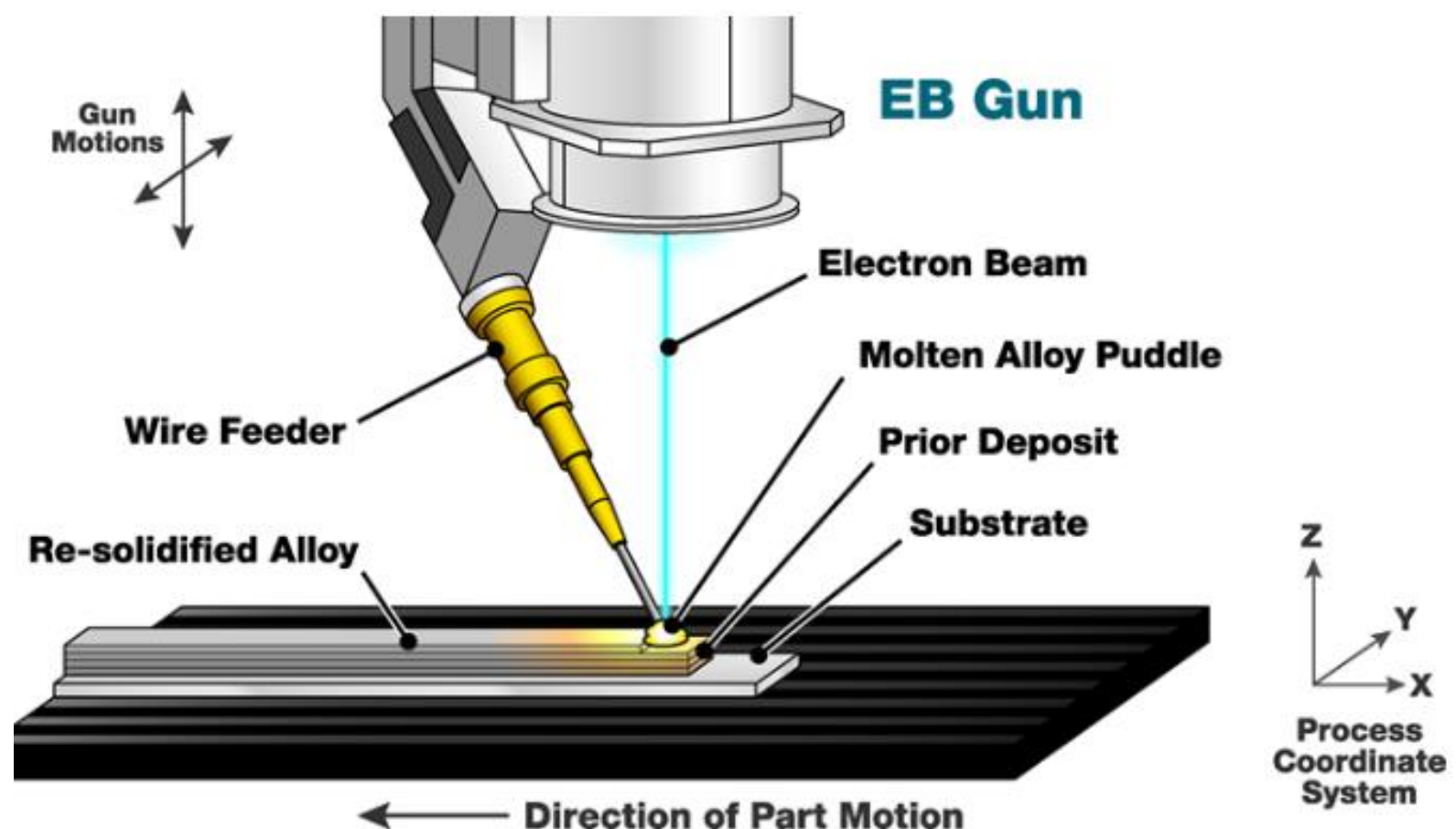

Figure 29: EBAM process

\subsection{Cranfield University}

In terms of emerging platforms, Cranfield University is developing Wire Arc Additive Manufacturing (WAAM). WAAM uses a robotic system and a metal inert gas (MIG) welding process to manufacture parts layer by layer. The process uses conventional robotic and arc welding processes. The advantage is the potential for very low cost systems. The challenge with WAAM is the control of residual stress.

To help scope out the interest and technical challenges, ORNL hosted a metal BAAM workshop on March 11, 2016. 


\subsection{Metal BAAM Workshop}

The charter for the workshop was outlined by the Department of Energy (DOE) Advanced Manufacturing Office program manager. Attendees included representatives from the aerospace, automotive, energy, construction, and machine tool industries as well as national labs and government officials. The status and impact of the BAAM for polymer matrix composites was presented as the background motivation for the workshop. Additionally, the extension of underlying technology to low-cost metals was proposed with the following goals:

(i) High deposition rates (approaching $100 \mathrm{lbs} / \mathrm{h}$ );

(ii) Low cost $(<\$ 10 / \mathrm{lbs})$ for steel, iron, aluminum, and nickel as well as higher cost titanium,

(iii) Large components (major axis greater than $6 \mathrm{ft}$ ) and

(iv) Compliance of property requirements

The above concept was discussed in depth by representatives from different industrial sectors including welding, metal fabrication machinery, energy, construction, aerospace and heavy manufacturing. In addition, DOE's newly launched High Performance Computing for Manufacturing (HPC4MFG) program was reviewed. This program used thermo-mechanical models to illustrate and clarify the interactions between design, process, and materials during additive manufacturing. Following the presentations, all the attendees took part in a brainstorming session where everyone identified the top 10 challenges in large-scale metal AM from their perspective. The feedback was analyzed and grouped in different categories including:

(i) CAD to PART software,

(ii) selection of energy source,

(iii) systems development,

(iv) material feedstock,

(v) process planning,

(vi) residual stress \& distortion,

(vii) postprocessing,

(viii) qualification of parts,

(ix) supply chain, and

(x) business case

Furthermore, an open innovation network methodology was proposed to accelerate the development and deployment of new large-scale metal AM technology. The goals of the open innovation network methodology were to create a new generation of high deposition rate 
equipment, affordable feed stocks, and large metallic components to enhance America's economic competitiveness. This workshop was conducted during the execution of this program to help reinforce the motivation for research from an industry perspective and tohelp establish future applications and opportunities for the technology. The results of this study were shared with the team prior to publication. ${ }^{4}$

\subsection{Program overview}

Although polymer composites hold great promise for many applications such astooling or lightweight structures, most military structures must be manufactured using metallic materials like steel, aluminum, and iron. Therefore, the second objective of this project is to expand BAAM capabilites to allow production of metal components. Figure 30 shows a review of metal joining processes in comparison with the current BAAM technology and project targets, with respect to deposition rates, build volume, and feedstock cost. From perspective of deposition rate and build volume, arc welding, ultrasonic consolidation, and shape metal deposition welding hold the greatest potential for metal-BAAM as noted in Figure 30. Aluminum, steel powder, and wire are the only structural feedstock costs under $\$ 10 / 1 b$, depicted in Figure 30.

\footnotetext{
${ }^{4}$ http://info.ornl.gov/sites/publications/files/Pub62831.pdf
} 

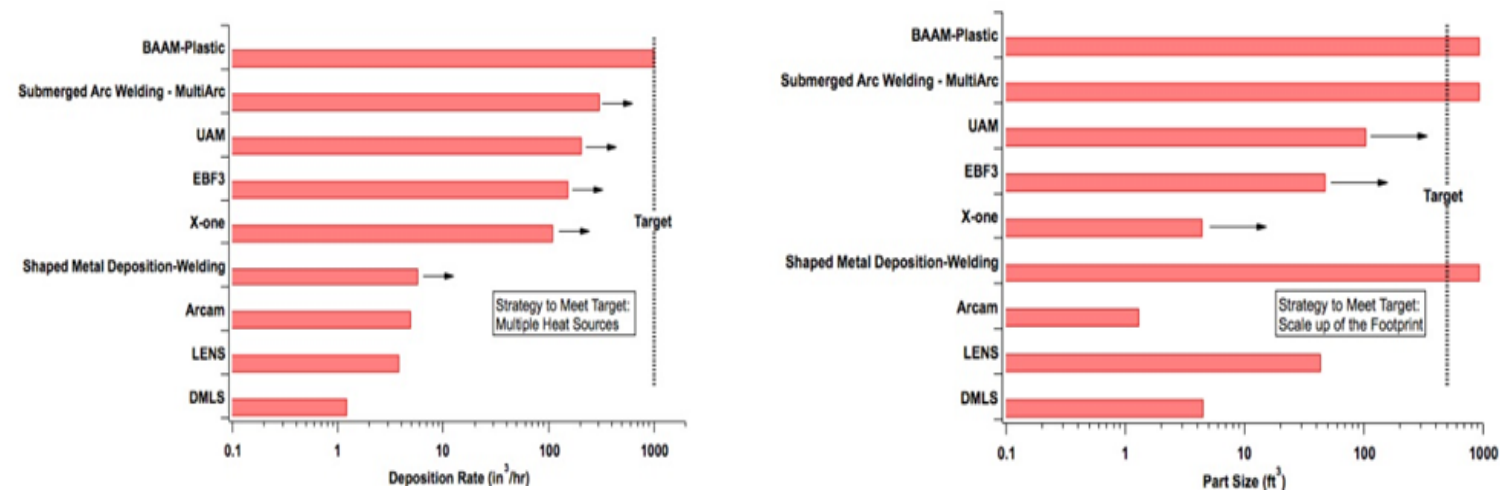

Metal AM deposition rates Metal AM volume

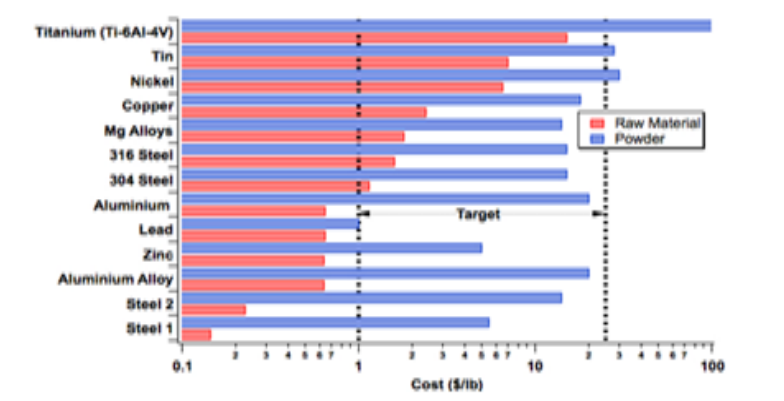

Figure 30: Metal AM feedstock cost

The proposed work was divided into two tasks. The first task identified a process to enable rapidly manufactured metallic parts. The project extensively leveraged previous work in BAAM with the use of existing infrastructure (robot and gantry systems) and slicing software at ORNL. For the first task, ORNL focused on identifying a process for rapid deposition of low cost steel and/or aluminum. At the end of the first task, the objective was to manufacture a large metal structure, which would be less than four feet in maximum length, in approximately 24 hours using the identified metal additive manufacturing process. If successful, the component will be integrated onto an operational Willy's Jeep.

\subsection{Metal Injection Molding feedstock to BAAM}

For high throughput, or the amount of material passing through the system, one option considered during the execution of this program was replacing the carbon fiber reinforced pellets in BAAM with metal injection molding (MIM) pellets. MIM pellets are highly loaded (up to $50 \%$ by volume, $90 \%$ by weight) with metal powder, and they use a thermoplastic binder to hold the powder together. One of the challenges with metal AM technologies is the large temperature gradients needed to melt the feedstock and the resultant residual stress because of the high temperatures that can lead to part distortion. ORNL's hypothesis was to melt the binder, which has a melt temperature close to 200 degrees Celsius, rather than the metal and build a "green" part (e.g unsintered) layer by layer. Preliminary efforts demonstrated that this process is viable with production rates that can exceed the $100 \mathrm{lb} / \mathrm{hr}$ target. Once the part is manufactured near- 
net shape, it is moved into a furnace and sintered to manufacture the final part. Like the traditional binder jet AM technology, the final part would have high levels of porosity approaching $40 \%$. A conventional approach to densification is to back infiltrate the sintered part with a lower melt temperature filler metal such as bronze. Preliminary work has shown feasibility. As an example, Figure 31 shows the BAAM being used to manufacture rare earth magnetic material.

In this work, we utilized the Big Area Additive Manufacturing (BAAM) system located at the Manufacturing Demonstration Facility at Oak Ridge National Laboratory to fabricate near-netshape isotropic $\mathrm{NdFeB}$ bonded magnets. The BAAM system deposits high-performance engineered thermoplastics and customized thermoplastic composites via melt extrusion processing, which enables rapid manufacturing of parts completely unbounded in size. Figure 31(a) shows the BAAM printing process of the bonded magnets: the nozzle deposits layers of magnetic materials which are fused together and solidify to form the desired shape. Instead of requiring pre-extruded filament feedstock commonly used in industry standard extrusion-based system, BAAM combines melting, compounding, and extruding functions to deposit polymer product at a controlled rate, a schematic is shown in Figure 31(b). The feedstock materials here are magnetic pellets composed of $65 \mathrm{vol} \%$ isotropic NdFeB powder (MQP-B+-10118-070) and $35 \mathrm{vol} \%$ Nylon-12. It is worth mentioning that the printing of the extruded nylon magnet composite flows even better than the widely explored 3D printing plastic filament acrylonitrile butadiene styrene (ABS), and renders high accuracy. The magnetic, mechanical, and microstructural properties of the BAAM fabricated bonded magnets are investigated and compared with respect to the traditional injection molded commercial products made from the same starting materials. The results obtained with the BAAM fabricated bonded magnets are much better than those of traditional injection molded magnets.

\section{(a)}

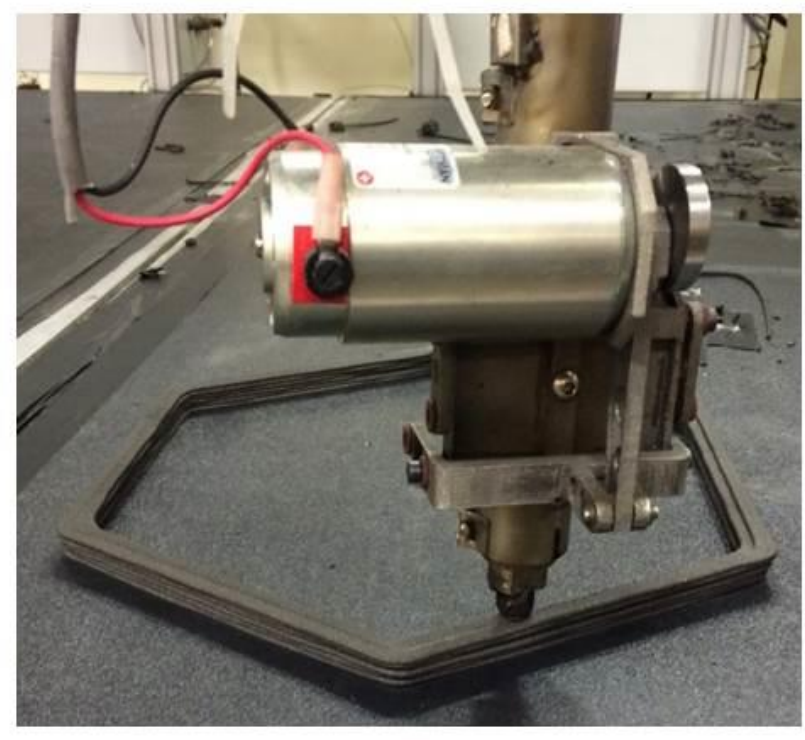

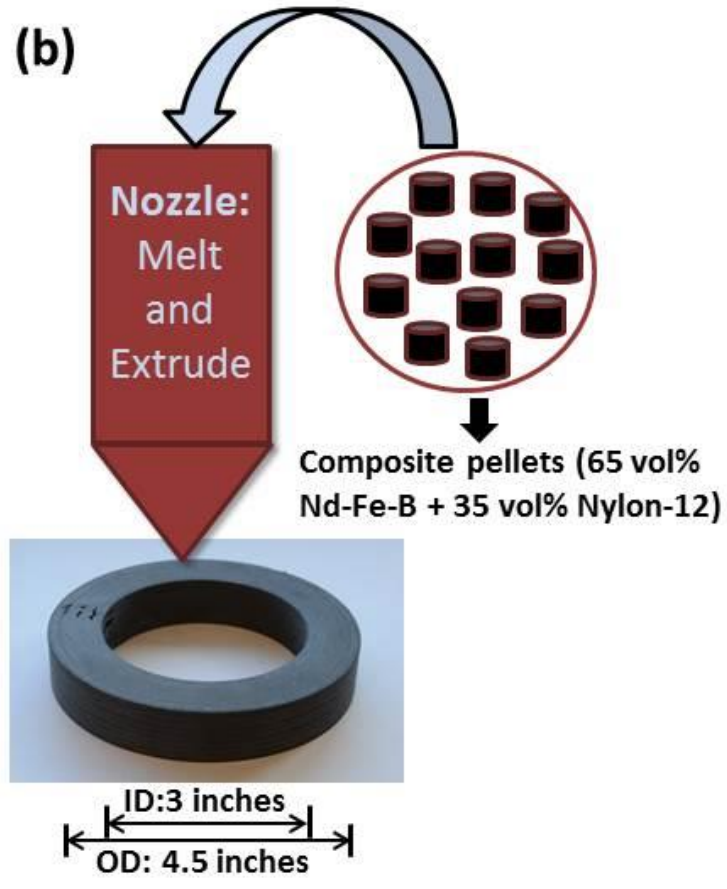

Figure 31: Printed rare earth magnets 
There were two fundamental challenges that were not effectively solved during the execution of this project. First, with conventional metal injection molding, part sizes are restricted to relatively small volumes to effectively remove the binder from the part during the sintering process. As part features thicken, the binder is heated, so it becomes difficult for the binder to escape the part. This can create defects in the part. Second, the sintering process would require an extremely large furnace for the final parts, which limits the facilities that could use the technology. However, this process still holds great promise. Recent efforts at ORNL demonstrated the ability to rapidly manufacture large magnets using the process. Rather than loading the pellets with structural material, they were loaded with rare earth magnetic powders. After the part was printed, it was exposed to high magnetic fields to magnetize the structure.

Follow-up efforts for metal BAAM based on MIM feedstock need to focus on solving two issues: First, is it possible to locally (layer by layer) sinter the material and remove the binder? Processes can include exposing the layer, after it is printed, to infrared energy to burn off the binder and lightly sinter the remaining powder. Second, is the issue of back infiltration. Is it possible to go over the same layer with a secondary material that can be locally melted and infiltrate the layer without excessive temperatures or resultant stress?

The second approach, which became the focus of the remaining work, was to develop a robotic wire arc melting system.

\subsection{Robotic Tungsten Inert Gas Welding Metal AM System}

The robotic metal AM work cell consists of a walled 11 -ft by 11 -ft by 8 -ft high opaque safety enclosure with a viewing panel and welding curtain on the front. The cell front also includes an access door. The robot is a Mitsubishi PA10-7C manipulator. Welding capability is provided by a Miller Dynasty 350 tungsten inert gas (TIG) welder and a CK Worldwide WP-5 wire feed unit. A Red-D-Arc portable fume extractor is used to meet ORNL safety requirements and to permit observation level human access during welding. The work cell is shown in Figure 32 and Figure 33.

The PA10 robot is a seven degree-of-freedom (DOF) manipulator with a one-meter reach and a $10 \mathrm{~kg}$ end-effector payload. Normal industrial robots typically have six DOF. The extra degree of freedom on the PA10 permits better use of a larger percentage of its work volume, but it also requires additional software to manage the use of the extra joint axis. The purpose of the robot is to position the welder torch and precisely maintain the wire feed position and orientation with respect to the torch. This is done with a custom 3D-printed end-effector mounted on the end of the robot manipulator.

The Miller Dynasty 350 TIG welder is designed to supply a maximum of 350A and is rated for a continuous $250 \mathrm{~A}$ at a $100 \%$ duty cycle and $300 \mathrm{~A}$ at a $60 \%$ duty cycle. Turning the machine on and off during a duty cycle at high weld currents can impact 3D print time. The welder is located outside of the work cell where it can be readily accessed during operation. The welder is equipped with an optional automation kit that permits the robot computer to control most welder functions as well as receive status and error messages. 
Several welding tables have been used during the development of this system. The final version is a 38 in deep by 46 in wide by 24.5 in high unit. The table can be modified by shortening the legs for larger or taller printed objects. Steel plates, 1 in thick, of various sizes are clamped to the table and are used to build the base plate.

The CK Worldwide model WP-5 wire feeder was used because it was designed as a stand-alone unit. Most welding robots are substantially larger and can mount wire feeder hardware directly on the robot upper arm, but this was not practical with the Mitsubishi PA10-7C. No automation kit for the CK Worldwide model WP-5 was available. Therefore, a custom computer interface was created that managed wire feed on/off, wire feed rate, and the various delays and retracts necessary for proper wire feed welding. As with the welder, the robot controller also controls the wire feeder.

The custom robot end-effector mounts both the torch and the feed nozzle for the wire feed system. While the torch is fixed in position and orientation in the end-effector, the wire feed delivery system is designed to provide several degrees of freedom for positioning the wire feed nozzle. There is also an extended straight length of tubing on the wire feed mechanism to minimize the curl of the wire as it exits the feed nozzle. This characteristic is especially problematic during print motions that require a wrist rotation because it is important to keep the wire feed ahead of the weld pool to successfully complete the TIG cold wire process. The endeffector is shown in Figure 34.

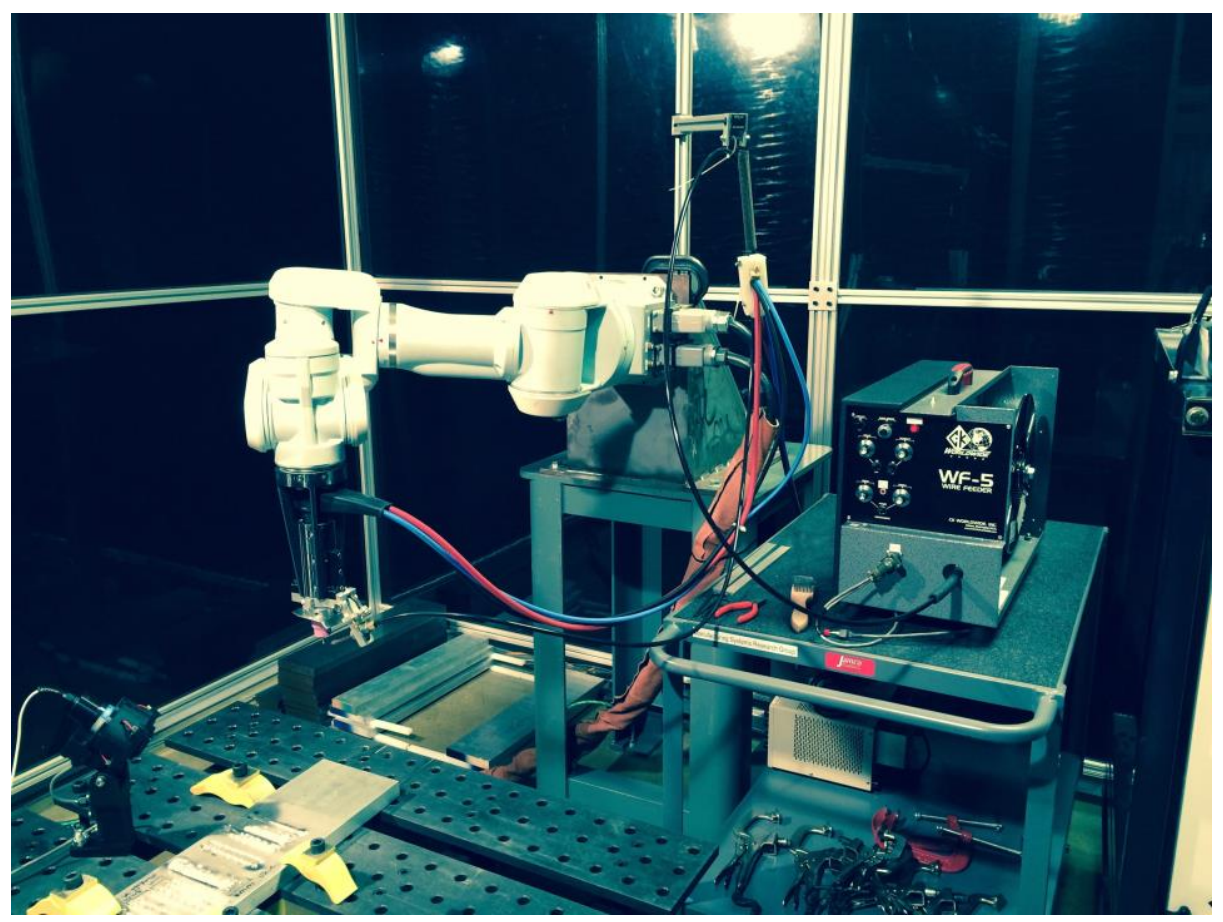

Figure 32: Robotic work cell. 


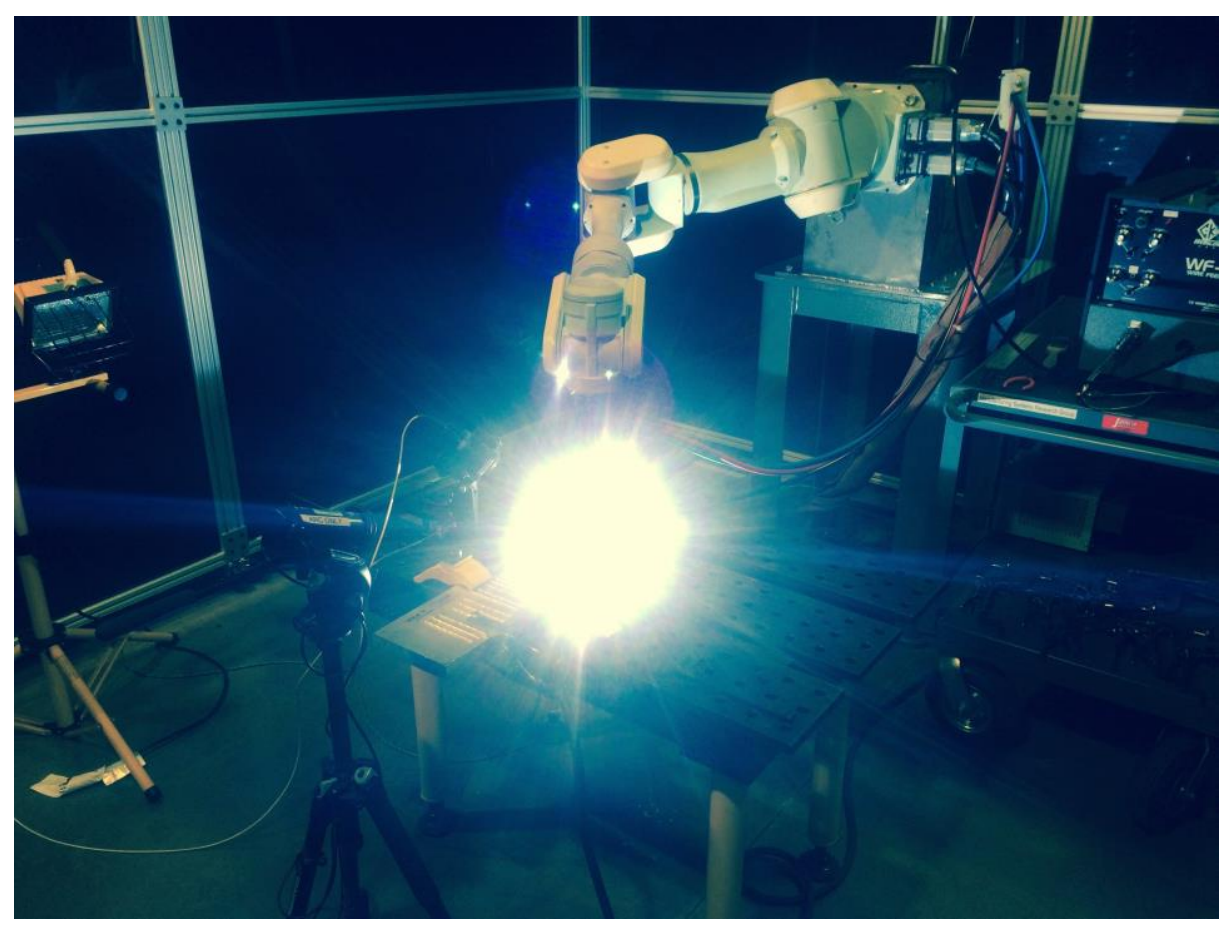

Figure 33: Robotic work cell during active printing

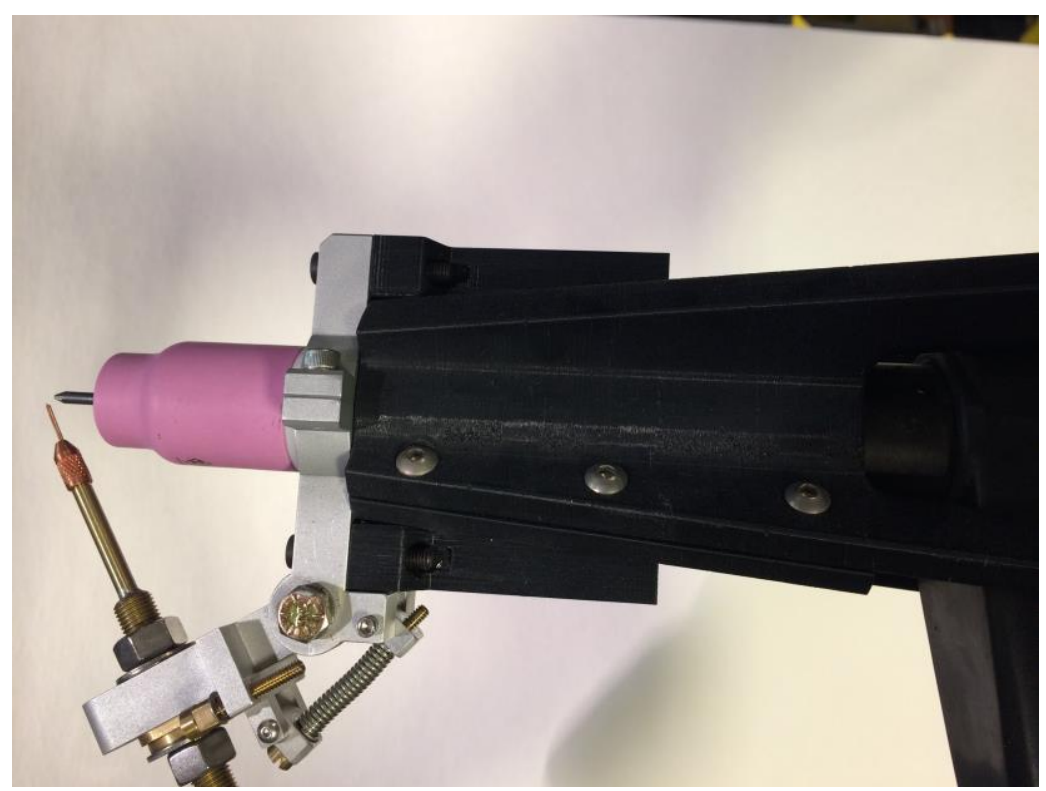

Figure 34: Custom torch and wire feed alignment mechanism

Two wire materials have been successfully used for builds on the Mitsubishi PA10-7C TIG system — mild steel and aluminum. The steel wire is Radnor brand ER70S-6 alloy. The aluminum wire is Lincoln Electric brand SuperGlaze 5356 series wire - $\mathrm{AlMg} 5 \mathrm{Cr}(\mathrm{A})$. While the torch and wire feeder can accommodate various wire sizes, all process parameters have been optimized for .045 in wire, and that is all that has been used to date. 
In summary, the robot, welder, wire feeder, and all auxiliary equipment function seamlessly as an integrated system and are controlled directly by the robot control computer. Welder and wire feeder automation provide the ability to drive weld pool generation and wire addition, which builds metal objects. Well established commercial welding components, including standard welding wire, were used to maximize system reliability wherever possible.

\subsection{Slicing Software (CAD to Part)}

The ORNL Slicer is a software program developed at Oak Ridge National Laboratory for creating machine instructions in AM. Parts that are to be built, or printed, on a 3D Printer are first designed in a CAD package, such as Solidworks. The part is then exported as an STL file and loaded into the ORNL Slicer. The slicer then creates GCode, which is a file with instructions for the machine on how to create the part.

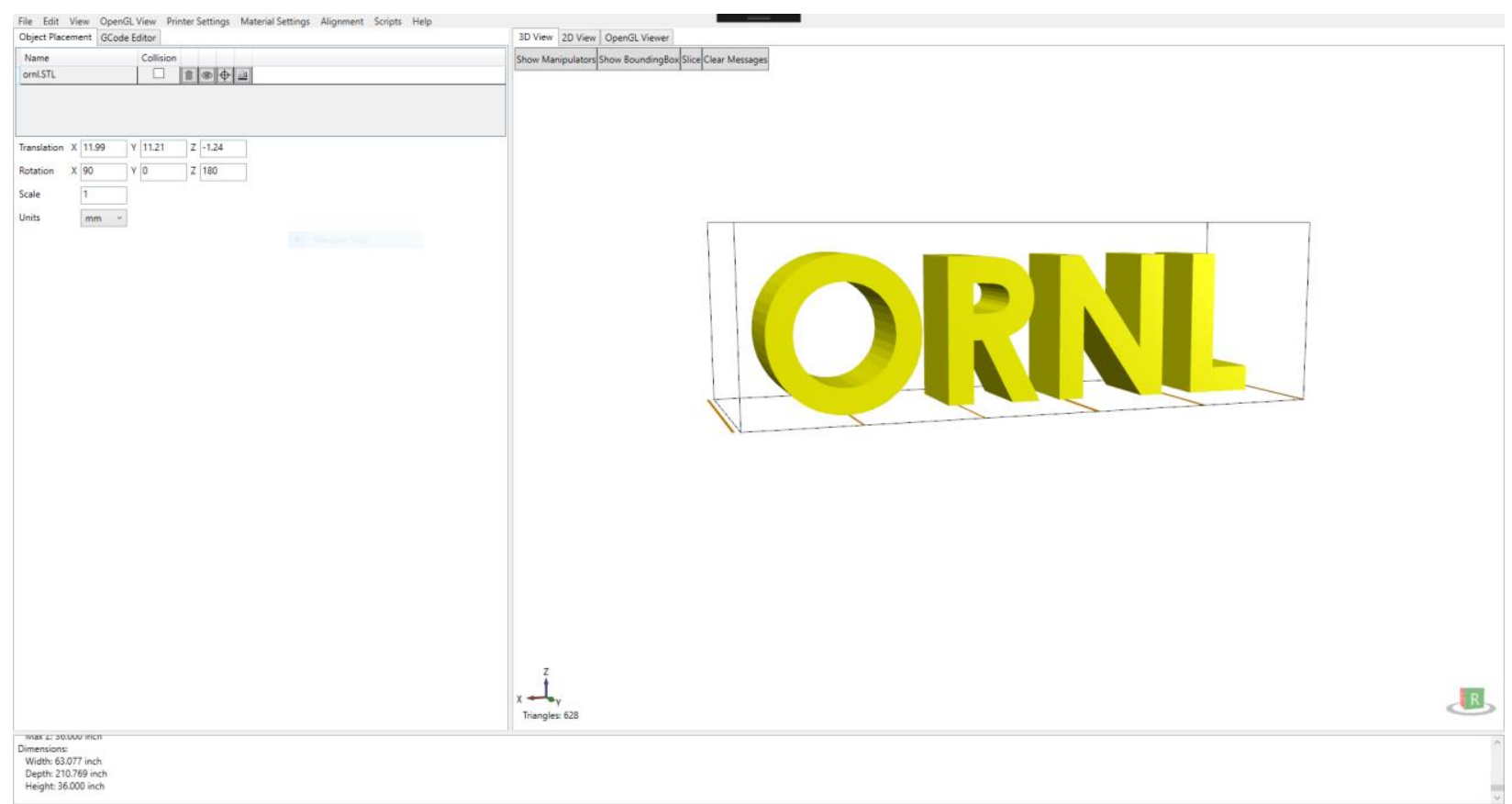

Figure 35: The ORNL Slicer with an ORNL part loaded into the visualizer

The interface for ORNL Slicer can be seen in Figure 35. The user first loads in an STL, such as the ORNL letters seen in Figure 35. Next, settings can be adjusted, such as the infill density and layer thickness. Once the settings are configured as desired, the slicing happens. It's called slicing because the software takes the solid part model and "slices" it into thin cross sectional layers of thickness equal to the layer height the user has input. These slices are made by planar intersections of the triangular facets of the STL. It creates one slice for every layer of the part. The slices are treated as polygons, where each intersection of a triangle's edge results in a point on the perimeter of the polygon. These polygons are then fit with toolpaths specific to the settings the user has input. These toolpaths tell the machine how to traverse the layer and where and when to deposit material. The toolpaths are then converted into a GCode file, which has the toolpaths formatted as strings specific to the machine that will be printing the part. The Slicer 
can visualize these toolpaths to allow the user to see an approximation of the printed object, Figure 36 and Figure 37.

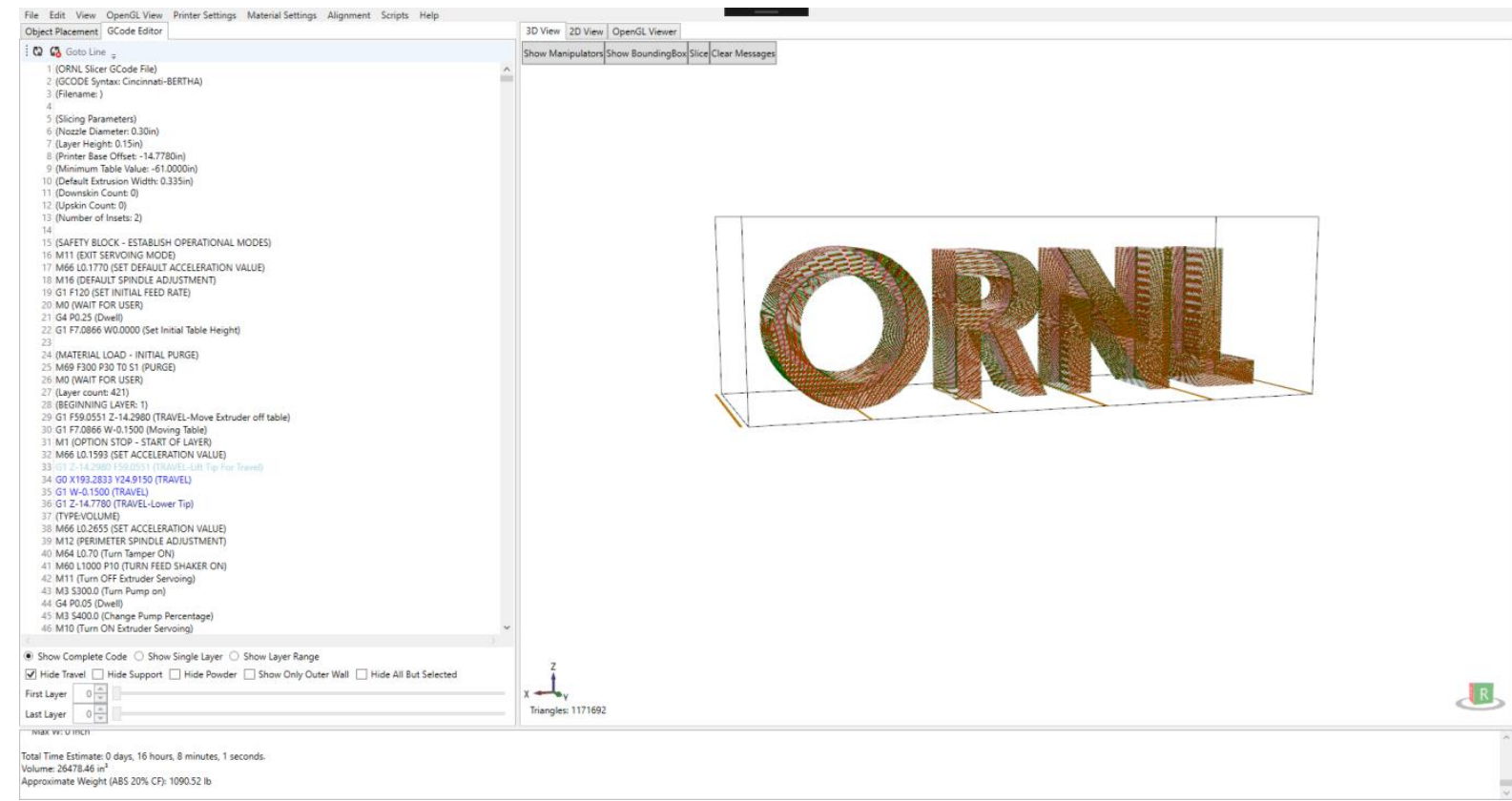

Figure 36: Toolpaths for the ORNL letters visualized

The Slicer was originally developed for polymer printing on BAAM in 2014. It has since been adapted for metal welding on Metal BAAM. These processes have many similarities but just a few differences that required new settings and algorithms in the slicing software. The new settings and algorithms allowed metal parts to be created with high accuracy and repeatability. With the growing number of machines, even the way machines are described in the slicer had to be modified.

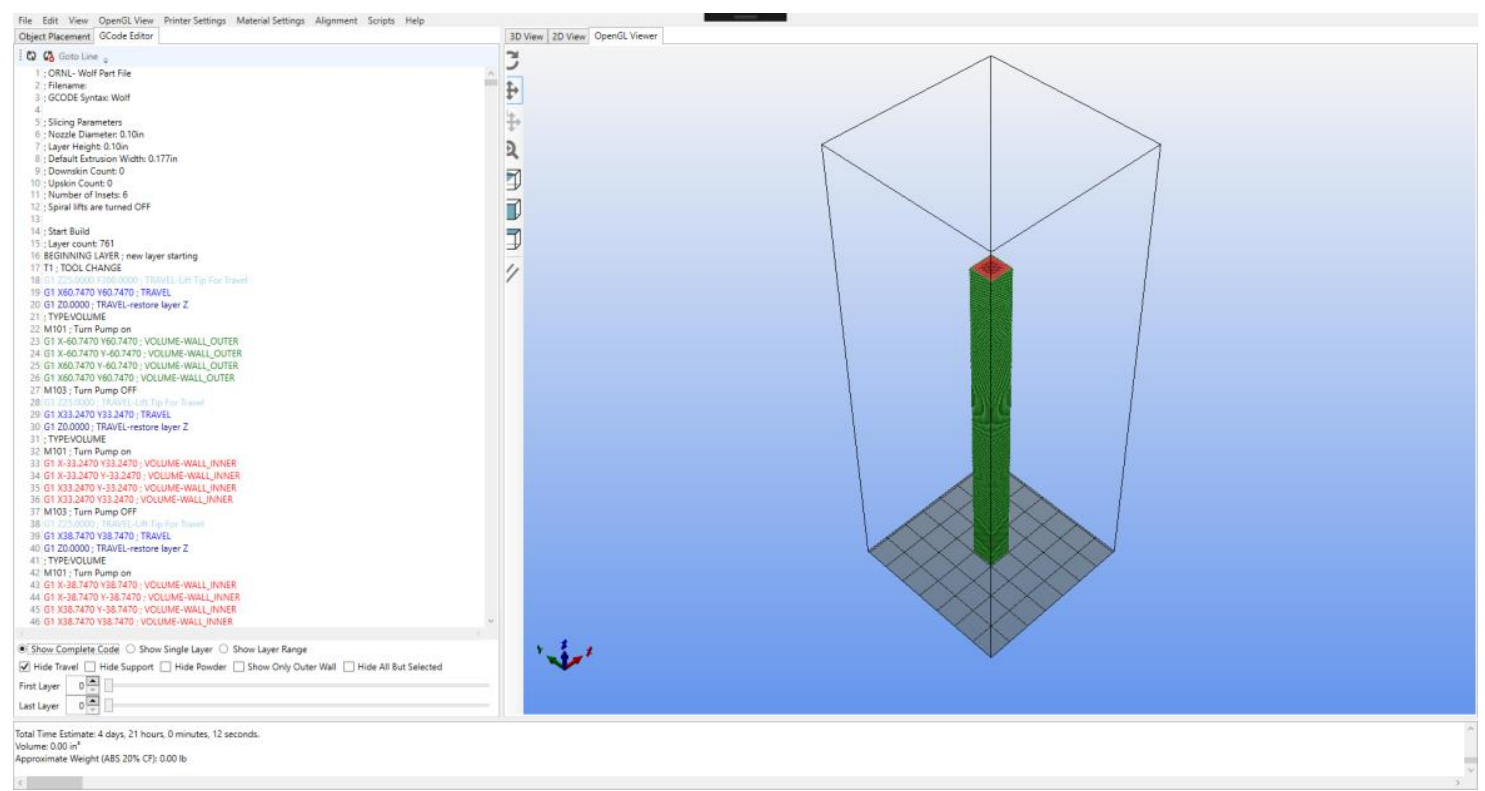

Figure 37: Printing visualization for metal BAAM 
The metal printing process varies from the polymer printing process in many ways. These discrepancies required major rewriting of certain sections of the Slicer. A big difference between metals and polymers is cooling. On the polymer machines, less heat is put into the part during printing. The typical ABS part is printed at $250 \mathrm{C}$ whereas the typical Metal BAAM part is at 1600C. This means that the metal part needs longer to cool down and needs to have paths more optimized for thermal history than geometry. The way the slicer accounts for this increased heat buildup is the addition of cooling passes. The slicer determines if it needs to add a cooling pass automatically and writes the command into the GCode. This cooling pass is a retrace of the previous layer, but the welder is turned off. The robot blows cooling gas over the metal to cool it down so that the next layer can be added.

The following is a list of slicer changes for metal BAAM:

- Inset printing from inside out

- Island order optimization

- Based on $\mathrm{x}$, $\mathrm{y}$ of center point to maintain even heat distribution

- Pick the island furthest away that hasn't been printed

- Random ordering process

- Seam selection

- Find the first line that is longer than a threshold and start in the middle of it

- Random

- Rotating seam based on index in array

- Rotating with incremental offset

- Alternate inset and perimeter directions

- Skeleton printing without percentage paths

- Reverse tip wiping with extrusion

- Cooling mode to retrace path with gas

- New GCode Syntax

Another issue of metal printing is seams. The starting and stopping point for polymer printing is often unsightly, but it is not a huge structural or process issue like it is with metal printing. Often when printing polymer parts, it is desirable to align the seams along a single edge so the rest of the part is relatively flawless. In metal printing, the welder's starting and stopping pointoften has a defect, which significantly intensifies if the machine starts and stops there every layer. This defect weakens the structural integrity of the part and can cause failure during printing. This issue is compensated for by adjusting the starting location for each layer and adjusting the direction of the printing.

Layer height is the same layer after layer on polymer BAAM, but this is not so for metal BAAM. The layer height on metal BAAM is affected by the previous layer. The temperature, size, and surface finish all affect how thick the layer being deposited will be. The slicer must compensate for this and accurately predict where material will flow. If too much material is present, it will build up and cause the torch to crash. If too little material is present, there will be voids in the print which could affect the printing of the next layer. 
Slicer development for metal BAAM is an active project, and new changes are being made each week to adapt the process as needed. Dozens of small changes, not listed here, have been made to account for the difference in techniques between metal BAAM and polymer BAAM. The Slicer is imperative for the successful operation of metal BAAM and will continually be developed as long as metal BAAM research continues. .

\subsection{Sample Generation and Analysis}

Test pieces were generated in both steel and aluminum to create "dog bones" and "charpys" for structural testing. The test builds were designed to permit bead orientation in $\mathrm{X}, \mathrm{Y}$, or Z along the long axis of the test pieces. ASTM dog bone samples were used for tensile testing. Charpy samples underwent impact testing. The details of sample generation and the results of the testing are presented in the following sections.

\subsubsection{Sample Generation}

Figure 38 shows the path for the motions used to generate a single bead. Blocks were printed with specific bead orientations to using as base material to machine the $\mathrm{X}, \mathrm{Y}$, and Z-oriented dog bones and Charpys. Table 3 outlines the process parameters of bead generation.

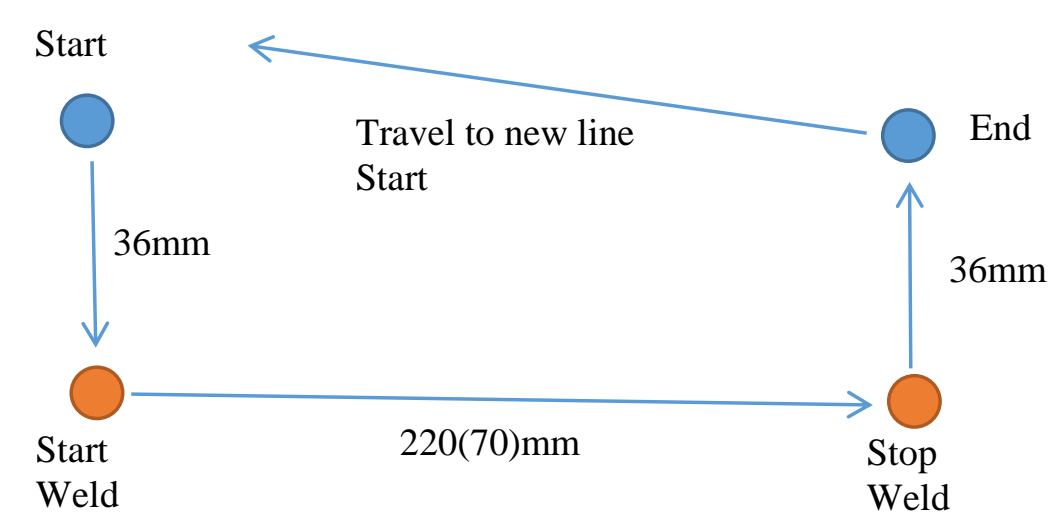

Figure 38: Print execution path

Table 3: Weld parameters

\begin{tabular}{|l|l|}
\hline Parameter & Value \\
\hline Deposition speed & $8 \mathrm{~mm} / \mathrm{s}$ \\
\hline Travel speed (transition when not welding) & $75 \mathrm{~mm} / \mathrm{s}$ \\
\hline Wire speed & $51 \mathrm{~mm} / \mathrm{s}$ \\
\hline Current & $270 \mathrm{~A}$ initial, ramp down to $250 \mathrm{~A}$ \\
\hline
\end{tabular}


Start Weld Sequence: gas on, arc (50A) on, gas on, 700ms delay, arc 100A, 700ms delay, arc final Amps (270), wire On, 700ms delay.

Stop Weld Sequence: 200ms, wire off, 1500ms, Amp 120, 300ms, Amp 50, 300ms, arc off, gas off (automatic 10s post flow).

The data collection test procedure sequence is as follows:

1. Record base line temperature

2. Record time/current settings

3. Initiate print

4. Record time "in" and "out" for pauses

5. Record temperature snapshot after each layer

6. Record current for each layer

7. Record final time after the print is finished

\section{Z-Direction Build}

The z-direction is defined as the vertical build direction. The resulting layer to layer adhesion is of interest. Degradation of the properties may occur because of porosity from unfilled seams between layers and variability in prior surface oxidation and temperature. The basic geometry consisted of 3 beads per layer, 200mm long (tapered to about 160mm),131 layers, $3.5 \mathrm{~mm}$ spacing between beads roughly $10.5 \mathrm{~mm}$ wide, and about $1.6 \mathrm{~mm}$ per layer thickness.

The following settings apply only to $\mathrm{Z}$ direction

Start Weld Sequence: gas on, arc (50A) on, gas on, 700ms delay, arc 100A, 700ms delay, arc final Amps (270), wire On, 700ms delay

Stop Weld Sequence: 300ms, wire off, 1300ms, Amp 120, 300ms, Amp 50, 300ms, arc off, gas off (automatic 10s post flow)

Current range: $270 \mathrm{~A}-230 \mathrm{~A}$ (steady state). Depending on the plate type, the starting current was $270 \mathrm{~A}$ or $200 \mathrm{~A}$ and immediately ramped up to $270 \mathrm{~A}$.

Temperature: After the upper layers heated up to over 340C, there was a cooling period after every layer. This cooling period ensured that the temperature would return to $340 \mathrm{C}$. The period lasted about 2.5 minutes. 
Figure 39: Z build architecture top view

\section{$X$-Direction Build}

The $x$-direction is defined as the welding direction. The mechanical property of the weld material in the direction of the weld bead is of interest. The basic test samples (shown in Figure 40) were 16 beads per layer, 220mm long, minimum 6 layers, maximum 10 layers, $3.5 \mathrm{~mm}$ spacing between beads roughly $56 \mathrm{~mm}$ wide, and about $2 \mathrm{~mm}$ per layer thickness.

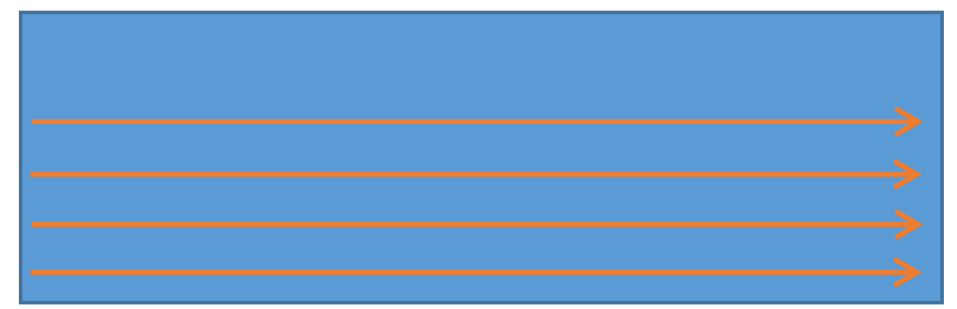

Figure 40: $\mathrm{X}$ build architecture top view

\section{Y-Direction Build}

The y-direction is defined as the bead-to-bead interface on a given layer. The bonding strength between adjacent beads is of interest. The basic test samples (shown in Figure 41) were 64 beads per layer, $70 \mathrm{~mm}$ long, minimum 6 layers, $3.5 \mathrm{~mm}$ spacing between beads roughly $224 \mathrm{~mm}$ wide, and about $2 \mathrm{~mm}$ per layer thickness.

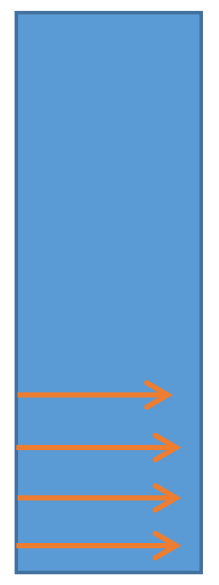

Figure 41: Y build architecture top view 
After the X, Y, and Z builds were generated, the resulting blocks were cut from the build plate, and dog bones were machined for testing. Dog bone dimensions and samples are shown in Figure 42 and Figure 43 respectively. Charpy dimensions are illustrated in the following data analysis section. Tested sample Charpys are shown in Figure 44. Additional samples were cut from the tested dog bones and processed for micrograph generation. A few representative samples are shown in Figure 45.

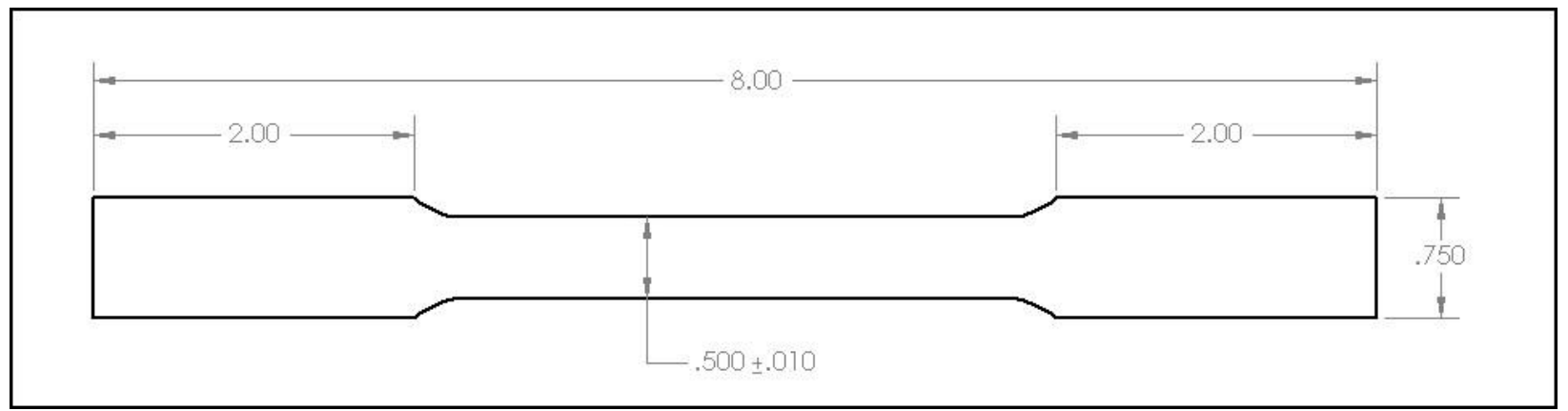

Figure 42: Tensile testing dog bone dimensions (in inches)

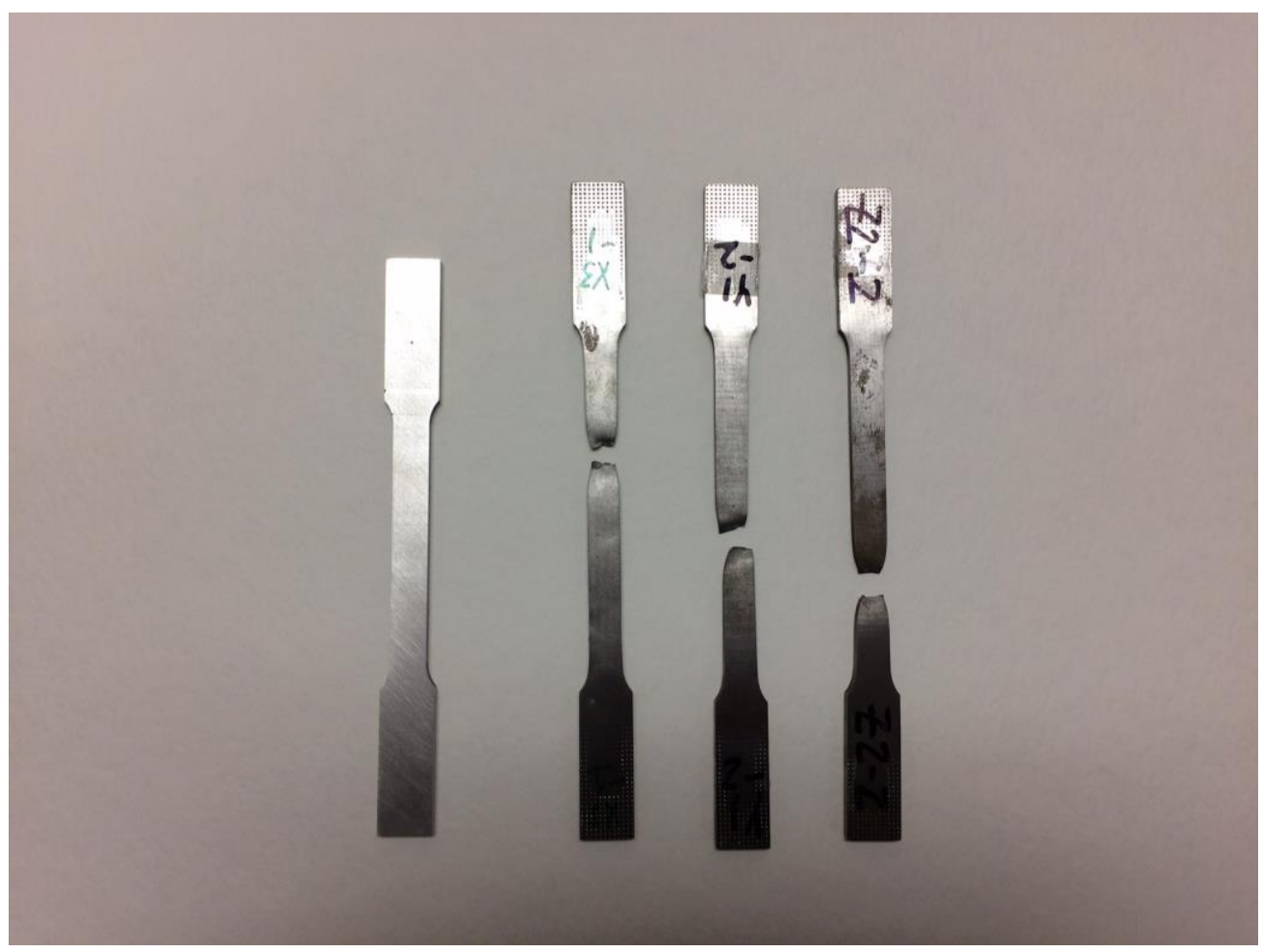

Figure 43: Tensile testing dog bone samples 


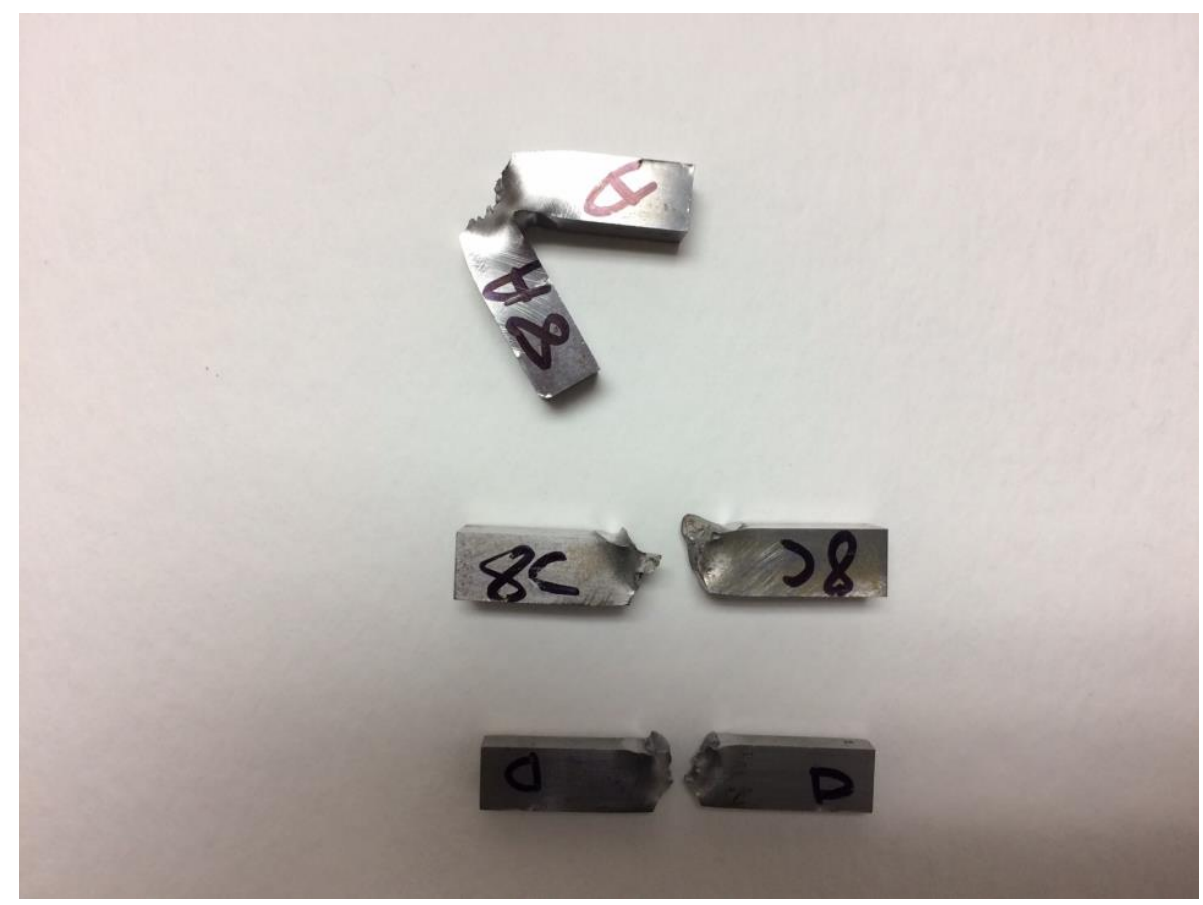

Figure 44: Charpy samples

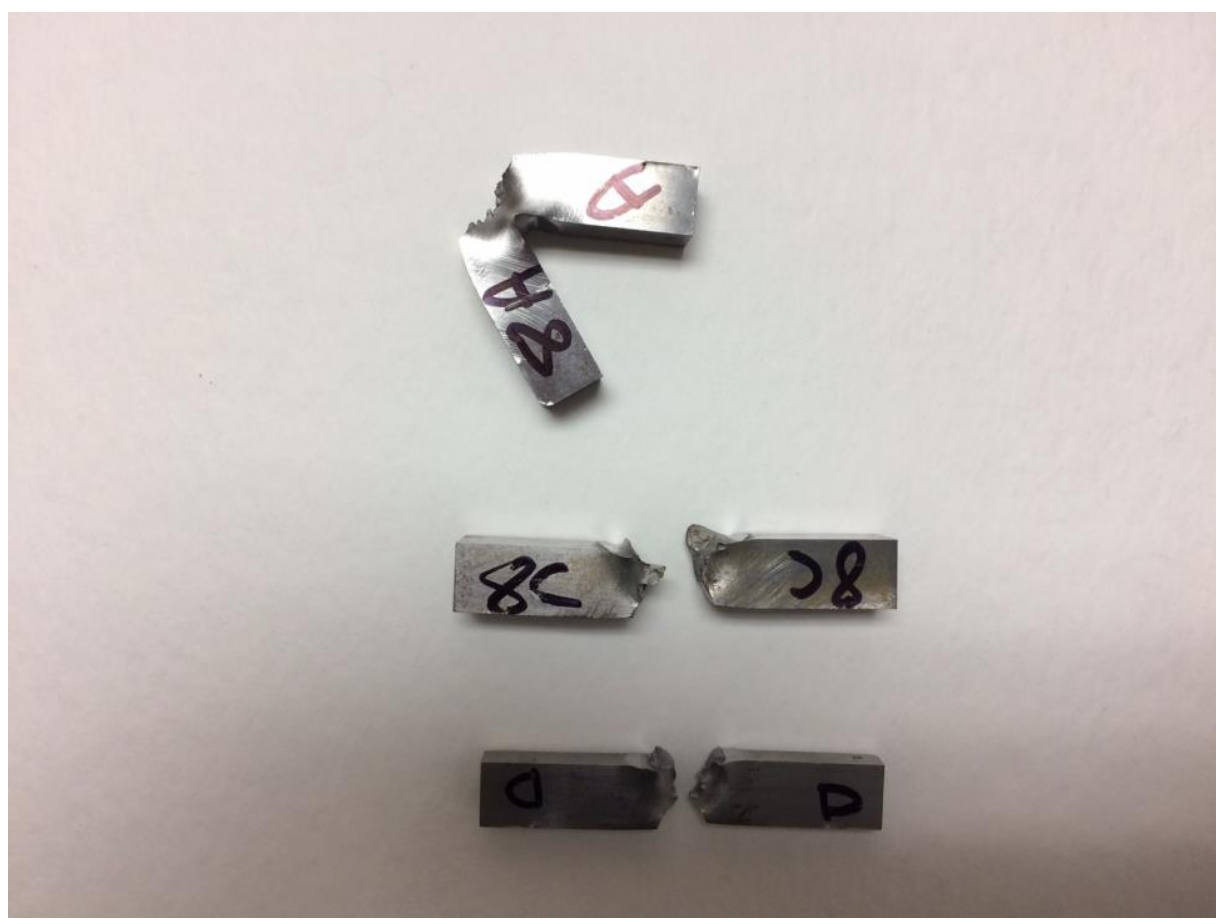

Figure 45: Micrograph samples

\section{Data Analysis}

Mechanical testing was performed on the builds created with ER-70S-6 feed wire through TIG welding. The composition is indicated in Table 4. 
Table 4: Composition of the filler wire

\begin{tabular}{|c|c|c|c|c|c|}
\hline Element & $\mathrm{C}$ & $\mathrm{Mn}$ & $\mathrm{S}$ & $\mathrm{Si}$ & $\mathrm{P}$ \\
\hline $\mathrm{Wt} \%$ & $0.09 \%$ & $1.63 \%$ & $0.007 \%$ & $0.90 \%$ & 0.007 \\
\hline
\end{tabular}

Figure 46 shows the results from after tensile testing. Note the significant anisotropy, ordifferent material strengths in the various axes of printing, in the properties of the builds fabricated along the $X$-direction. The percent elongation varies from $4 \%$ to $30 \%$. Note that the anisotropy in the $Y$ and $\mathrm{Z}$ are relatively low. The percent elongation varies from $\sim 22 \%$ to $25 \%$ for the $\mathrm{Z}$ samples while the total elongation varies from $\sim 12 \%$ to $30 \%$ for the samples fabricated along the $\mathrm{Y}$ direction. This is an extremely important finding because it shows that the scatter in the mechanical properties depends on the orientation in which the sample is fabricated.

Figure 47(a) schematically shows the sample orientation and extraction. Figure 47(b) shows the charpy toughness data. Note the significant scatter in the charpy impact toughness data as well. Also note the samples fabricated in the X-direction suffer from poor impact toughness, while samples fabricated in the $\mathrm{Y}$ and Z-directions show significantly higher impact toughness. This scatter in toughness could be attributed to the changes in thermal cycles between the samples fabricated in the $\mathrm{X}, \mathrm{Y}$, and $\mathrm{Z}$ direction. The finding shows that the samples fabricated in the Zdirection have much stronger properties than the samples fabricated in $\mathrm{X}$ and $\mathrm{Y}$, which is contrary to what has been reported in the literature of additive parts. This shows that for the fabrication of large-scale structures, one must always orient the samples along the Z-axis to fabricate the parts. The reason for such anisotropy is not yet understood, but research on the subject is currently in progress.

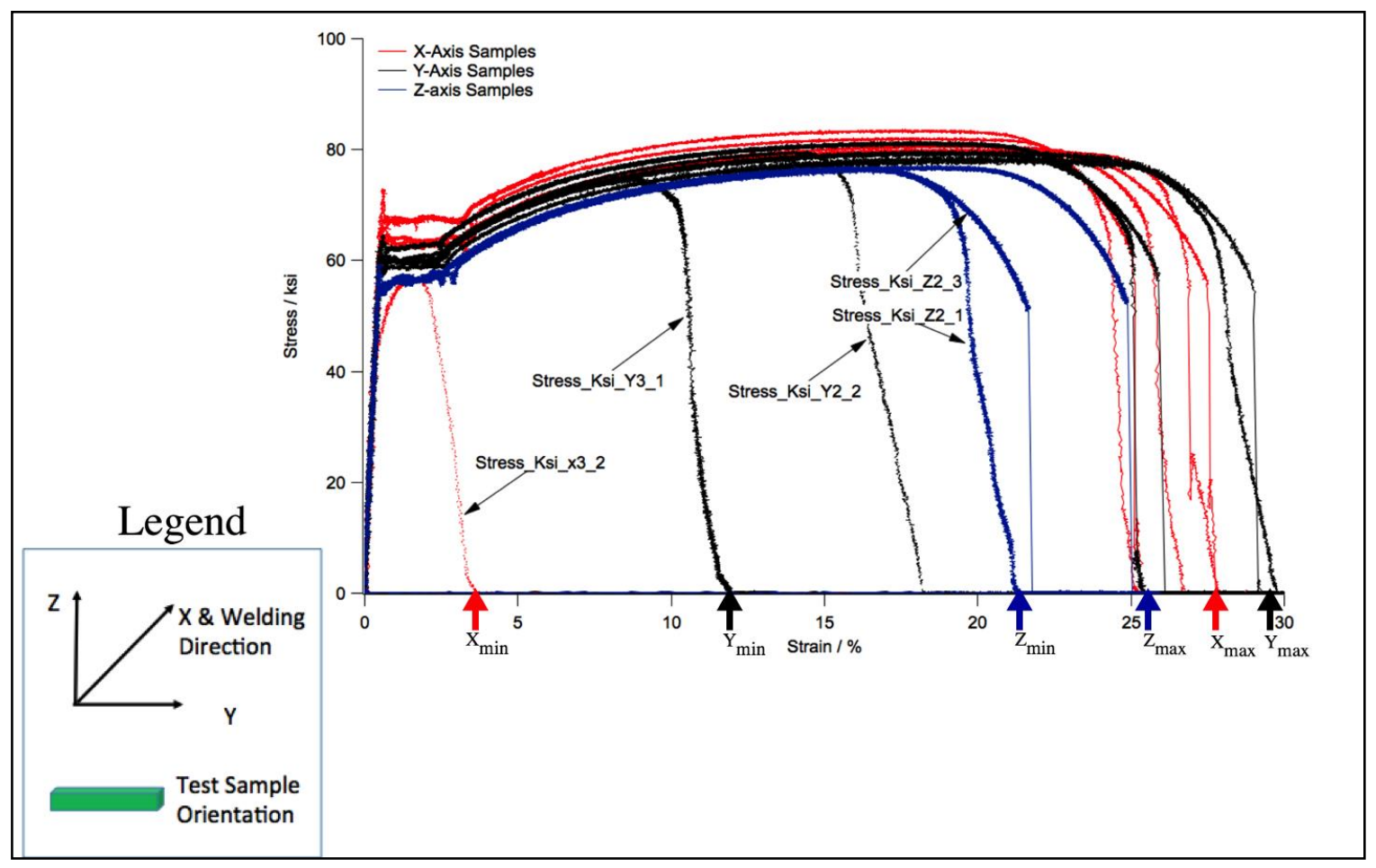

Figure 46: Tensile curves for steel samples 

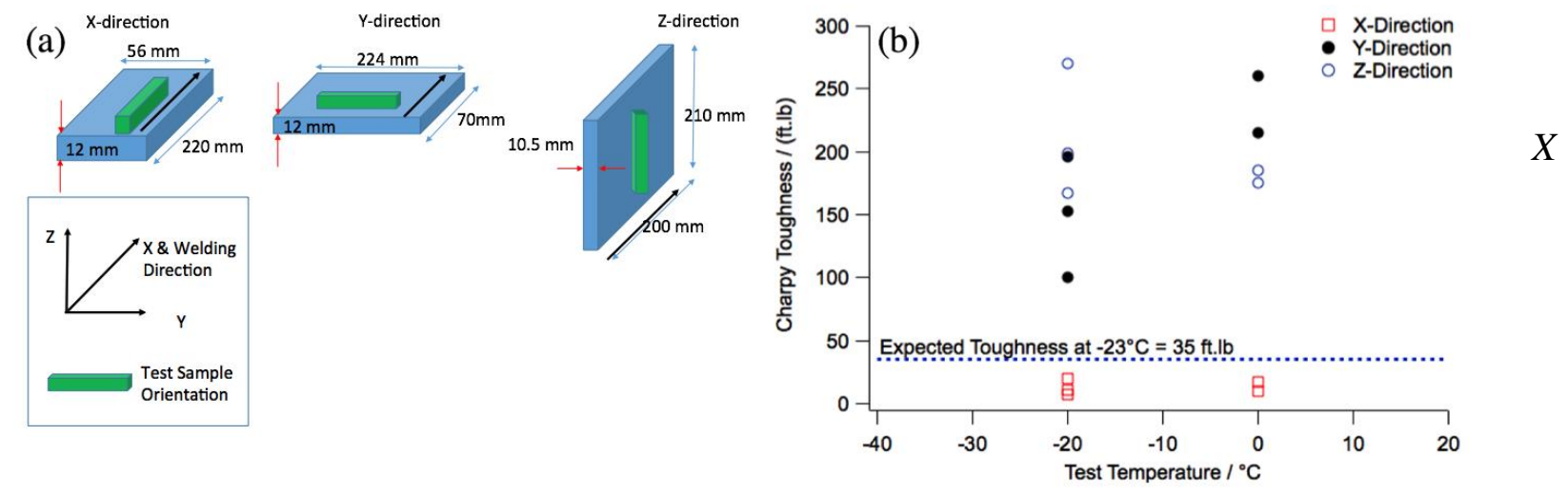

Figure 47: (a) Schematic illustrating the various testing orientations of the samples (b) Charpy impact toughness test results showing that the sample fabricated in the X-direction shows a significant reduction in toughness

This anisotropy could have resulted from microstructural heterodeneity in the samples fabricated in the $\mathrm{X}$ and $\mathrm{Y}$-directions. It is also possible that because the samples experienced different thermal cycles, a difference in the inclusion content occurred; this affected the toughness. To characterize the microstructure, sections were extracted from each of the samples and characterized using light optical microscopy and electron back-scattered diffraction. The results are presented in Figure 48. The Figure 48(a-c) are light optical micrographs corresponding to the samples fabricated in the X, Y, and Z-directions respectively. All the samples show the presence of oxide inclusions. Inclusion density and size has been reported to control the weld metal toughness, both of which are a function of thermal cycles. However, the inclusion density and sizes have not been quantified. Further work is required on those fronts to determine if the toughness in the X-direction could be related to the inclusion content of steel. In addition, the samples fabricated in the $\mathrm{X}$-direction show a predominantly polygonal ferrite microstructure, while the samples fabricated in the $\mathrm{Y}$ and Z-directions show an increased Widmanstätten or acicular (needle-shaped) ferrite microstructure. Further detailed characterization will be necessary to identify if the microstructure present is Widmanstätten ferrite or acicular ferrite. The presence of this microstructure in the builds fabricated in the $\mathrm{Z}$ and $\mathrm{Y}$-directions confirm the fact that the samples in the $\mathrm{Y}$ and $\mathrm{Z}$-directions indeed underwent a completely different thermal cycle compared to the sample fabricated in the X-direction. 

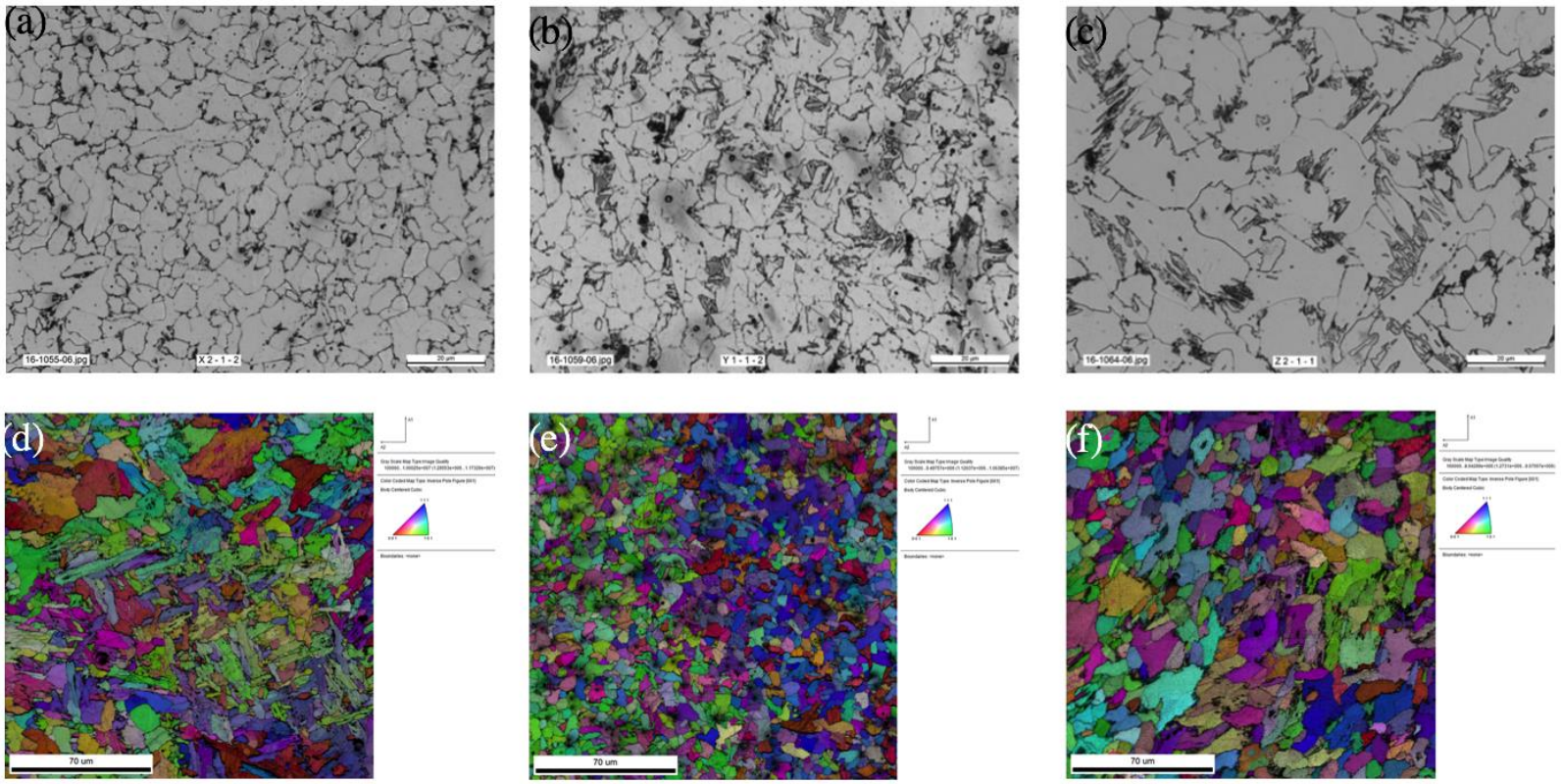

Figure 48: (a-c) Light optical micrographs of samples fabricated in X, Y, and Z-directions respectively. Note the changes in the microstructure (d) electron backscatter diffraction (EBSD) micrograph of the sample fabricated in the X-direction that showed good ductility (30\% total elongation) (e) EBSD micrograph of the sample that showed a reduction in ductility (4\% total elongation) (f) EBSD micrograph of the sample that was fabricated in the Z-direction. Note the fine polygonal ferrite with islands of Widmanstätten ferrite.

The EBSD micrographs represent the crystallographic orientation of the individual grains. The orientations are color coded with red representing grains that are oriented along the <001> direction, while blue represents the grains oriented along the $<111\rangle$ direction. EBSD was performed to understand the difference in the microstructure of the X-direction samples because they showed a scatter in tensile elongation. The microstructure analysis performed using EBSD showed that a sample exhibiting good elongation until failure is composed almost predominantly of acicular ferrite, while the sample that failed in a brittle fashion has almost no acicular ferrite and is predominantly composed of polygonal ferrite. This heterogeneity in the microstructure promotes significant scatter in the mechanical behavior of the build. This has been well recognized. Future work involves more detailed characterization of the microstructure using electron microscopy to characterize the heterogeneity in the microstructure. This heterogeneity in the microstructure will then be correlated to the scatter in the mechanical properties of the builds. Table 5 provides a summary of the baseline mechanical properties of the wire and the resulting as-manufactured properties of the test articles. 
Table 5: Mechanical properties of steel

\begin{tabular}{|l|c|c|}
\hline & Material & \multicolumn{2}{|c|}{ High Carbon Steel (ER-70) } \\
\hline Testing & Baseline & Experiment \\
\hline Density & $0.283 \mathrm{lb} / \mathrm{ci}$ & $0.283 \mathrm{lb} / \mathrm{ci}$ \\
\hline Ultimate strength & $80 \mathrm{ksi}$ & \\
\hline x-direction & & $80 \mathrm{ksi}$ \\
\hline y-direction & & $80 \mathrm{ksi}$ \\
\hline z-direction & $65 \mathrm{ksi}$ & $75 \mathrm{ksi}$ \\
\hline Yield strength & & $65 \mathrm{ksi}$ \\
\hline x-direction & & $65 \mathrm{ksi}$ \\
\hline y-direction & & $60 \mathrm{ksi}$ \\
\hline z-direction & $28.50 \%$ & \\
\hline Elongation & - & \\
\hline Hardness (Brinell) $500 \mathrm{~kg}$ load, 10 mm ball & \\
\hline Charpy V-notch & $20 \mathrm{ft} \mathrm{lb}$ & 15 to 25 \\
\hline x-direction & & $100-250$ \\
\hline y-direction & & $150-260$ \\
\hline z-direction & & \\
\hline Microscopy & & \\
\hline
\end{tabular}

\section{Thermal Imaging}

The TIG additive process was also explored using thermal imaging. A large array of images was taken using a FLIR SC7600 mid wave (3 - 5 micron spectral bandwidth) infrared camera equipped with a $50 \mathrm{~mm}$ lens. Images were taken at a $100 \mathrm{~Hz}$ frame rate. Two images from that database are shown here. Figure 49 below shows a close up of the weld pool during the first layer of a hexagon build. Figure 50 shows an overall thermal image of a build with temperature distribution. While temperatures are shown as assigned to color in Figure 50, the image is uncalibrated because emittance of the deposited material will need to be completed as part of a separate study. 


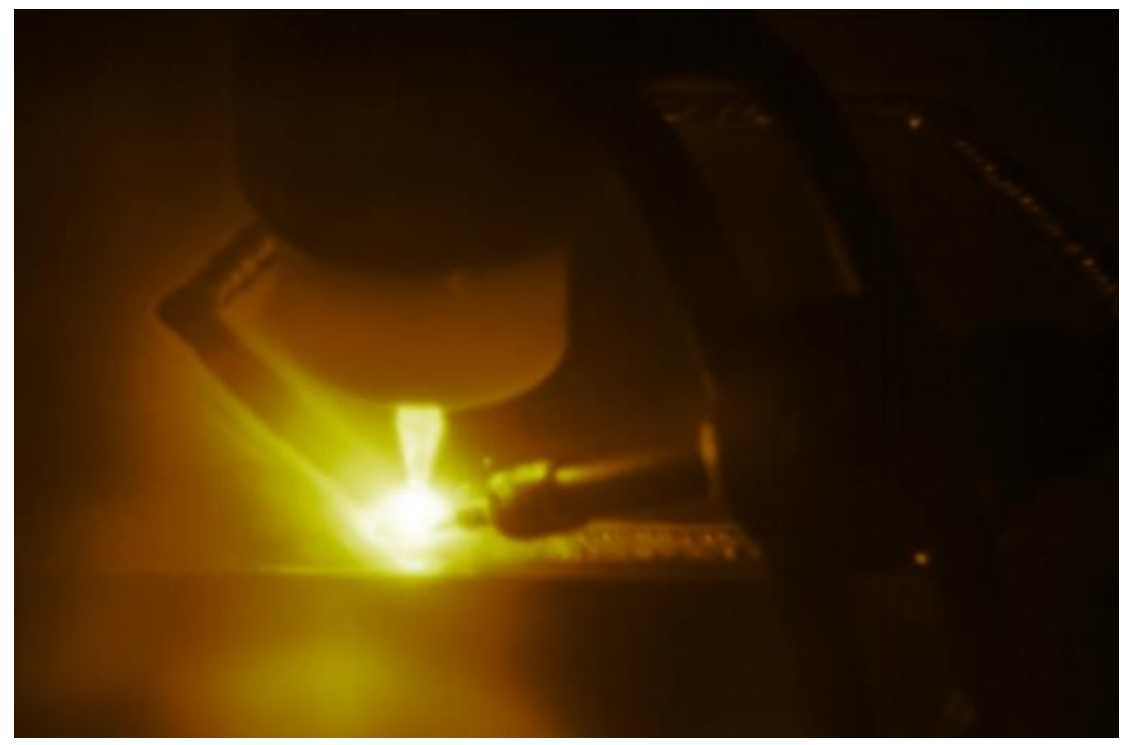

Figure 49: Close-up of weld pool during a hexagon build

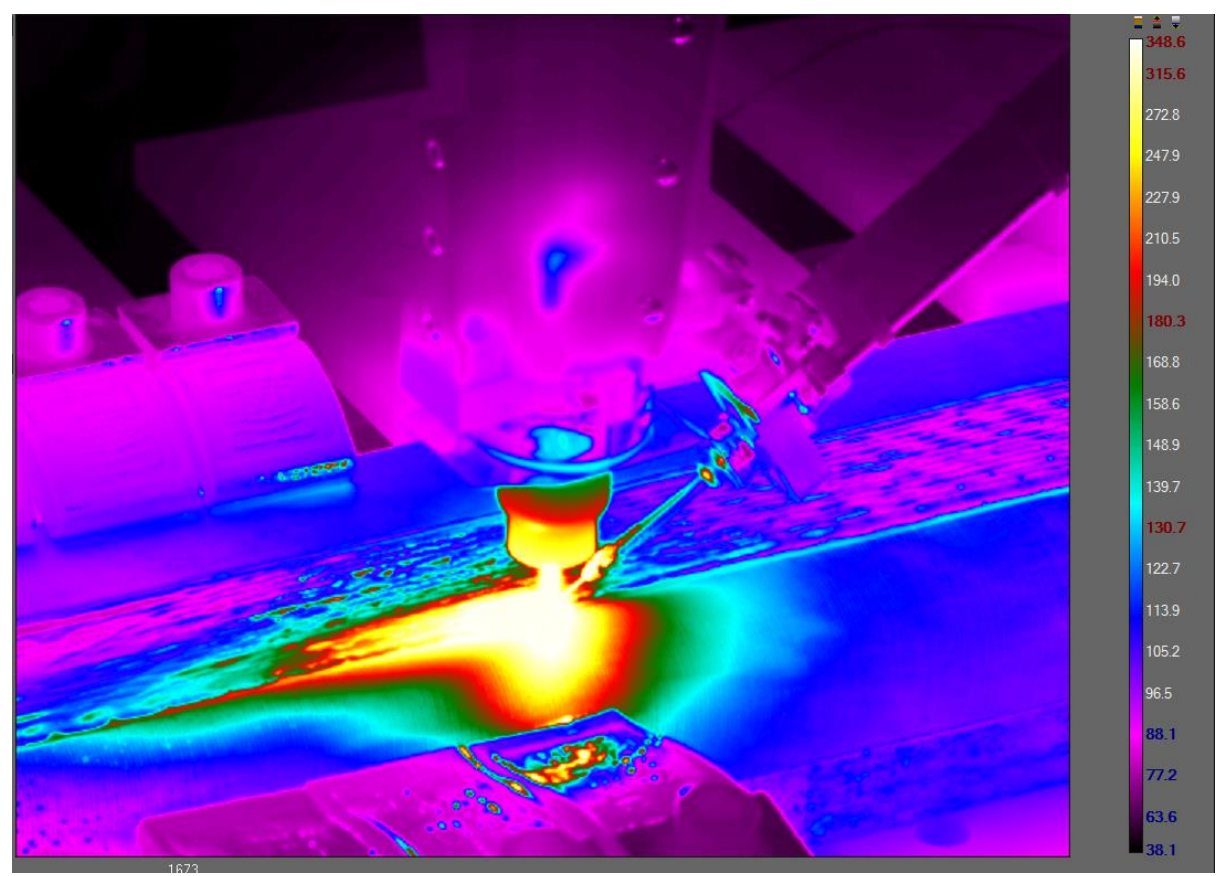

Figure 50: Thermal image of the build in process with temperature scale

\subsection{Mechanical Testing of Aluminum}

This section covers mechanical testing and characterization of Al-5356 samples fabricated using the large-scale metal additive manufacturing process. 


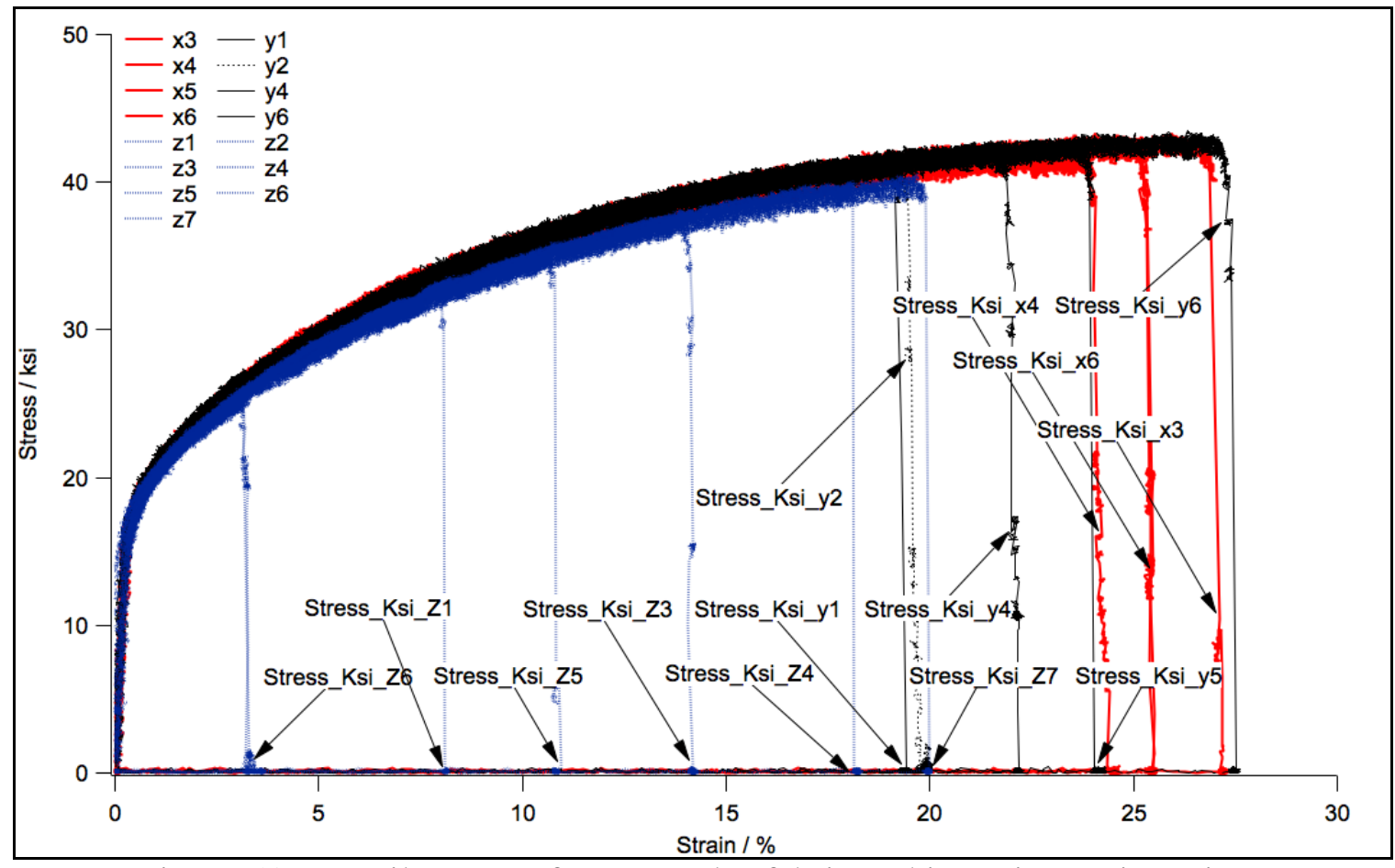

Figure 51: Tensile curves from samples fabricated in various orientations

The tensile curves shown in Figure 51 illustrate a high degree of scatter in the properties of the samples fabricated in the Z-direction, while the scatter in the samples fabricated in the Y and Xdirections are relatively small. Note the decrease of ductility for samples fabricated in the Zdirection. The builds were fabricated using ER 5356 aluminum welding wire. The nominal composition of the feed wire is presented in Table 6.

Table 6: Composition of filler wire

\begin{tabular}{|l|l|l|l|l|l|l|l|l|l|}
\hline Element & $\mathrm{Si}$ & $\mathrm{Fe}$ & $\mathrm{Cu}$ & $\mathrm{Mn}$ & $\mathrm{Mg}$ & $\mathrm{Cr}$ & $\mathrm{Zn}$ & $\mathrm{Ti}$ & $\mathrm{Al}$ \\
\hline $\mathrm{Wt} \%$ & 0.25 & 0.4 & 0.1 & 0.12 & 5.0 & 0.13 & 0.1 & 0.13 & $\mathrm{Bal}$ \\
\hline
\end{tabular}

The tensile specimens show significant scatter in deposit properties fabricated along the Z-axis, especially the total elongation. This ranges from $4 \%$ to $20 \%$ of total elongation. However, the scatter in the $\mathrm{X}$ and $\mathrm{Y}$-directions are limited. They have a range of $22 \%$ to $26 \%$ total elongation along the $\mathrm{Y}$-axis and $24 \%$ to $28 \%$ along the $\mathrm{X}$-axis respectively. This is surprising because the samples fabricated using steel showed the opposite behavior, but the samples fabricated along the X-direction showed maximum scatter. One reason for this scatter could be attributed to the difference in the thermal cycles that the samples experience during fabrication. For example, the microstructure of the samples fabricated in the Z-direction could be completely different compared to those in the $\mathrm{X}$ and $\mathrm{Y}$-directions. The optical micrographs are shown in Figure 51.

The optical micrographs clearly show the samples fabricated in the $\mathrm{X}$ and $\mathrm{Y}$-directions have much more precipitate density, while the samples fabricated in the Z-direction show limited precipitation. This is because the sample in the Z-direction is a thin wall sample with $\sim 13 \mathrm{~mm}$ wall thickness. It conducts heat rapidly and experiences a rapid cooling rate, which prevents the precipitation of any $\mathrm{Mg}_{2} \mathrm{Al}_{3}$ precipitates. The precipitates in the $5 \mathrm{XXX}$ series of aluminum alloys 
normally precipitate at the grain boundaries, resulting in a weakened ultimate tensile strength (UTS). Therefore, absence of these precipitates is not the cause of the properties being low along the Z-direction. The other factor could be the presence of porosity and interlayer lack of fusion. It was shown in earlier work that the presence of porosity, while decreasing the percent elongation, does not significantly affect the UTS. This is shown in Table 7.

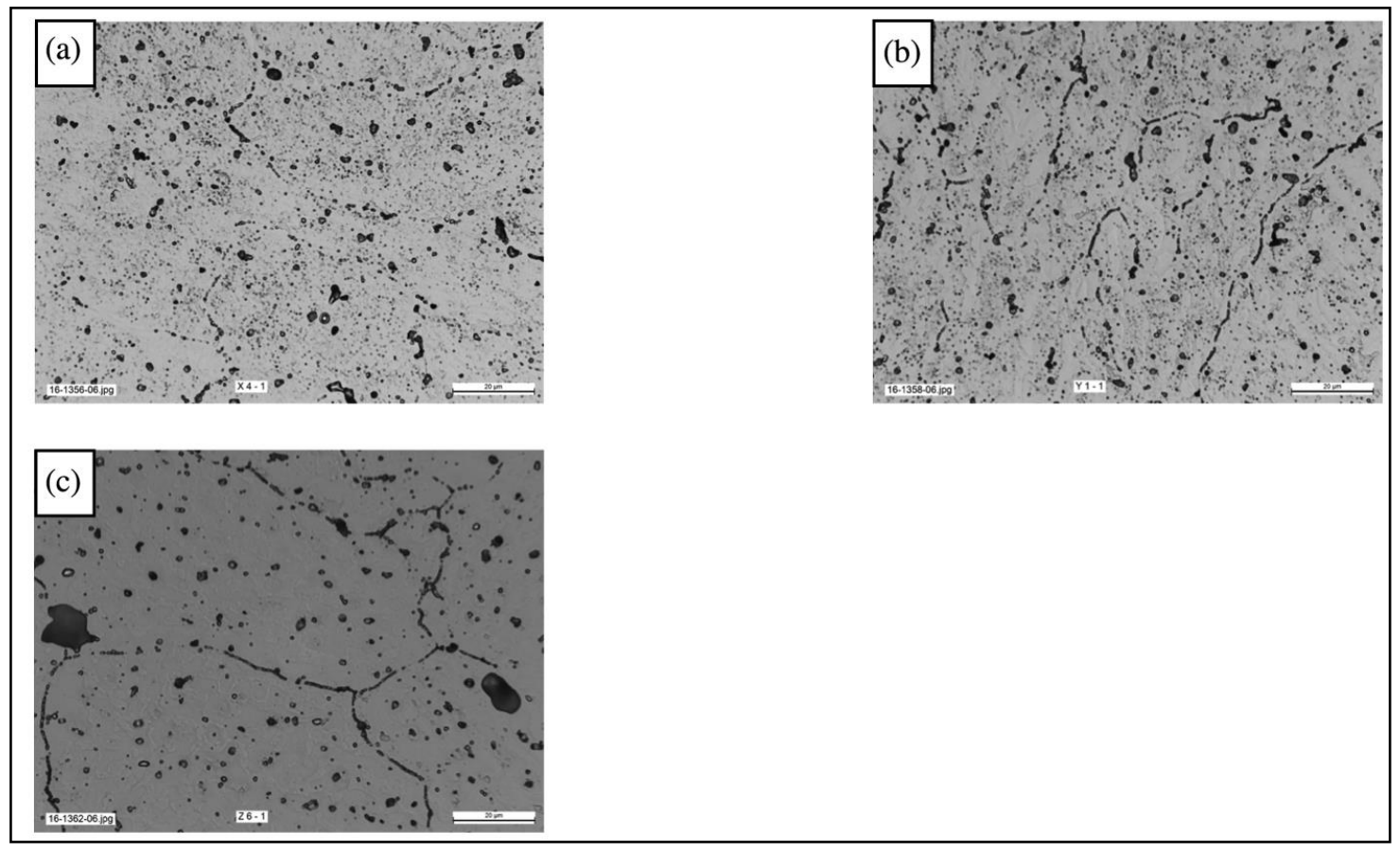

Figure 52: Optical micrographs of the samples (a) Fabricated in the X-direction (b) Samples fabricated in the Y-direction (c) Samples fabricated in the Z-direction

Table 7: Effect of porosity on the mechanical strength of Al-5XXX samples

\begin{tabular}{|l|l|l|l|}
\hline & Porosity Vol \% & UTS Ksi & \% Elongation \\
\hline 1 & 4.2 & 33.2 & $7.5 \%$ \\
\hline 2 & 4.0 & 32.2 & $7.3 \%$ \\
\hline 3 & 3.6 & 35.0 & $8.5 \%$ \\
\hline 4 & 2.9 & 36.9 & $10.0 \%$ \\
\hline 5 & 1.1 & 38.8 & $13.0 \%$ \\
\hline 6 & 0.16 & 38.8 & $13.2 \%$ \\
\hline 7 & 0.03 & 38.9 & $15.0 \%$ \\
\hline
\end{tabular}

The drop in the percent elongation in the samples fabricated and tested along the Z-axis should have resulted solely from the increase in the porosity or interlayer lack of fusion. It is well known that the Al-5356 alloy has a relatively low wettability on a cold substrate because of high thermal conductivity. The rapid cooling and the high contact angle of molten aluminum on a cold substrate causes the following tracks to possibly not wet during the initial stages of the deposition. Therefore, those zones could have a high content of inter layer lack of fusion in them. 
so the sample extracted from the initial zones of the build could show a low ductility. However, as the deposition progresses the temperature of the substrate builds up. It has been shown that at a pre-heat of $\sim 100^{\circ} \mathrm{C}$, the wettability of aluminum improves drastically, so a decrease in the interlayer lack of fusion and other discontinuities may occur. It is hypothesized that this scatter in the interlayer lack of fusion leads to the scatter in elongation. This is shown schematically in Figure 52.

Based on the above observations, it is beneficial to pre-heat the substrate to increase the wetting of the adjacent layers while depositing aluminum samples.

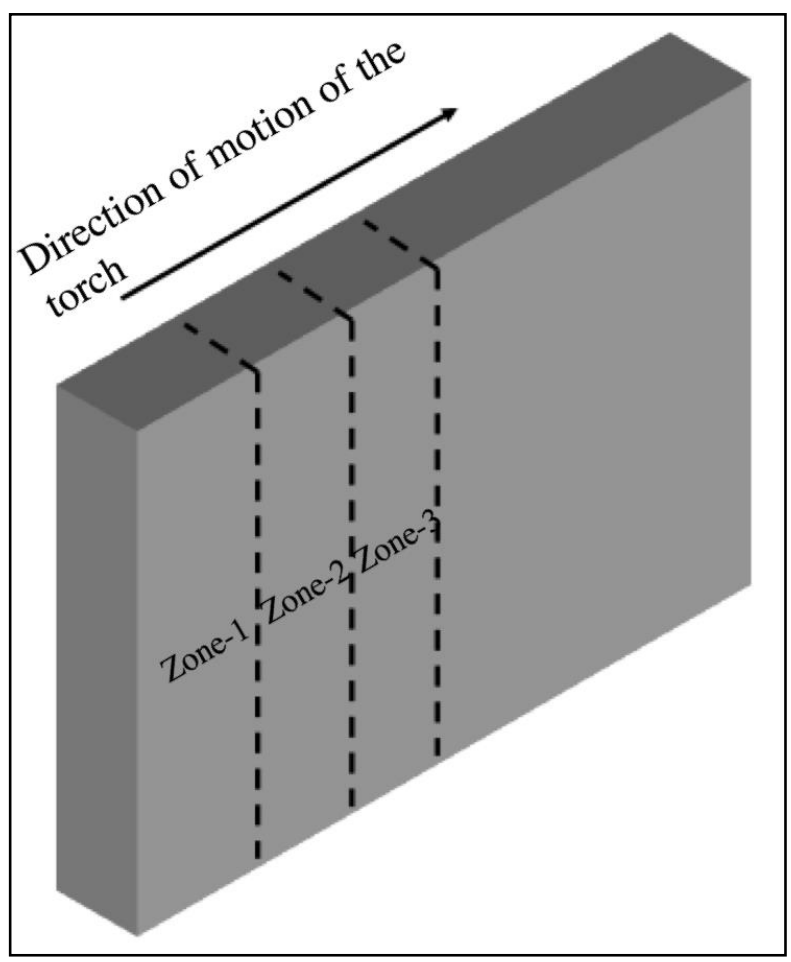

Figure 53: Schematic of the deposited sample

Zone-1 is where deposition begins. This zone will be at the lowest pre-heat temperature and will contain the maximum inter layer lack of fusion. During the process zone- 2 and 3 will begin to pre-heat, and interlayer lack of fusion decreases. Zones 2 and 3 will show an increased elongation compared to the samples from zone-1. 


\section{METAL BAAM FOLLOW-UP EFFORTS.}

The results of this research has triggered a number of follow-up efforts. First, the Department of Energy's Advanced Manufacturing Office (AMO) has initiated a metal BAAM program with ORNL's MDF. This is currently yearly program focusing on:

i) Process and material development,

ii) System development,

iii) CAD to part and,

iv) Processes modeling and simulation.

This program is currently funded by a budget of $\$ 2.4 \mathrm{M}$ per year. The goal of the program is to further the science behind metal additive manufacturing with a specific focus on using process modeling to help identify optimal design, part orientation, and tool paths to minimize residual stress of the metal additive process.

Second, ORNL has initiated a Cooperative Research and Development Agreement (CRADA) with Wolf Robotics. The goal of the agreement is to develop a metal BAAM system that uses MIG welding technology and steel as the primary material. Wolf Robotics is providing the robotic system, called Lincoln Electric, the feedstock, and welding technologies. ORNL will focus on in-situ process monitoring, toolpath generation, and control. The system is shown in Figure 54 through Figure 56. Slicing software was developed to enable direct CAD-to-part printing. (samples shown Figure 57 and Figure 58). This work led to a new multi-million dollar America Makes program. The America Makes program is a partnership between ORNL and Wolf Robotics. ORNL and Wolf Robotics will use a similar test bed, a laser hot wire, and laser powder feed as the energy source. 


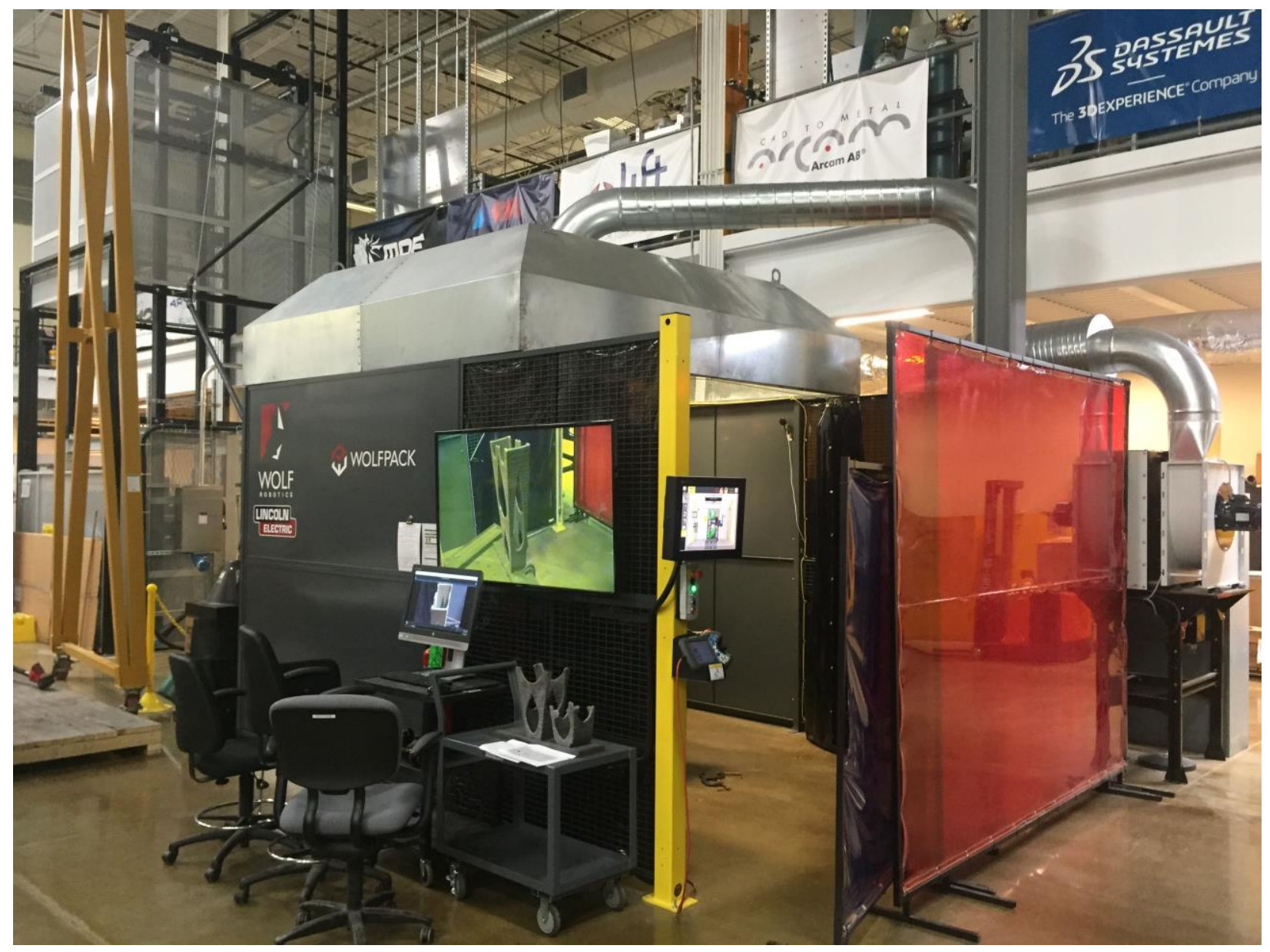

Figure 54: Wolf Robotic test cell 


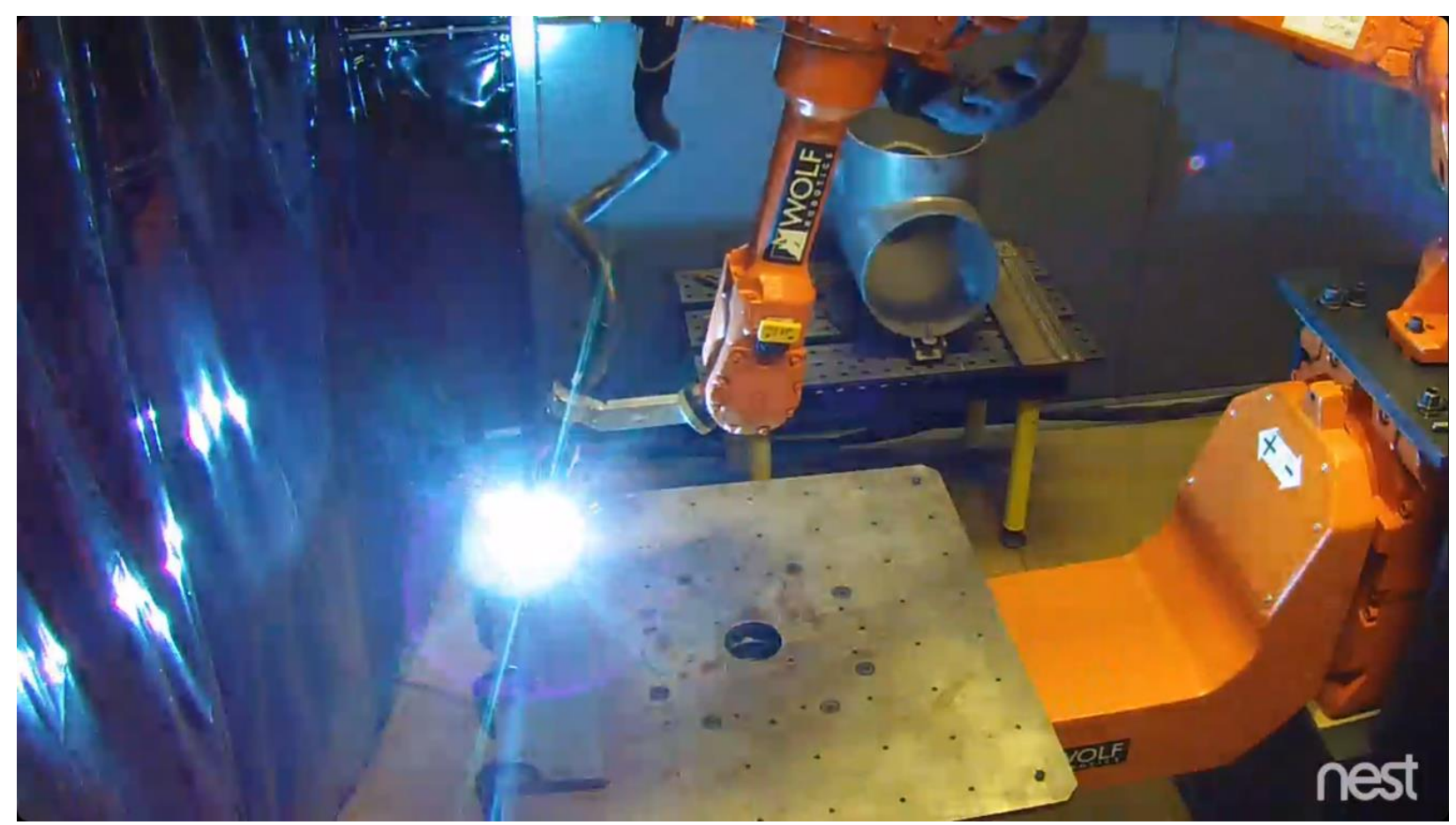

Figure 55: Wolf Robotic test cell operating

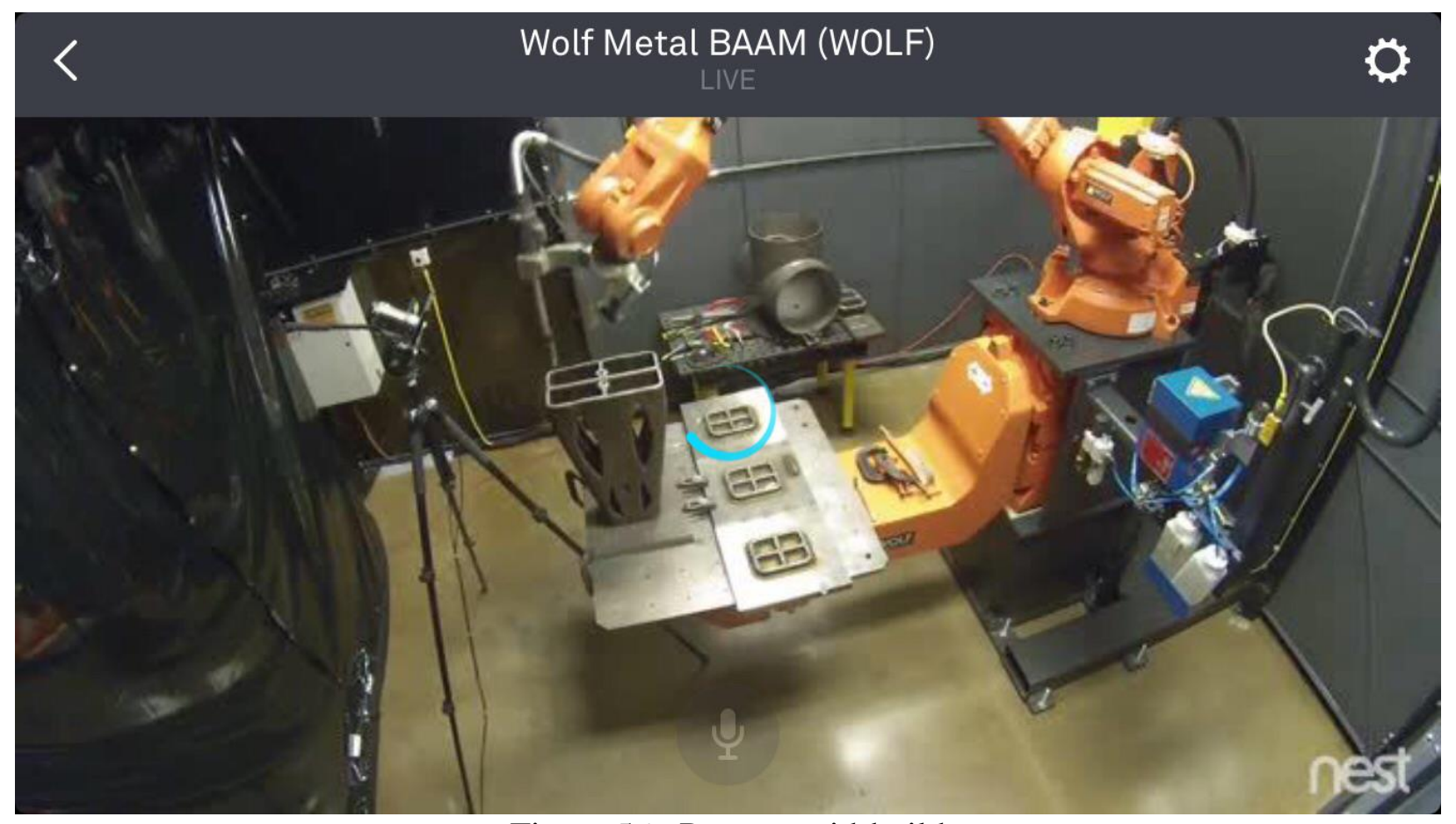

Figure 56: Process mid-build 


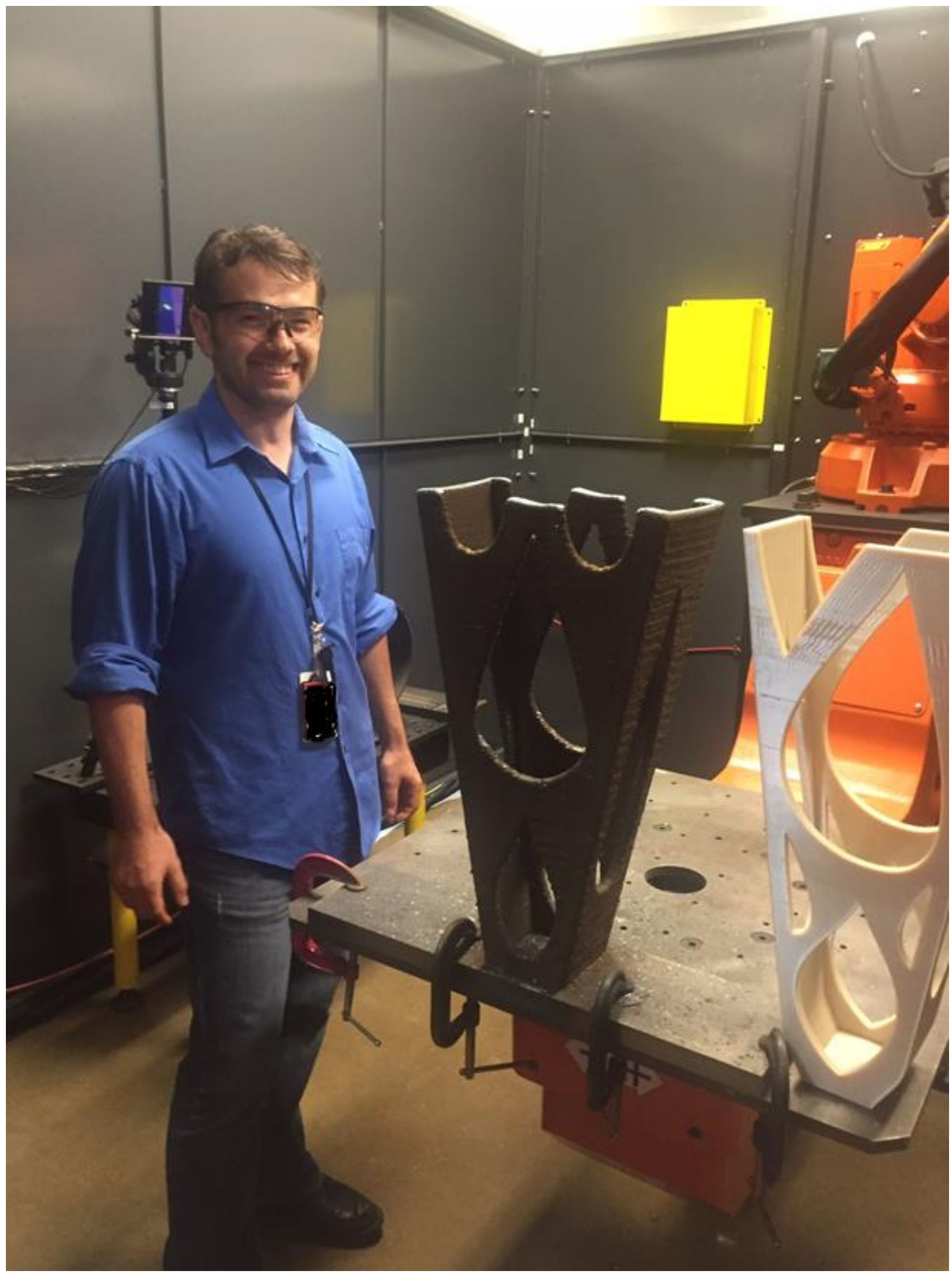

Figure 57: Printed steel part 


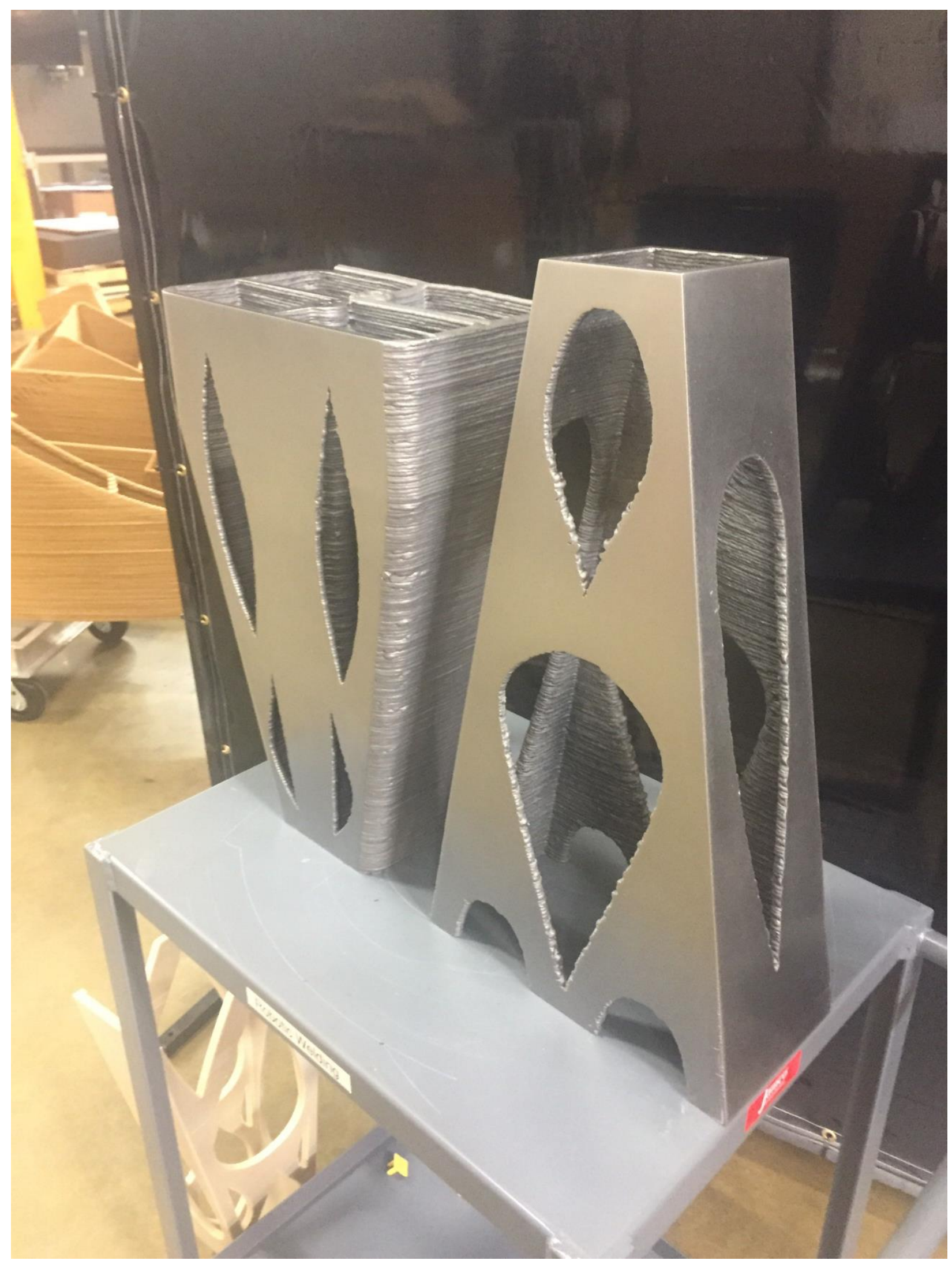

Figure 58: Finished parts 
Finally, ORNL has leverage this work into a CRADA with GKN Aerospace to build a new laser wire feed robotic system using titanium as the main printing material. The energy sources include a $4 \mathrm{~kW}$ coax laser wire feed system, a $20 \mathrm{~kW}$ laser wire feed system, and two $25 \mathrm{~kW}$ laser powder feed systems.

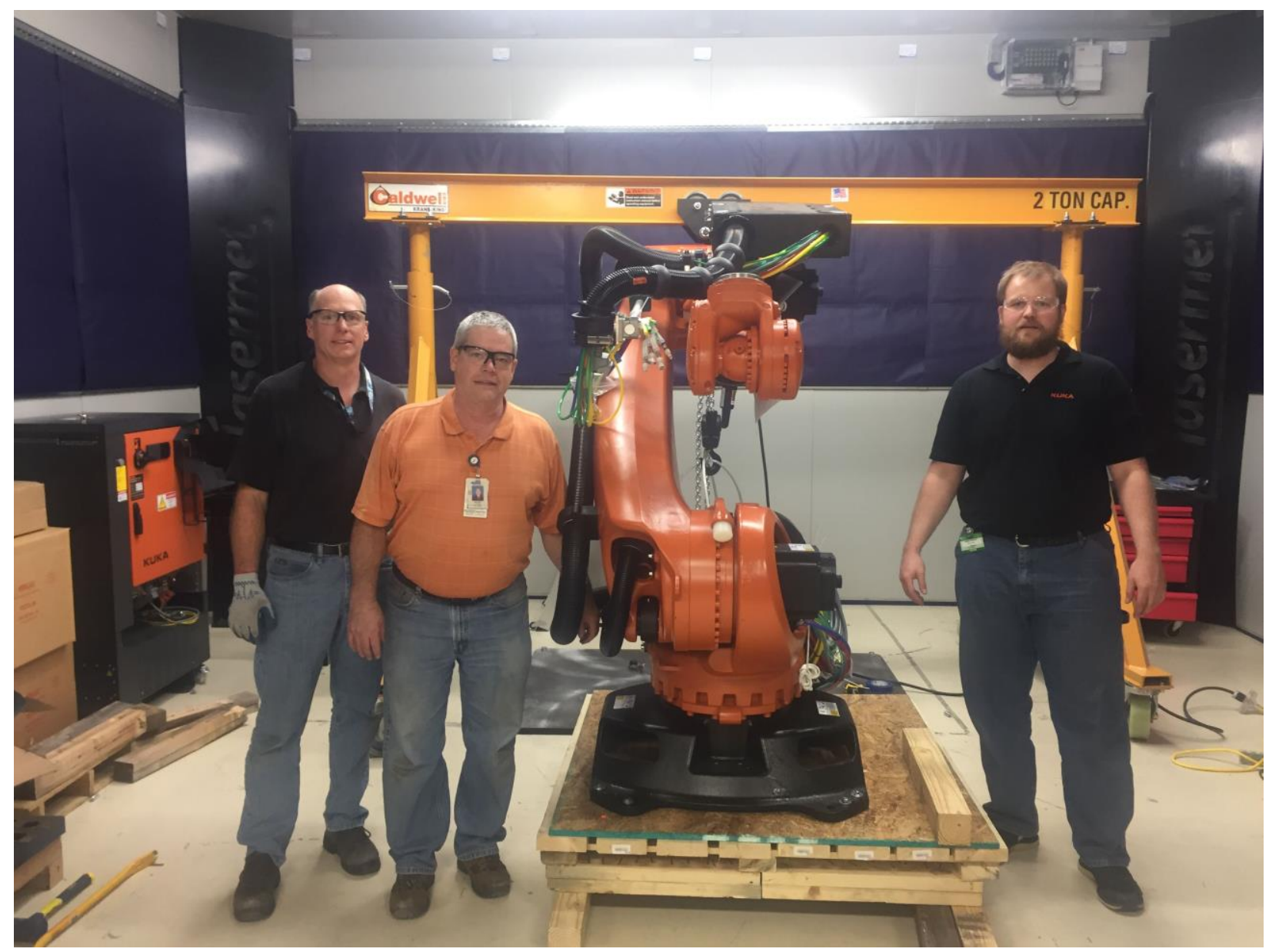

Figure 59: GKN Laser wire feed titanium system

In conclusion, the work funded and completed because of the development of large-scale metal additive manufacturing for military vehicle applications project has led to multiple additional programs and partnerships. A total investment of more than \$25 million from both government and private industries has directly resulted from this project. 


\section{REFERENCES}

B. Wendell, D. Rietzel, F. Kuhnlein, R. Feulner, G. Hulder, E. Schmactenbert. "Additive Processing of Polymers." Macromolecular Materials and Engineering, 2008: 799-809.

Canis, Bill. The Tool and Die Industry: Contributions to U.S. Manufacturing and Federal Policy Considerations. Washington, DC: Congressional Research Service, 2012.

Charmas, D. "Stratasys 3-D Modeler Forms Prototype of Plastic or Wax." Plastic News, 1990.

Elenora Atzeni, Alessandro Salmi. "Economics of Additive Manufacturing for End-Usable Metal Parts." International Journal of Advanced Manufacturing Technology, 2012: 1147-1155.

Estimating 2003 Building-Related Construction and Demolition Materials Amound. EPA, 2003.

K.Al-Jabri, A. Hago, A. Al-Nuaimi, A. Al-Saidy. "Concrete blocks for thermal insulation in hot climates." Cement and Concrete Reserach, 2005: 1472-1479.

Kianian, B., Tavassoli, S., and Larsson, T. "The Role of Additive Manufacturing Technology in Job Creation: An Exploratory Case Study of Suppliers of Additive Manufacturing in Sweded." 12th Global Conference on Sustainable Manufacturing. 2015. 93-98.

Love, L.J, Kunc, V., Rios, O., Duty, C., Elliott, A. and Post, B. "The Importance of Carbon Fiber to Polymer Addtivie Manufacturing." Journal of Materials Research, 2014: 1893-1898.

Marcel Boger, Ronen Hadar, Arne Bilberg. "Additive manufacturing for consumer-centric business models: Implications for suppy chains in consumer goods manufacturign." Technological Forecasting and Social Change, 2016: 225-239.

Rauwendaal, Chris. Polymer extrusion. Carl Hanser Verlag GmbH Co KG, 2014.

Salmi, E. Atzeni and A. "Economics of Additive Manufacturing for End-Use Metal Parts." International Journal of Advanced Manufacturing Technology, 2012: 1147-1155. 
Widdowson, G.1, Youyong, L., A.S. Gaunekar, T.H. Kuah, and N Srikanth. "Design of a high speed linear motor driven gantry table." Int. Conf. on Power Electronic Drives and Energy Systems for Industrial Growth. 1998. 936-941 .

Wohlers, Terry. The Wohlers Report. Fort Collins: Wohlers Associates, Inc., 2015.

Wohlers, Terry. Wohlers Report 2015. Fort Collins: Wohlers Associates, Inc, 2015.

Wolhlers, T. Wohlers Report. Fort Collins, Co.: Wohlers Associates, Inc, 2013. 